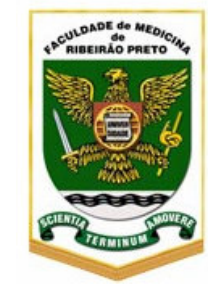

UNIVERSIDADE DE SÃO PAULO

FACULDADE DE MEDICINA DE RIBEIRÃO PRETO

DEPARTAMENTO DE CLÍNICA MÉDICA

Carlos Alberto Werutsky

\title{
AS BASES MOLECULARES DAS HIPERCOLESTEROLEMIAS FAMILIARES NO BRASIL: O RIO GRANDE DO SUL
}

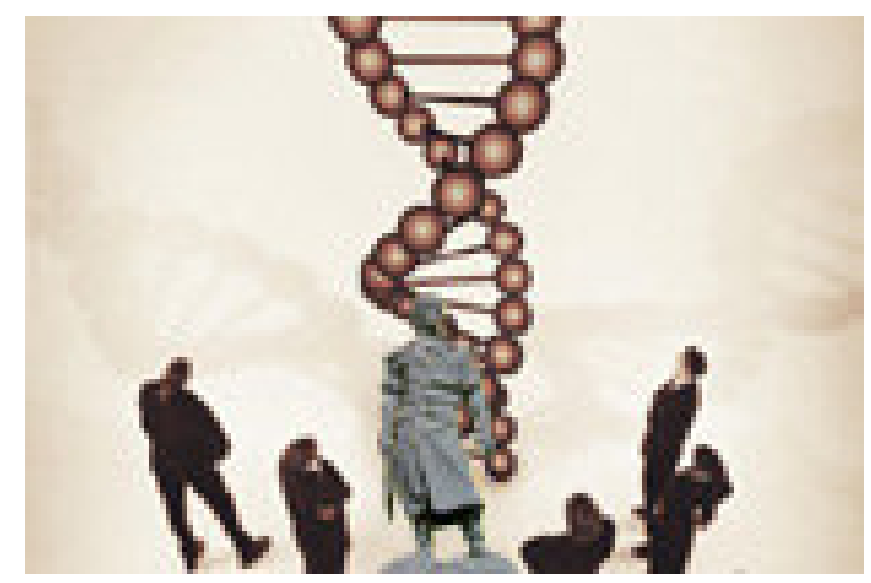

Ribeirão Preto 


\section{Carlos Alberto Werutsky}

\section{AS BASES MOLECULARES DAS HIPERCOLESTEROLEMIAS FAMILIARES NO BRASIL: O RIO GRANDE DO SUL}

Tese para obtenção do título de Doutor em Clínica Médica - Investigação Clínica da Faculdade de Medicina de Ribeirão Preto - Universidade de São Paulo.

Orientador: Prof. Dr. José Ernesto dos Santos 
FICHA CATALOGRÁFICA

Werutsky, Carlos Alberto

As bases moleculares das hipercolesterolemias familiares no

Brasil: o Rio Grande do Sul. Ribeirão Preto, 2006.

88 p. : il. ; $30 \mathrm{~cm}$

Tese de Doutorado, apresentada à Faculdade de Medicina de Ribeirão Preto/USP - Área de concentração: Clínica Médica. Investigação Clínica.

Orientador: Santos, José Ernesto dos.

1. Hipercolesterolemia familiar. 2. Receptor do LDL (LDLR). 3. Bases moleculares. 4. Mutações. 
A Leila, minha esposa, e aos nossos filhos Gustavo, Ricardo e Lucas pela compreensão e tolerância e, também, aos amigos Lara e Terezinha pelo incansável apoio ao longo desses anos. 
Havia uma vela no chão, e todos tropeçavam.

Colocou-se a vela acima, e todos se enxergavam.

(Autor desconhecido) 
Em especial, a todos os pacientes participantes desse estudo, sem os quais não seria possível concretizá-lo.

Ao meu orientador Prof. Dr. José Ernesto dos Santos pela confiança e apoio no meu trabalho.

Ao Prof. Dr. Julio Sérgio Marchini pela receptividade que tive na FMRP-USP e pela indicação do meu orientador.

A Adriana Ferreira pela sua solicitude em orientações tão necessárias para quem vem de fora da USP.

Ao Prof. Dr. Wilson Araújo da Silva Junior e sua equipe do Laboratório de Genética Molecular do Departamento de Genética da FMRP-USP, em especial ao Israel Tojal, a Lidiane Cristina Melato, a Adriana Aparecida Marques, a Greice Andreotti de Molfetta, a Carla Martins Kaneto e a Cristiane Ayres Ferreira pelo trabalho conjunto na elaboração dos resultados dessa pesquisa.

A Julia Keiko do Laboratório de Nutrição do HC-FMRP pelo tratamento, conservação, triagem do material coletado e extração do DNA.

Ao Prof. Dr. Giuseppe Repetto, Chefe do Serviço de Endocrinologia do Hospital São Lucas da PUCRS, pela amizade e apoio técnio-científico..

À Dra. Vera Portal, responsável pelo Projeto no Instituto de Cardiologia - Fundação de Cardiologia do Rio Grande do Sul, instituição parceira da FMRP-USP, e seus estagiários, na obtenção dos dados desse estudo. Ao Dr. Ricardo SantaLucia Bruch do Laboratório do Instituto de Cardiologia pelo tratamento do material coletado. 
Ao Programa de Pós-Graduação em Endocrinologia da Faculdade de Medicina da UFRGS - Áreas de Concentração: Endocrinologia Clínica \& Metabolismo e Nutrição, pela oportunidade de cursar cinco disciplinas reconhecidas pelo Programa de Pós-Graduação da FMRP-USP.

Ao Sr. Miguel Duarte do Instituto Histórico e Geográfico do Rio Grande do Sul pelas informações documentais sobre os movimentos imigratórios para o Estado.

Ao amigo Jorge Mendes Ribeiro Filho que acreditou na importância desse trabalho para a população do nosso Estado.

À Secretaria Estadual de Saúde do Estado do Rio Grande do Sul através da suas Coordenadorias Regionais de Saúde (CRS), em especial ao Dr. Paulo Domingos Savaris $\left(19^{\circ} \mathrm{CRS}\right)$, ao Dr. Gilberto Feldens $\left(15^{\circ} \mathrm{CRS}\right)$ e à Dra. Sonia Regina Gheller Egert $\left(4^{\circ}\right.$ CRS) pela apresentação do Projeto aos Serviços de Saúde dos demais Municípios. Às Secretarias de Saúde, seus médicos e demais servidores, pela presteza e envolvimento na coleta de dados, em Dom Feliciano, Dra. Adriana Chaves e Equipe, em Rio Grande, Enf ${ }^{\text {a }}$. Lorena Rimoli, Tânia Mara Ortiz Souza e Nutric. Roberta Araújo, em São Lourenço do Sul, Enf ${ }^{a}$ Mara Dulce Mendes Soares, em Tupanciretã, Drs. Antonio Carlos Mazo Martins e Adonir Belmiro Campra e Sr. Luiz Carlos Martins, em Ijuí, Drs. Jorge Ralf Brust, Armindo Pydd, e Sra. Beatriz Kusbick, em Frederico Westphalen, Enf ${ }^{a}$ Marta Hermes Cocco.

À Elci Ribeiro (cunhada) e Maria Mercedes Ribeiro (sogra) pelo apoio junto às comunidades dos municípios de Pinhal, Erval Seco, Rodeio Bonito, Frederico Westphalen, Alpestre, Planalto e Ametista.

Ao Laboratório Bom Pastor (Taquara, Igrejinha), responsável Técnico Dr. Jorge Alberto Schaefer e Laboratório Martel (Ijuí), Responsável Técnico Dr. Gilson Martel, pela coleta apropriada de material para essa pesquisa. 
À Prof ${ }^{a}$ Kátia Gonçalves dos Santos, do Laboratório de Pesquisa Cardiovascular do Centro de Pesquisas do HCPA, pela revisão técnica da Tese e sugestões oportunas que contribuíram para a sua apresentação.

À bibliotecária Rosária Geremia pela ajuda imprescindível na normalização das referências.

Ao Sr. Giquitibá Moraes de Melo, do Serviço de Imagem Digital do Hospital São Lucas da PUCRS, pela dedicação e competência na formatação desse trabalho. 


\section{RESUMO}

WERUTSKY, C. A. As bases moleculares das hipercolesterolemias familiares no Brasil: o Rio Grande do Sul. 2006. 88 f. Tese (Doutorado) - Faculdade de Medicina de Ribeirão Preto, Universidade de São Paulo, Ribeirão Preto, 2006.

A hipercolesterolemia familiar (HF) é uma doença autossômica dominante causada por mutações no gene do receptor de LDL (LDLR) (cromossomo 19p13.1 - p13.3), que alteram parcialmente ou totalmente a função do LDLR. A HF é também uma das doenças genéticas mais comuns com freqüências estimadas de heterozigotos e homozigotos de 1/500 e 1/1.000.000, respectivamente. Manifesta-se com altos níveis de LDL colesterol, arco corneal, xantomas tendíneos e sintomas prematuros de doença coronariana.. A grande heterogeneidade observada na manifestação clínica desta doença pode ser explicada, ao menos parcialmente, pelo amplo espectro de mutações no gene do LDLR. O presente estudo teve por objetivo a caracterização molecular do gene LDLR em pacientes com HF do Rio Grande do Sul (RS), Brasil. Para isso, foram obtidas amostras de DNA de 40 indivíduos provenientes de cinco macrorregiões do Estado, representando seis diferentes populações de ascendência européia, para a realização do seqüenciamento direto do gene do LDLR, com posterior análise por meio das ferramentas de bioinformática. Quinze mutações pontuais foram identificadas no gene do LDLR, a saber: c.408C >T (D115D), c.1616C >T (P518L), c.1773C $>$ T $(\mathrm{N} 570 \mathrm{~N})$ e c.2243A $>\mathrm{G}$ (D727G) na região codificadora, IVS6+36G >A, IVS6+171G >A, IVS11+56C >T, IVS1169G > T, IVS11-55A>C, IVS15-136A >G, IVS16+46C > T e IVS17-42A >G na região intrônica, e $* 52 \mathrm{G}>\mathrm{A}, * 105 \mathrm{~T}>\mathrm{G}$ e $* 141 \mathrm{G}>\mathrm{A}$ na região 3 '-UTR. Destas, oito ainda não foram descritas na literatura (três situadas nos exons, quatro nos introns e uma na região 3'-UTR). A mutação *52G $>$ A foi previamente identificada em pacientes com HF da região Sudeste do Brasil, sugerindo que possa exercer um importante efeito na patogênese da $\mathrm{HF}$ em pacientes 
brasileiros. Em relação às macrorregiões do RS, os portugueses, italianos e espanhóis apresentaram o maior número de mutações dentre os grupos étnicos analisados. Assim, os resultados obtidos confirmam que existe um amplo de espectro de mutações no gene do LDLR. As mutações nas regiões intrônicas precisam ser investigadas sobre seu efeito potencial no desenvolvimento de HF. Considerando que este é o primeiro estudo que teve por objetivo a caracterização molecular de pacientes com HF no RS, novos estudos que visem a elucidação das bases moleculares da HF devem ser realizados, a fim de obter uma melhor caracterização genética desta doença no Brasil.

Palavras-chave: hipercolesterolemia familiar, receptor do LDL (LDLR), bases moleculares, mutações. 
Werutsky, CA. The molecular bases of the familial hypercholesterolemia in Brazil: Rio Grande do Sul. 2006. 88 f. Thesis (Doctoral) - Faculdade de Medicina de Ribeirão Preto, Universidade de São Paulo, Ribeirão Preto, 2006.

Familial hypercholesterolemia (FH) is an autosomal dominant disorder caused by mutations in the low-density lipoprotein receptor (LDLR) gene (chromosome 19p13.1 - p13.3), which alter partially or totally the LDLR function. FH is also one of the most common inherited disorders with frequencies of heterozygotes and homozygotes estimated to be $1 / 500$ and $1 / 10^{6}$, respectively. Affected individuals display high levels of LDL cholesterol, arcus corneae, tendon xanthomas and premature symptomatic coronary heart disease. The extensive heterogeneity observed in the clinical manifestation of this disorder may be explained, at least partially, by the broad spectrum of mutations identified in the LDLR gene. The present study had as the main goal the molecular characterization of the LDLR gene in patients with FH from Rio Grande do Sul (RS) State, Brazil. For this, DNA samples were obtained from 40 individuals living in five macroregions of RS, representing six different isolated populations of European ascendancy. The LDLR gene was subjected to the direct sequencing with further analysis through bioinformatics tools. Fifteen punctual mutations were identified in the LDLR gene, namely: c.408C $>\mathrm{T}$ (D115D), c.1616C $>\mathrm{T} \quad$ (P518L), c.1773C $>\mathrm{T} \quad(\mathrm{N} 570 \mathrm{~N})$ and c. $2243 \mathrm{~A}>\mathrm{G}(\mathrm{D} 727 \mathrm{G})$ in the coding region, IVS6+36G $>\mathrm{A}, \mathrm{IVS6}+171 \mathrm{G}>\mathrm{A}, \mathrm{IVS} 11+56 \mathrm{C}>\mathrm{T}$, IVS11-69G > T, IVS11-55A >C, IVS15-136A>G, IVS16+46C > T and IVS17-42A $>$ G in the intronic region, and $* 52 \mathrm{G}>\mathrm{A}, * 105 \mathrm{~T}>\mathrm{G}$ and $* 141 \mathrm{G}>\mathrm{A}$ in the 3 '-UTR region. Of these, eight were not yet described in the literature (three situated in exons, four in introns and one in 3'UTR region). The $* 52 \mathrm{G}>\mathrm{A}$ mutation was previously identified in FH patients from Southeast Brazil, suggesting that it can exert an important effect in the pathogenesis of $\mathrm{FH}$ in Brazilian patients. In relation to the macroregions of Rio Grande do Sul, Portuguese, Italian and Spanish subjects carried the highest number of mutations among the ethnic groups analyzed. 
Thus, the results obtained confirm the existence of a broad spectrum of mutations in the LDLR gene. The mutations in intronic regions need to be investigated in relation to its potential effect in the development of FH. Taking into account that this is the first study that had as the goal the molecular characterization of FH patients in RS, further studies aimed at elucidating the molecular bases of FH should be performed, in order to obtain the better characterization of this disease in Brazil.

Key words: familial hypercholesterolemia, LDL receptor (LDLR), molecular bases, mutations. 
Tabela 1 - Etnicidade e $\mathrm{n}^{\circ}$ de mutações do gene LDLR

Tabela 2 - A contribuição da imigração forçada e imigração espontânea para o Brasil até a metade do século XX

Tabela 3 - Mutações encontradas em pacientes brasileiros com HF descritas por Salazar et al. (2002)

Tabela 4 - Imigração espontânea para o Estado do Rio Grande do Sul 30

Tabela 5 - Seqüência de primers utilizados para o seqüenciamento dos exons e introns do gene LDLR, temperatura de annealing e tamanho dos fragmentos amplificados. 36

Tabela 6 - Mutações encontradas na amostra e sua freqüência relativa (\%) por grupo étnico 40

Tabela 7 - Mutações identificadas no Brasil

Tabela 8 - Mutações descritas/não descritas em exons no presente estudo por grupo étnico .46

Tabela 9 - Mutações descritas/não descritas em introns e região 3' não traduzida (3'UTR) da amostra por população. 49 
Figura 1. Relação dos mapas físico e genético do cromossomo 19

Figura 2 - Heredograma dos membros da família, mostrando os valores do perfil lipídico em $\mathrm{mg} / \mathrm{dL}$

Figura 3. Macrorregiões do Estado do Rio Grande do Sul

Figura 4. Cromatograma do seqüenciamento do DNA

Figura 5. Alinhamento múltiplo da região de interesse com as ESTs e o respectivo SNP sinalizado através do círculo

Figura 6. Mutações no gene LDRL: Freqüência relativa (\%) por região do Rio Grande do Sul 


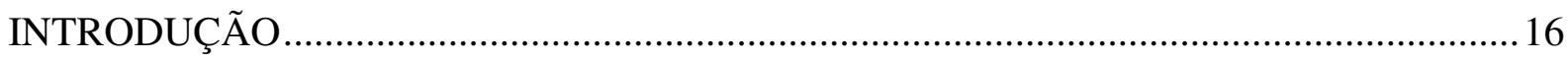

A hipercolesterolemia como doença genética e familiar............................................. 17

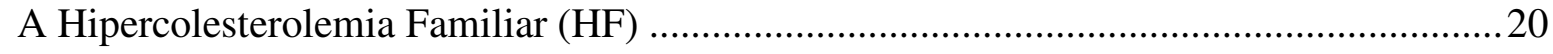

Mecanismo celular da HF: defeitos no receptor LDL-C (LDLR) ................................... 21

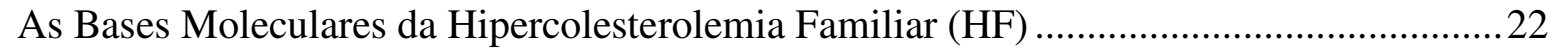

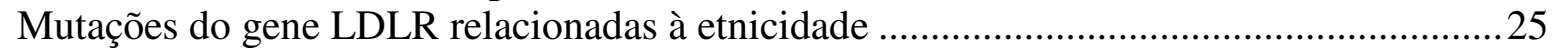

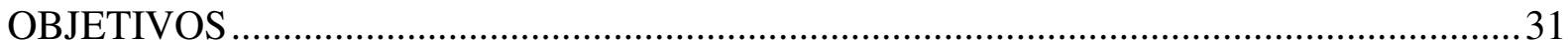

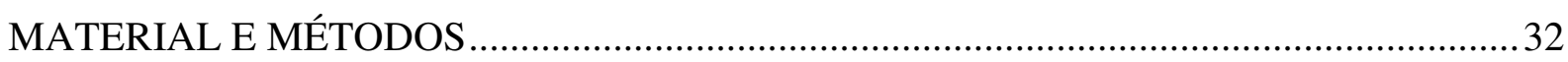

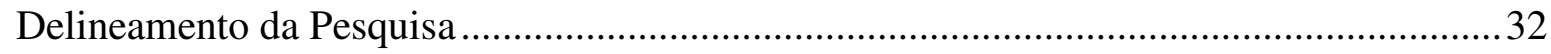

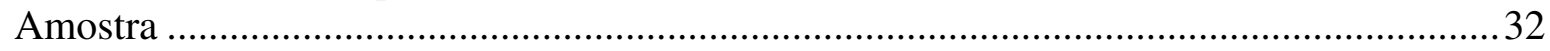

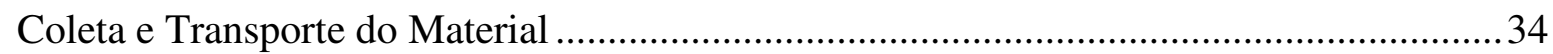

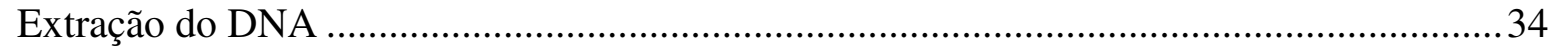

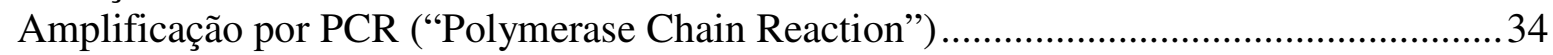

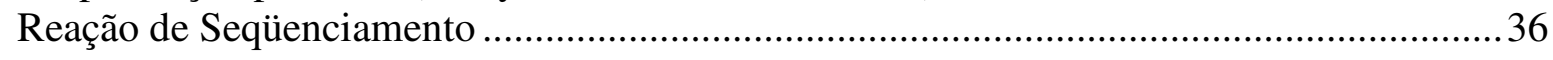

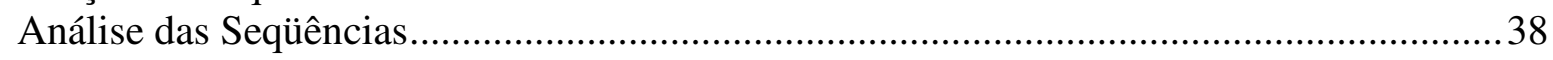

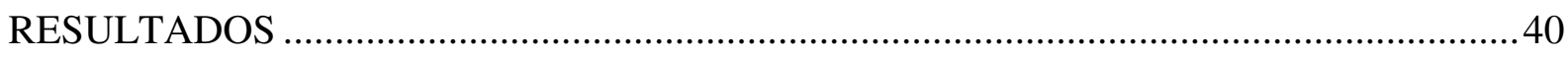

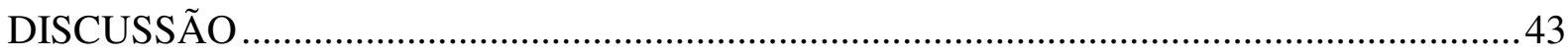

CONCLUSÃO

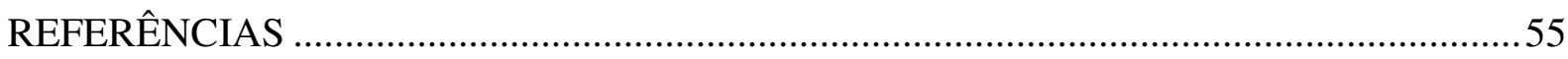

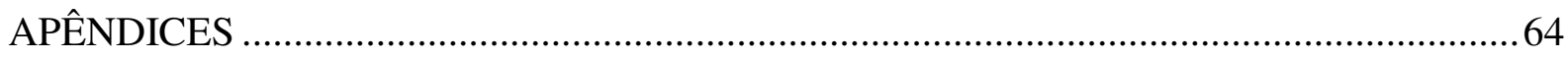

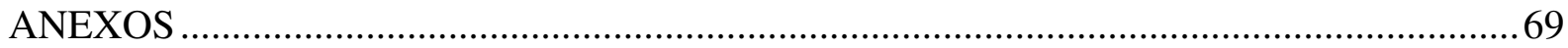


As doenças cardiovasculares são a principal causa de mortalidade e morbidade nas populações adultas de países ocidentais (ANDERSON; CASTELLI; LEVY, 1987). Anitshcoff (1913) sugeriu pela primeira vez em modelo animal, a associação do consumo de gordura e aterosclerose. Os níveis séricos elevados de colesterol total (CT) e de lipoproteína de baixa densidade (LDL, low-density lipoprotein cholesterol) são identificados como fatores de risco para desenvolver doença arterial coronariana (DAC) (KANNEL et al. 1971).

Os estudos epidemiológicos sugerindo a associação entre ingestão de gordura e DAC iniciaram com Keys em 1955 (KEYS et al. 1966) com o "Seven Country Study", seguido dos estudos Framinghan em 1961 (KANNEL et al. 1971) e o MRFIT (Multiple Risk Factor Intervention Trial) (LAROSA et al., 1990; MULTIPLE RISK FACTOR INTERVENTION TRIAL RESEARCH GROUP, 1982) demonstraram haver correlação entre níveis médios de CT de diferentes populações e índices de mortalidade por DAC (MENOTTI et al., 2000).

No Brasil, níveis elevados de CT foram encontrados em 8,8\% dos indivíduos, a partir de um estudo conduzido em 9 capitais, envolvendo 8.045 indivíduos com idade media de 34,7+/-9,6 anos, com valores mais elevados no sexo feminino e nas faixas etárias mais elevadas (GUIMARÃES, 1998).

A Campanha Nacional de Alerta Sobre o Colesterol Elevado mediu a colesterolemia de 81.262 indivíduos em 13 cidades brasileiras, identificando em 40\% deles, níveis de CT>200 mg/dL, sendo 42\% em Porto Alegre, capital do Rio Grande do Sul (MARTINEZ 
et al., 2003). Essa pesquisa serviu de referência para o relatório da Organização Mundial de Saúde sobre Vigilância de Fatores de Risco recentemente publicado (WHO, 2006).

No Rio Grande do Sul, uma pesquisa envolvendo 1.066 indivíduos em 19 cidades representantes da Secretaria Estadual da Saúde do Estado, os níveis elevados de CT atinge 20,3 \% da população (CT entre 200-239 mg/dL) e 5,6\% com CT =ou> $240 \mathrm{mg} / \mathrm{dL}$, com prevalência maior entre as mulheres $(6,9 \%)$ em relação aos homens $(4,1 \%)$ (RIO GRANDE DO SUL, 2003)

A principal causa de mortalidade no Rio Grande do Sul em 2002 foi a doença cardiovascular, que atingiu $31,6 \%$ da população, equivalente a 21.802 óbitos, considerada uma das mais altas do Brasil (RIO GRANDE DO SUL, 2006).

\section{A hipercolesterolemia como doença genética e familiar}

A história familiar tem sido mostrada como ajuda preditiva de risco numa variedade de doenças como a DAC. Williams et al. (2001) determinaram que o antecendente de dois ou mais parentes de primeiro grau com enfermidade coronoariana, era identificado em $8 \%$ da população com risco relativo entre 3-6 para enfermidade precoce coronariana antes dos 50 anos.

A hipercolesterolemia tem sido classificada como um dos escores qualitativos de risco familiar para a doença aterosclerótica precoce. Nora et al. (1980) mostraram evidências que o risco da enfermidade cardiovascular era 7.1 vezes maior se um familiar de primeiro grau era portador de patologia vascular manifesta antes dos 65 anos. Este risco era substancialmente maior que o associado com colesterol superior a $270 \mathrm{mg} / \mathrm{dL}$.

A eficácia do escore hipercolesterolemia se destaca quando da identificação das famílias e populações de alto risco, e a história familiar como instrumento para a detecção de população com risco cardiovascular elevado em family based case finding (THOMPSON, 2002). 
Os estudos ultrassonográficos de Wendelhag, Wiklund e Wikstrand (1992) mostraram que a espessura da parede arterial carotídea era significativamente maior em pacientes hipercolesterolêmicos, pertencentes a famílias portadoras de hipercolesterolemia familiar, comparados ao grupo controle. Essa "marca" patológica da placa aterosclerótica pode ser melhor entendida, se nos reportarmos aos estudos de Brown e Goldstein (1976) que elucidaram o mecanismo de ligação do LDL-C com os seus receptores e o metabolismo do colesterol.

As partículas de LDL-C têm um diâmetro de $19-23 \mathrm{~nm}$, e peso molecular 2,75 x $10^{6}$ daltons, apresentando uma parte central com cerca de 1.500 moléculas de colesterol esterificado, principalmente linoleato. Este núcleo altamente hidrofóbico é circundado por uma capa de fosfolípides e colesterol não-esterificado. A capa contém ainda uma única cópia de apoproteína B-100, com 514 kD. Esta proteína envolvida no transporte de lípides, tem basicamente 2 funções: solubiliza os lípides altamente hidrofóbicos e contém sinais que regulam o movimento das LDLs-C em sua entrada e saída de células-alvo específicas (RIFAI; BACHORIK; ALBERS, 1999). O fígado secreta LDLs-C como precursoras de partículas chamadas VLDL (very-low-density lipoproteins), que contêm triglicérides e ésteres de colesterol. Capilares musculares e adipocitários removem os triglicérides com a consequënte modificação da partícula lipídica em LDL-C. Estas partículas de LDL-C circulam no plasma até a ligação com os receptores da apoproteína B-100 na superfície do hepatócito e em outras células corporais. Por endocitose mediada pelos receptores, as partículas LDL-C entram nas células e são degradadas pelas enzimas dos lisossomos liberando colesterol para o pool celular, cuja quantidade produz retroalimentação negativa do número de receptores e sobre a síntese endógena de colesterol. A elevação do nível de colesterol hepatocitário suprime a transcrição dos genes dos receptores, e o LDL-C é retido no plasma. Reciprocamente, a diminuição do nível de colesterol hepatocitário estimula a transcrição dos genes receptores, e o LDL-C é removido do plasma. Quatro doenças 
monogênicas elevam os níveis plasmáticos de LDL-C, dentre elas a hipercolesterolemia familiar (HF) (NABEL, 2003).

Os níveis de colesterol total > $240 \mathrm{mg} / \mathrm{dL}$ e de LDL-C > $160 \mathrm{mg} / \mathrm{dL}$ são considerados de alto risco para o desenvolvimento da DAC de acordo com o Painel de Especialistas Sobre a Detecção, Avaliação e Tratamento dos Níveis Elevados de Colesterol Sangüíneo, que chamam a atenção para as pessoas que possuem formas genéticas de hipercolesterolemias, pela necessidade de detecção precoce para a prevenção da DAC prematura (NATIONAL CHOLESTEROL EDUCATION PROGRAM-NCEP, 2001).

A alta concordância de infarto do miocárdio entre gêmeos monozigóticos e dizigóticos (aproximadamente $40 \%$ e 20\%, respectivamente) sugere de maneira quase inequívoca, que uma fração significativa da predisposição da doença cardiovascular pode ser representada por fatores genéticos (BERG, 1983; DE FAIRE, 1974; HARVALD; HAUGE, 1965; LILJEFORS, 1970). Tem sido relatada uma dislipidemia geneticamente vinculada em até $2 / 3$ dos pacientes com DAC, e em até metade de seus descendentes de primeiro e segundo graus (GENEST et al., 1992).

A gradual progressão da aterosclerose a partir da infância e na adolescência, pode ser demonstrado pela presença de placas na artéria carótida com sua íntima-média mais engrossada do que os sujeitos controles (TONSTAD et al., 1996). Estudos realizados em autópsia sugerem que a aterogênese tem início na infância (STRONG et al., 1999), com a formação da placa aterosclerótica iniciando-se no desenvolvimento fetal, podendo ser acelerada pela hipercolesterolemia materna, com a subseqüente progressão rápida da lesão aterosclerótica na criança (NAPOLI et al., 1997).

Estas alterações precoces, que aceleram a doença aterosclerótica, têm forte componente familiar, atribuíveis à ocorrência da herança monogênica de um produto gênico anormal, envolvido num padrão metabólico determinado como é o caso da DAC precoce devido à hipercolesterolemia familiar (HF). 
Pela análise dos estudos atuais, existem pelo menos cinco genes envolvidos na etiologia das hipercolesterolemias (ABIFADEL et al., 2003; GOLDSTEIN; BROWN, 2001), ou seja:

1) O gene do receptor de LDL-C;

2) O gene da apoproteína B-100;

3) O gene da proteína adaptadora do receptor do LDL-C (Autosomal Recessive LDL-C (Hypercholesterolemia - ARH);

4) $\mathrm{O}$ gene do transportador do grupamento ligante adenosina-trifosfato ( $A B C G 5$ elou ABCG8 ATP - binding cassette transporters)

5) O gene PCSK9 (proprotein convertase subtilisin/kexin type 9) implicado na HCHOLA 3 ou FH 3 (hypercholesterolemia, autossomal dominant, 3)

As variações nos genes do LDLR, apolipoproteína B e apolipoproteína E têm um considerável efeito sobre as concentrações plasmáticas de colesterol, especialmente nos indivíduos com hipercolesterolemia familiar (HF), onde as variações no gene LDLR dos heterozigotos duplica as concentrações plasmáticas de colesterol em relação às apo B/E, sendo maior ainda nos homozigotos (BOER et al., 1998; KASTELEIN et al., 1999; KUIVENHOVEN et al., 1998).

\section{A Hipercolesterolemia Familiar $(\mathrm{HF})$}

O evento cardiovascular mais precoce que ocorre numa população, procede de famílias com história positiva de doença cardiovascular. A história familiar é ferramenta validada e de baixo custo para a medicina preventiva e para a pesquisa médica (WILLIAMS et al., 2001).

A detecção da HF se baseia na identificação de famílias com aterosclerose precoce e em indivíduos com antecedentes familiares de enfermidade cardiovascular.

Khachadurian e Uthman (1973) descreveram pela primeira vez 2 categorias de HF, autossômica dominante e recessiva.

A HF autossômica dominante é uma doença provocada por alterações do metabolismo das lipoproteínas, causando depósitos de colesterol em tendões (xantomas), nas pálpebras (xantelasmas), arco corneal precoce e doença arterial coronariana, 
usualmente na quarta e quinta décadas de vida nos heterozigotos, com ocorrência aproximada de 1/500 indivíduos com níveis séricos de colesterol que oscilam entre 300$400 \mathrm{mg} / \mathrm{dL}$. Os homozigotos, com ocorrência descrita de 1/1.000.000 nascimentos, são mais gravemente afetados, possuíndo níveis de colesterol variando entre 600-1.200 $\mathrm{mg} / \mathrm{dL}$, a maioria tendo infarto do miocárdio antes dos 20 anos de idade (GOLDSTEIN; BROWN, 2001).

A HF de herança autossômica dominante, possui as seguintes características gerais (THOMPSON, 2002):

1- O fenótipo em geral aparece em todas as gerações, com as pessoas afetadas tendo pelo menos um genitor afetado.

2- Qualquer filho de um genitor afetado tem um risco de $50 \%$ de herdar a característica, se for heterozigoto.

3- Membros da família fenotipicamente normais não transmitem o fenótipo para seus filhos.

4- Homens e mulheres têm igual probabilidade de transmitir o fenótipo para seus filhos de ambos os sexos. Pode ocorrer a transmissão de homem para homem, e os homens podem ter filhas não-afetadas.

5- Uma proporção significativa de casos isolados deve-se a mutações novas. Quanto menor é a adaptabilidade, maior é a proporção devida a uma mutação nova.

\section{Mecanismo celular da HF: defeitos no receptor $L D L-C(L D L R)$}

Entre 60-70\% do LDL-C circulante é removido da circulação pelo processo de endocitose mediado por receptores que são glicoproteínas sintetizados no retículo endoplasmático das células, parte deles se projetando para fora da célula, ligando-se às partículas circulantes de LDL pela apoproteína B-100 (BROWN; GOLDSTEIN, 1976; GOLDSTEIN; BROWN, 1984), nas chamadas "depressões revestidas" que se invaginam, trazendo a partícula LDL-C para dentro da célula. Nesse momento, separa-se do receptor, é captada e degradada pelas enzimas lisossômicas em seus constituíntes. O LDLR é recirculado para a superfície da célula para captação de outras partículas LDL-C (cada LDLR passa por este ciclo aproximadamente uma vez a cada dez minutos, mesmo que não esteja ocupado por uma partícula de LDL-C). O colesterol livre é liberado do vacúolo 
digestivo para incorporação às membranas celulares para o metabolismo de ácidos biliares, esteróides e, provavelmente, outras funções fisiológicas.

O excesso de colesterol pode ser armazenado na célula como éster de colesterol, ou removido da célula por associação com lipoproteínas de alta densidade (HDL high-density lipoprotein). À medida que se elevam os níveis de colesterol na célula, a síntese de colesterol celular é reduzida pela inibição da enzima da HMG-CoA redutase (3-hidroxi-3metilglutaril CoA redutase) e pela redução da síntese de LDLR. A elevação dos níveis de colesterol também aumenta a atividade de acilCoA: colesterol aciltransferase (ACAT), enzima que modifica o colesterol para armazenamento como ésteres de colesterol (GOLDSTEIN; BROWN, 1984).

A HF é causada por uma alteração na síntese ou capacidade funcional dos receptores de LDL-C. O número de receptores efetivos é reduzido em cerca da metade nos heterozigotos, e os homozigotos tem praticamente a ausência de receptores funcionais de LDL-C (GOLDSTEIN; BROWN, 2001). Em outras situações, os receptores podem ter atividade funcional reduzida.

\section{As Bases Moleculares da Hipercolesterolemia Familiar (HF)}

Francke, Brown e Goldstein (1984) identificaram a localização do gene do LDLR no cromossomo 19 com base nos estudos de células somáticas híbridas de hamster e de células humanas. O gene do LDLR foi localizado na região 19p13.1-p 13.3 pelo seu sítio de hibridização (LINDGREN et al., 1985). Na construção computacional do mapa físico desse cromossomo, comparado com o mapa genético, foram identificadas mais recombinações em direção aos telômeros e uma taxa de recombinações masculina/feminina variada, sendo o mapa feminino $10 \%$ mais longo que o mapa masculino (MOHRENWEISER et al., 1998) como mostra a Figura 1. 

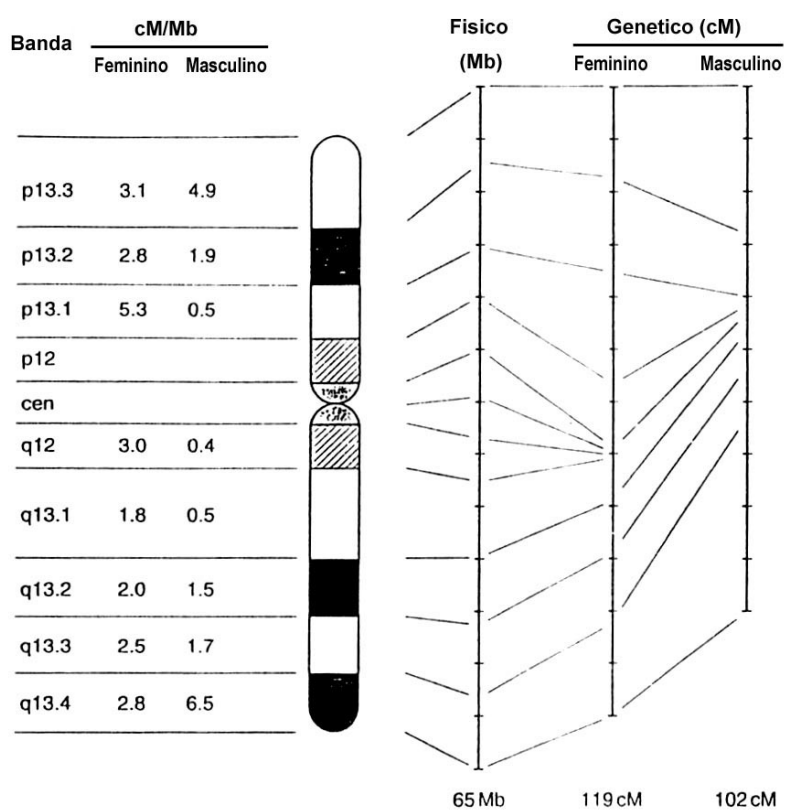

Figura 1. Relação dos mapas físico e genético do cromossomo 19 $\mathrm{Mb}$ (megabase $)=$ distância física entre dois loci

$\mathrm{cM}($ centimorgan $)=$ distância entre dois loci com $1 \%$ de recombinação cen $=$ centrômero

O LDL-r ou LDLR ou LDL-R é sintetizado como uma glicoproteína precursora de $120 \mathrm{kD}$ e que sofre modificações para glicoproteína madura de $160 \mathrm{kD}$, pela adição covalente de uma proteína de $40 \mathrm{kD}$ (TOLLESHAUG et al., 1982). Yamamoto et al. (1984) relataram que o LDLR é uma proteína de 839 aminoácidos, rica em cisteína e com múltiplas cópias da família $A l u$ de DNA repetitivo.

O gene LDLR possui 18 exons (sequiências codificadoras de proteínas), 17 introns e 5 domínios (regiões conservadas importantes, cada uma com função específica), cobrindo uma região de cerca de $45 \mathrm{~kb}$ (SÜDHOF et al., 1985). O domínio amino-terminal com função de ligação com o LDL-C apresenta 292 aminoácidos e, ainda, uma seqüência rica em cisteína de aproximadamente 40 aminoácidos, a qual é repetida, com algumas variações, sete vezes. Existem nesse domínio cadeias laterais de aminoácidos carregados negativamente, que interagem com um domínio positivamente carregado da apoproteína B100. A liberação da proteína receptora de seu ligante (apoB-100) se faz, no endossomo, por ruptura das cadeias laterais de glutamato e aspartato nele presentes. Em seguida a esse domínio, encontra-se uma região constituída por 350 aminoácidos, homóloga a uma parte 
do precursor do fator de crescimento epidérmico (EGF). Neste domínio, existem duas cadeias oligosídicas $\mathrm{N}$-ligadas, que são inseridas no retículo endoplasmático e depois modificadas quando da passagem no aparelho de Golgi. Um terceiro domínio rico em serina e treonina, formado por 58 aminoácidos, contém várias oses O-ligadas. É possível que sirvam como escoras para manter o domínio de ligação com a apoB-100 adequadamente posicionada para o acesso desta proteína. O quarto domínio corresponde à região transmembrana, sendo formado por 22 aminoácidos hidrófobos que atravessam a membrana plasmática. O quinto domínio, carboxiterminal, consiste em 50 aminoácidos e está localizado no lado citossólico da membrana, participando da interação entre o receptor e a fossa revestida para o processo de endocitose (LEHNINGER, 1995).

Sudhof et al. (1985) mostraram em dezoito exons do gene, que treze deles são homólogos a seqüências em outras proteínas: cinco codificam uma seqüência similar existente no componente do complemento C9 (5p13); três codificam uma seqüência similar a uma repetida no precursor do EGF e em três proteínas do sistema de coagulação sanguínea - fator IX (Xq27.1-q27.2), fator X (13q34) e proteína C (2q13-q14) - e 5 outros exons codificam seqüências não repetidas que participam somente com o precursor do EGF. Subseqüentemente, o LDLR é um mosaico composto de exons em que os domínios são compartilhados por diferentes proteínas, e se constitui um membro das diversas famílias de supergenes. A relevância desses achados permitiu a compreensão do significado da segregação dos genes e o rearranjo dos exons durante a evolução (GILBERT, 1985).

A análise do gene LDLR em pacientes com HF já permitiu identificar 477 mutações de sentido alterado (missense) ou sem sentido (nonsense), 57 mutações que alteram o sítio de splicing, 12 mutações que deslocam o quadro de leitura (frameshift), 91 grandes deleções, 130 pequenas deleções, 19 grandes inserções, 55 pequenas inserções, 15 pequenas inserções/deleções (indels) e 1 rearranjo complexo (BIOBASE, 2005). 
Essas mutações estão organizadas em cinco classes:

Classe I, contém as mutações mais comuns e levam a uma falta total de síntese da proteína receptora (alelo nulo) (HOBBS et al., 1988);

Classe II, são aquelas mutações que causam o acúmulo de LDLR endoplasmático, por não poderem ser transportados para o complexo de Golgi;

Classe III, são mutações que afetam o domínio de ligação da molécula de LDL-C no receptor. As proteínas codificadas atingem a superfície, mas não se ligam ao LDL-C ou ligam-se muito pouco (alelos de ligação deficiente) (TOLLESHAUG et al., 1983);

Classe IV, mutações que levam a síntese de proteínas que são transportadas eficientemente para a superfície celular. Elas se ligam normalmente ao LDL-C, mas não se situam nas depressões revestidas e, portanto, a ligação com o LDL-C não é internalizada (GOLDSTEIN et al., 1985); e

Classe V, sendo aquelas mutações que fazem com que o complexo receptor-molécula de LDL-C não se dissocie. Desta forma, o receptor é enzimaticamente degradado junto com a molécula de LDL-C no endossomo (DAVIS et al, 1987; ROBBINS et al., 1996).

Este acúmulo de moléculas mutantes de LDLR no retículo endoplasmático, foi mostrado em modelo animal, pela técnica da microscopia imunofluorescente (KIM et al., 2004) onde a imagem da LDLR selvagem localizada primariamente sobre a superfície da célula é comparada com a imagem da LDRL mutante, que forma um padrão reticular através do citoplasma, com alta intensidade luminosa na região perinuclear.

\section{Mutações do gene LDLR relacionadas à etnicidade}

De acordo com informações do On Line Mendelian Inheritance in Man (OMIM, 2005) o número de mutações do gene LDLR relacionadas à etinicidade são apresentados no Tabela 1. 
Tabela 1 - Etnicidade e $\mathrm{n}^{\mathrm{o}}$ de mutações do gene LDLR

\begin{tabular}{|c|c|}
\hline Etnia & $\mathrm{N}^{0}$ de Mutações(Locus LDLR) \\
\hline Afriacanos * & 21 \\
\hline Sul Africanos * & 43 \\
\hline Australianos & 45 \\
\hline Judeus & 05 \\
\hline Afro-americanos & 19 \\
\hline Canadenses & 11 \\
\hline Chineses * & 15 \\
\hline Austríacos & 27 \\
\hline Belgas & 19 \\
\hline Tchecos & 12 \\
\hline Dinamarqueses & 44 \\
\hline Libaneses & 01 \\
\hline Sírios & 06 \\
\hline Costa-riquenhos & 81 \\
\hline Holandeses & 29 \\
\hline Russos & 09 \\
\hline Finlandeses & 20 \\
\hline Franceses * & 28 \\
\hline Ingleses * & 110 \\
\hline Alemães * & 98 \\
\hline Gregos * & 13 \\
\hline Húngaros & 124 \\
\hline Coreanos & 18 \\
\hline Mexicanos & 04 \\
\hline Italianos $*$ & 14 \\
\hline Japoneses & 36 \\
\hline Poloneses * & 13 \\
\hline Irlandeses & 14 \\
\hline Noruegueses & 22 \\
\hline Escoceses & 05 \\
\hline Suecos & 26 \\
\hline Espanhóis & 57 \\
\hline Portugueses & 03 \\
\hline
\end{tabular}

* de várias procedências

A freqüência de diferentes mutações no gene LDLR varia no mundo, em diferentes regiões e podem ser comuns a várias etnias. No Brasil, a sua população é formada pela contribuição de um grande número de componentes étnicos (Tabela 2). 
Tabela 2 - A contribuição da imigração forçada e imigração espontânea para o Brasil até a metade do século XX

\begin{tabular}{llr}
\hline Séculos $16-19$ & \multicolumn{2}{c}{ Imigração forçada } \\
\hline & Negros africanos & 2.500 .000 \\
\hline $1819-1947$ & \multicolumn{1}{c}{ Imigração espontânea } \\
\hline & Italianos & 1.513 .151 \\
& Portugueses & 1.142 .117 \\
& Espanhóis & 598.802 \\
& Alemães e Austríacos & 348.302 \\
& Eslavos & 202.430 \\
& Japoneses & 188.622 \\
& Libaneses + Sírios & 79.509 \\
& Outros & 511.058 \\
& Total & 4.903 .991 \\
& & 40.000 .000 \\
\hline
\end{tabular}

Fonte: Instituto Brasileiro de Geografia e Estatística. 1986

A frequiência de diferentes mutações também deve variar em diferentes regiões, refletindo a variedade de imigração e os vários graus de miscigenação dos diferentes grupos étnicos (ALBERTO et al., 1999; FIGUEIREDO et al., 1992; SALAZAR et al., 2000).

O Brasil participa do Programa MED-PED (“Make Early Diagnoses to Prevent Early Deaths”) da Organização Mundial da Saúde que estimou cerca de 320.000 indivíduos com heterozigose para a HF no Brasil (WHO, 1999).

O estudo molecular dos defeitos do gene LDLR no Brasil foi iniciado em Ribeirão Preto (região Sudeste do Brasil) por um grupo de pesquisadores liderados por Zago e Santos (ALBERTO et al., 1999; FIGUEIREDO et al., 1992) que encontraram em 14 famílias das 16 pesquisadas, o "alelo libanês", uma mutação $\mathrm{C}>\mathrm{A}$ no exon 14 , do tipo nonsense $\mathrm{C660X}$, que resulta na produção de uma proteína truncada, sem atividade funcional. Apesar da pequena contribuição do povo árabe (menos de 1\%), a mutação 
C660X tem prevalência de 30\% entre os pacientes atendidos no Ambulatório de Nutrologia do Hospital das Clínicas da Faculdade de Medicina de Ribeirão Preto da Universidade de São Paulo. Provavelmente, a mutação C660X representa uma das mais importantes, senão a mais importante causa de HF no Brasil, que pode se dever ao efeito fundador "inbreeding" por causa da endogamia que ocorreu entre os imigrantes da primeira geração.

Mais recentemente, Salazar et al. (2002) definiram a base molecular de um grupo de pacientes com HF, residentes no município de São Paulo, todos de origem européia, identificando 15 mutações no gene LDLR, das quais sete são mutações novas, cinco do tipo sinônimas e duas do tipo frameshift, que alteram a seqüência original de aminoácidos a partir do ponto onde a mutação ocorreu (Tabela 3).

Tabela 3 - Mutações encontradas em pacientes brasileiros com HF descritas por Salazar et al. (2002)

\begin{tabular}{ccllc}
\hline Região & Mutação & \multicolumn{1}{c}{ Tipo } & $\begin{array}{c}\text { Substituição do } \\
\text { aminoácido }\end{array}$ & Nome \\
\hline Exon 1 & $\mathbf{c . 4 G}>\mathbf{C}$ & Não-sinônima & Gly $\rightarrow$ Arg & G (-20)R \\
Exon 4 & c.337G $>$ T & Codon de parada & Glu $\rightarrow$ stop & E92X \\
Exon 5 & c.769C $>$ T & Não-sinônima & Arg $\rightarrow$ Trp & R236W \\
Exon 7 & c.1027G $>$ A & Não-sinônima & Gly $\rightarrow$ Ser & G322S \\
Exon 8 & c.1118G $>$ A & Não-sinônima & Gly $\rightarrow$ Asp & G352D \\
Exon 8 & c.1171G $>$ A & Não-sinônima & Ala $\rightarrow$ Thr & A370T \\
Exon 8 & c.1176C $>$ A & Codon de parada & Cys $\rightarrow$ stop & C371X \\
Exon 10 & c.1489A $>$ G & Não-sinônima & Thr $\rightarrow$ Pro & T476P \\
Exon 10 & $\mathbf{c . 1 5 7 1 T > G}$ & Não-sinônima & Val $\rightarrow$ Gly & V503G \\
Exon 12 & $\mathbf{c . 1 8 0 1 G ~}>$ C & Não-sinônima & Asp $\rightarrow$ His & D580H \\
Exon 14 & $\mathbf{c . 2 0 1 7 A ~}>$ C & Não-sinônima & Ser $\rightarrow$ Arg & S652R \\
Exon 14 & c.2088C $>$ C & Não-sinônima & Cys $\rightarrow$ Trp & C675W \\
Exon 14 & c.2093G $>$ A & Não-sinônima & Cys $\rightarrow$ Tyr & C677Y \\
Exon 16 & $\mathbf{c . 2 3 3 3 i n s C ~}$ & Frameshift & R757fsX760 & FsR757 \\
Exon 17 & $\mathbf{c . 2 5 4 6 d e l C ~}$ & Frameshift & S828fsX828 & FsS828
\end{tabular}

As mutações novas estão representadas em negrito (BIOBASE, 2005) (cDNA sequence)

Inocêncio (2003) em Ribeirão Preto, analisou as mutações do gene LDLR em 32 casos índices e suas famílias, previamente caracterizados nos estudos de Alberto et al. (1999) e Figueiredo et al. (1992), identificando oito mutações novas, que ainda não haviam sido descritas na literatura. 
Van de Kerkhof et al. (2003) identificaram uma mutação do gene LDLR nunca descrita, onde a serina é substituída por uma cisteína na posição do aminoácido 305 da proteína (S305C) em descendentes de italianos no Brasil. Essa família, cujo heredograma é mostrado na Figura 1, com análise da seqüência dos exons 7 e 14, revelou a presença da mutação S305C proveniente da herança materna, e da mutação C660X da herança paterna. Ambas as mutações segregaram com a hipercolesterolemia por três gerações, sendo a família do pai (probando) de origem libanesa e a família da mãe de origem italiana.

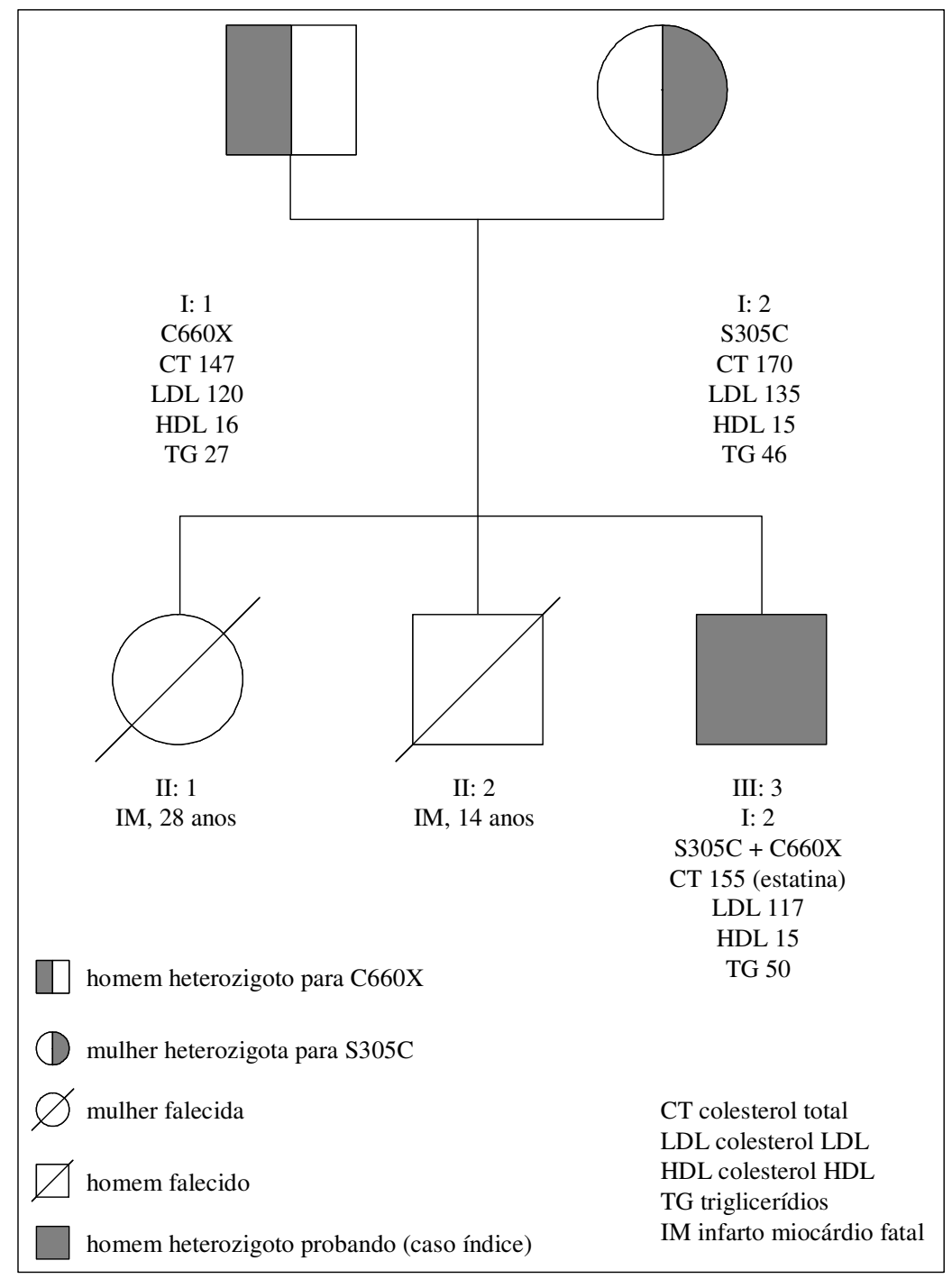

Figura 2 - Heredograma dos membros da família, mostrando os valores do perfil lipídico $\mathrm{em} \mathrm{mg} / \mathrm{dL}$

Os poucos estudos no Brasil que relatam cerca de 20 mutações associadas com a deficiência na função do gene LDLR e a identificação de mutações distintas, além de 
novas mutações envolvendo pacientes da mesma região, predominantemente de origem européia, foi o que motivaram a ampliação do estudo para a região Sul do Brasil, especificamente o Estado do Rio Grande do Sul colonizado por imigrantes vindos principalmente da Europa (Tabela 4).

Tabela 4 - Imigração espontânea para o Estado do Rio Grande do Sul

\begin{tabular}{lcc}
\hline Nacionalidade & Período da Imigração & N $^{0}$ de Imigrantes \\
\hline Italianos & $1875-1914$ & 76.000 \\
Alemães & $1885-1937$ & 43.115 \\
Poloneses & $1885-1937$ & 23.796 \\
Uruguaios & $1882-1940$ & 19.739 \\
Russos & $1885-1912$ & 19.525 \\
Austríacos & $1885-1912$ & 4.779 \\
Portugueses & $1886-1954$ & 4.141 \\
Franceses & $1844-1852$ & 955 \\
Espanhóis & $1844-1852$ & 720 \\
Sírios + Libaneses & $1880-1926$ & 700 \\
Judeus & $1904-1926$ & 178 famílias \\
Letonianos & $1890-1895$ & 32 famílias \\
Japoneses & Século XX & Sem registro \\
\hline \multicolumn{1}{c}{ Fonte: Enciclopédia Rio-Grandense (1958a, $1958 \mathrm{~b}, 1958 \mathrm{c}, 1958 \mathrm{~d}, 1958 \mathrm{e}, 1958 \mathrm{f})$}
\end{tabular}

Fonte: Enciclopédia Rio-Grandense (1958a, 1958b, 1958c, 1958d, 1958e, 1958f) 


\section{OBJETIVOS}

O objetivo desse estudo foi o de identificar, na população do Rio Grande do Sul, as características genéticas da hipercolesterolemia familiar, por três motivos fortes:

a) o tipo de imigração predominantemente européia;

b) uma das regiões do Brasil com a maior prevalência de hipercolesterolemia; e

c) a região do Brasil com uma das mais altas taxas de mortalidade por doença cardiovascular.

Para tanto, procedemos o seqüenciamento direto do gene LDLR e posterior identificação das mutações pela análise dos cromatogramas pela bioinformática. 


\section{Delineamento da Pesquisa}

Este é um estudo descritivo-exploratório (VAN DALEN; MEYER, 1979) das mutações do gene LDLR em indivíduos portadores de hipercolesterolemia familiar e residentes no Estado do Rio Grande do Sul.

\section{Amostra}

Para estimar a proporção de ocorrência de mutações de quaisquer tipos no gene LDLR, foram selecionados por amostragem de conveniência 40 indivíduos de ambos os sexos, cadastrados em serviços assistenciais de saúde (hospitais, ambulatórios, postos de saúde) do Estado do Rio Grande do Sul, e que atenderam aos seguintes critérios de inclusão:

-ter idade mínima de 18 anos;

-serem hipercolesterolêmicos:

a) com colesterol total igual ou superior a $280 \mathrm{mg} / \mathrm{dL}$ sem tratamento

b) com colesterol total maior que $200 \mathrm{mg} / \mathrm{dL}$ e menor que $280 \mathrm{mg} / \mathrm{dl}$ em tratamento com estatinas por 6 meses ou mais

-ter história de infarto do miocárdio ou angioplastia ou doença arteriosclerótica ou, ainda,

-ter cardiopatia isquêmica

-apresentar xantomas 
Todos os pacientes são pertencentes a famílias viáveis de serem acessadas e de origem étnica oriunda dos movimentos imigratórios para o Rio Grande do Sul, e concentrados nas macrorregiões do Estado, conforme Figura 2.

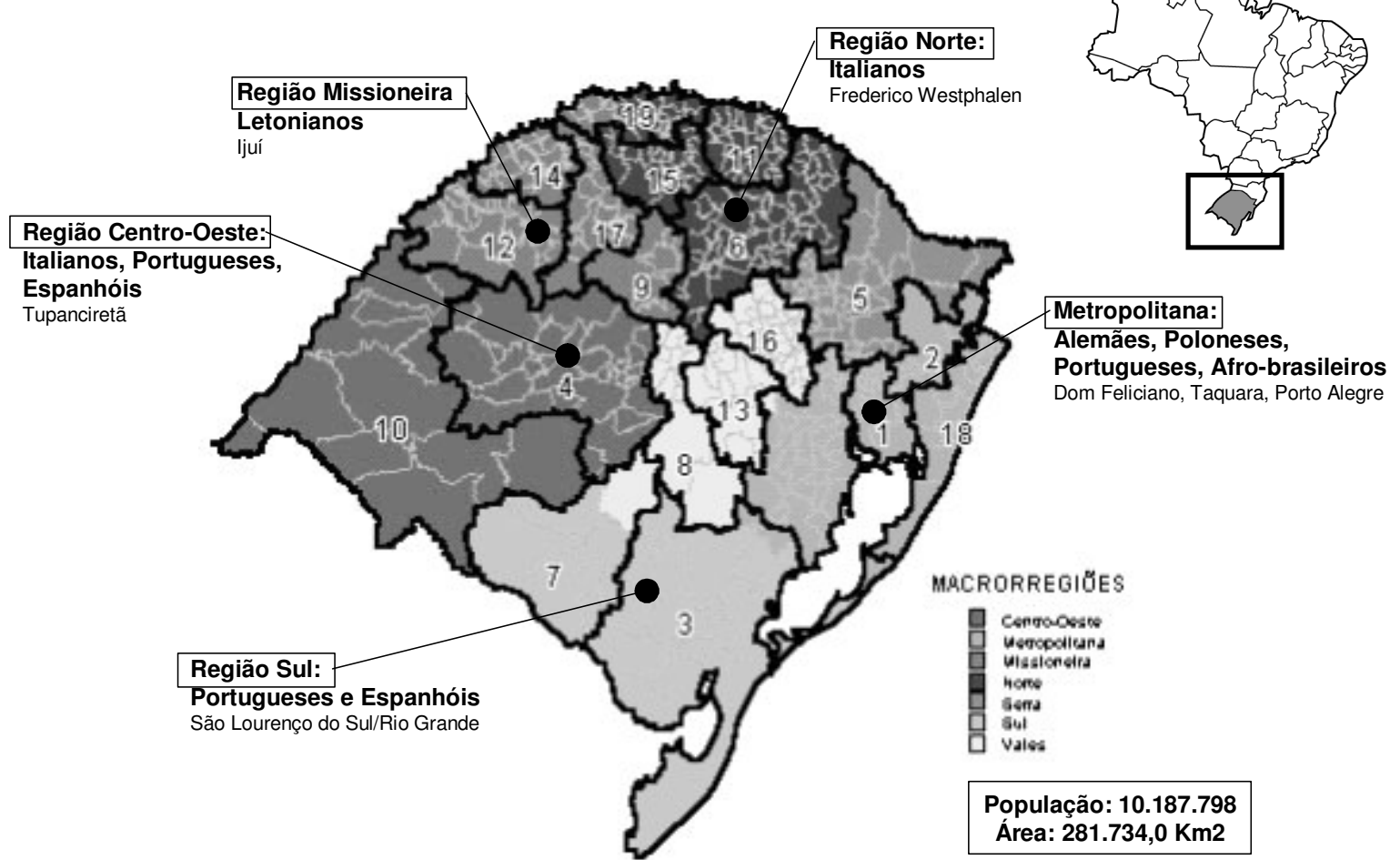

Figura 3. Macrorregiões do Estado do Rio Grande do Sul

Nas unidades de assistência médica de cada município visitado, depois da explicação pelo pesquisador aos participantes do estudo sobre os objetivos da pesquisa e esclarecimentos a respeito da doença e seu modo de herança, foi preenchida ficha de identificação individual pelos funcionários da unidade(ANEXO A), e assinado o Termo de Consentimento Livre e Esclarecido (ANEXO B) aprovado pelo Comitê de Ética em Pesquisa do Hospital das Clínicas da Faculdade de Medicina de Ribeirão Preto da Universidade de São Paulo (ANEXO C) 


\section{Coleta e Transporte do Material}

No ambulatório dos serviços de saúde, atendido por pessoal técnico, foram coletados 10 mililitros de sangue venoso de cada paciente, em tubos de hemólise contendo o anticoagulante EDTA.

Estes tubos foram submetidos à centrifugação (2.500 rpm) por 20 minutos e invertidos para a obtenção do "creme leucocitário", em tubos cônicos (Falcon - 15 ml). Devidamente identificados, estes tubos foram embalados adequadamente para o transporte via aérea do Rio Grande do Sul para o Laboratório de Lípides da Faculdade de Medicina de Ribeirão Preto, São Paulo.

\section{Extração do DNA}

No Laboratório de Lípides, estes tubos foram centrifugados com um tampão de lise de glóbulos vermelhos para eliminá-los, até a obtenção dos leucócitos, e a seguir o isolamento do DNA desses leucócitos (Apêndice A). Após essa extração, o DNA foi quantificado e diluído para a formação de alíquotas de 100 microlítros, com uma concentração de 100 nanogramas por microlitros de DNA, e posteriormente estocados a 20 ${ }^{\circ} \mathrm{C}$ negativos.

\section{Amplificação por PCR (“Polymerase Chain Reaction”)}

A PCR (Reação em Cadeia de Polimerase) explora a capacidade de duplicação do DNA. Uma fita simples de DNA é usada como molde para a síntese de novas cadeias complementares sob a ação da DNA polimerase, capaz de adicionar os nucleotídeos presentes na reação que são complementares à fita mode. A enzima polimerase do DNA requer, entretanto, um "ponto de início" ligado à fita molde que serve de apoio para que os nucelotídeos subsequentes sejam adicionados. Esse "ponto de início" da síntese é fornecido 
por um oligonucleotídeo, de cerca de 20 pb, que se hibrida (se anela) à fita molde simples, o qual é denominado de primer. Ambas as fitas simples iniciais servem de fita molde para a síntese, desde que se forneça primers específicos a cada uma delas. Dessa forma, a região do DNA genômico a ser sintetizada é definida pelos primers, que se anelam especificamente as suas seqüências complementares na fita molde, delimitando o fragmento de DNA que se deseja amplificar.

O processo que requer diferentes reagentes (APÊNDICE B) inicia-se com a desnaturação da dupla fita do DNA que contém a seqüência a ser amplificada. Geralmente, a desnaturação é realizada a uma temperatura ao redor de $94^{\circ} \mathrm{C}$ durante 5 minutos, uma temperatura na qual as duas fitas do DNA se separam.

O passo seguinte, consiste em baixar a temperatura para níveis ao redor de $60^{\circ} \mathrm{C}$, permitindo que os oligonucleotídeos iniciadores anelem-se especificamente nas extremidades flanqueadas da seqüência alvo e nas fitas opostas. Finalmente, a temperatura é elevada para aproximadamente $72^{\circ} \mathrm{C}$ e com isto a DNA-polimerase copia a sequiência alvo a partir dos oligonucleotídeos iniciadores, é a fase de extensão.

As condições de PCR e primers utilizados na amplificação dos exons e introns estão demonstrados na Tabela 5. 
Tabela 5 - Seqüência de primers utilizados para o seqüenciamento dos exons e introns do gene LDLR, temperatura de annealing e tamanho dos fragmentos amplificados

\begin{tabular}{|c|c|c|c|c|}
\hline $\begin{array}{c}\text { Regiões } \\
\text { Amplificadas }\end{array}$ & Primers & Sequiência 5' $\rightarrow$ 3' & TA & $\begin{array}{l}\text { Produto do PCR } \\
(\mathrm{pb})\end{array}$ \\
\hline \multirow[t]{2}{*}{ Exon 3} & LDLrEx3F & CTCGGCTCAGTGGGTCTTTC & $57^{\circ} \mathrm{C}$ & $260 \mathrm{pb}$ \\
\hline & LDLrEx3R & GAGCAGGACCCCGTAGAGACAAA & & \\
\hline \multirow[t]{2}{*}{ Exon 4} & LDLrEx4F & AATGGGCTGGTGTTGGGAGACTTC & $60^{\circ} \mathrm{C}$ & $497 \mathrm{pb}$ \\
\hline & LDLrEx4R & GAGCCCAGGGACAGGTGATAGGAC & & \\
\hline \multirow[t]{2}{*}{ Exon 5} & LDLrEx5F & AGGCCCTGCTTCTTTTTCTCT & $56^{\circ} \mathrm{C}$ & $414 \mathrm{pb}$ \\
\hline & LDLrEx5R & CTGCCGTGAGCTGTGATTGTG & & \\
\hline \multirow[t]{2}{*}{ Exon 6} & LDLrEx6F & GTGCCCGACGCGTTTTCTTA & $59^{\circ} \mathrm{C}$ & $699 \mathrm{pb}$ \\
\hline & LDLrEx6R & ATCCACCGCGCCCAGCATC & & \\
\hline \multirow[t]{2}{*}{ Exon 7} & LDLrEx7F & GGCGAAGGGATGGGTAGGGGC & $59^{\circ} \mathrm{C}$ & $236 \mathrm{pb}$ \\
\hline & LDLrEx7R & GGTGCCATGTCAGGAAGCGC & & \\
\hline \multirow[t]{2}{*}{ Exon 8} & LDLrEx8F & TGTCTCCTGGCTGCCTTCGAA & $58^{\circ} \mathrm{C}$ & $406 \mathrm{pb}$ \\
\hline & LDLrEx8R & GGCAAGCCCAAGTCCTAACA & & \\
\hline \multirow[t]{2}{*}{ Exon 9} & LDLrEx9F & TCCATCGACGGGTCCCCTCTGACCC & $53^{\circ} \mathrm{C}$ & $272 \mathrm{pb}$ \\
\hline & LDLrEx9R & AGCCCTCATCTCACCTGCGGGCCAA & & \\
\hline \multirow[t]{2}{*}{ Exon 10} & LDLrEx10F & ATGCССтTCTCтсCTCCTGCСTCAG & $63^{\circ} \mathrm{C}$ & $280 \mathrm{pb}$ \\
\hline & LDLrEx10R & AGCCCTCAGCGTCGTGGATAGGCAC & & \\
\hline \multirow[t]{2}{*}{ Exon 11} & LDLrEx11F & CCAGCAGGACTATTTCCCAA & $58^{\circ} \mathrm{C}$ & $346 \mathrm{pb}$ \\
\hline & LDLrEx11R & GGAAACCTTCAGGGAGCAGCTT & & \\
\hline \multirow[t]{2}{*}{ Exon 12} & LDLrEx12F & AGGCTCACATGTGGTTGGAG & $54^{\circ} \mathrm{C}$ & $360 \mathrm{pb}$ \\
\hline & LDLrEx12R & GCTTGAGTGATCTATAGTCTGTGT & & \\
\hline Exon 14 & LDLrEx14R & GGAGGGGGCAGTTGGAGGACAC & $60^{\circ} \mathrm{C}$ & $661 \mathrm{pb}$ \\
\hline \multirow[t]{2}{*}{ Exon 15} & LDLrEx15F & GAGACTTTCGTCATTAGGCG & $54^{\circ} \mathrm{C}$ & $435 \mathrm{pb}$ \\
\hline & LDLrEx15R & GTTATTAGACCCACTTTACAG & & \\
\hline \multirow[t]{2}{*}{ Exon 16} & LDLrEx16F & GTCCTACAACCTCGATAACTCAC & $56^{\circ} \mathrm{C}$ & $401 \mathrm{pb}$ \\
\hline & LDLrEx16R & GAGGCCGTGGGGGTGATAAAGGAC & & \\
\hline \multirow[t]{2}{*}{ Exon 17} & LDLrEx17F & CCACAAGGCGATCTCTAAAC & $56^{\circ} \mathrm{C}$ & $491 \mathrm{pb}$ \\
\hline & LDLrEx17R & TGCTTATCCAACATTCCTCTACAC & & \\
\hline \multirow[t]{2}{*}{ Exon 18} & LDLrEx18F & TGCCAGGCCCAGAAGGTGAGAA & $60^{\circ} \mathrm{C}$ & $355 \mathrm{pb}$ \\
\hline & LDLrEx18R & CCCCCGGGCCTGTTTCTCTTAT & & \\
\hline
\end{tabular}

$\mathrm{TA}=$ temperatura de annealing $; \mathrm{F}=$ Forward $; \mathrm{R}=$ Reverse

As regiões mutantes amplificadas são analisadas por eletroforese em gel de agarose

$1,5 \%$ e são utilizados para a reação de sequenciamento.

\section{Reação de Seqüenciamento}

A partir do primeiro PCR, as placas são preparadas para a eletroforese no ciclador automático (APÊNDICE C).

O seqüenciamento foi realizado em seqüenciador automático MegaBace ${ }^{\mathrm{TM}} 1000$ (Amersham Biosciences, Piscataway, NJ, USA) utilizando DYEnamic ET Dye Terminator Sequencing kit (Amersham Biosciences, Piscataway, NJ, USA) (APÊNDICE D) em que os nucleotídeos que compõem a cadeia do DNA (dCTP, dATP, dGTP, dTTP) foram 
marcados com fluorocromos. Quatro diferentes fluorocromos foram empregados e, uma vez excitados por um feixe de laser, emitem luz em diferentes comprimentos de onda. É possível marcar com estes fluorocromos o primer universal M13 ou então cada um dos dideoxinucleotídeos (terminadores).

Assim, uma vez que em cada uma das reações (A, T, C, G) foi empregado um fluorocromo diferente, é possível juntar estes produtos e realizar a corrida em uma única raia do gel de seqüenciamento. Os produtos da reação de seqüenciamento, marcados com fluorocromos, ao serem submetidos à eletroforese, passam pelo feixe de laser que promove a excitação dos fluorocromos. A luz emitida pelos fluorocromos é detectada por um fotomultiplicador, e a informação é processada e traduzida na forma de seqüência de bases, representadas por sinais (picos) coloridos ou cromatogramas, conforme ilustra a Figura 3.

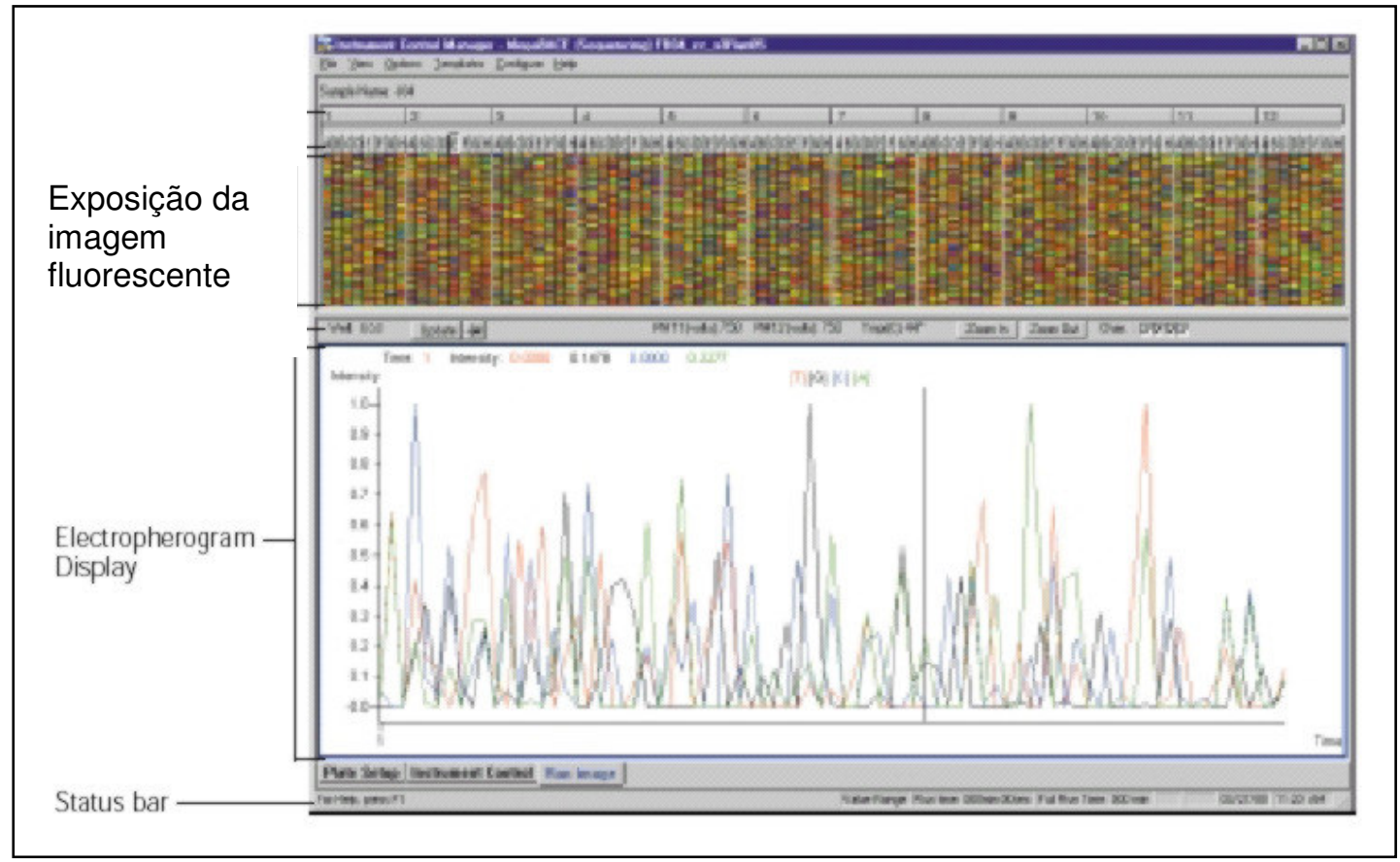

Figura 4. Cromatograma do seqüenciamento do DNA

Os sinais (picos) coloridos representam uma seqüência de bases marcadas com fluorocromos. 


\section{Análise das Seqüências}

A abordagem computacional para identificação dos SNPs (Single Nucleotide Polymorphism) foi realizada pelo Laboratório de Genética Molecular do Departamento de Genética da FMRP-USP - Centro de Terapia Celular, através do software SNPIndex via web disponível no portal GDM (GENOME DATA MINING, 2006). Esta ferramenta executa uma seqüência de programas que incluem:

\begin{tabular}{l|l}
\hline \multicolumn{1}{c|}{ Programa } & \multicolumn{1}{c}{ Análise } \\
\hline $\begin{array}{l}\text { Phred et al } \\
\text { Ewing et al. (1998) e Ewing e Green (1998) }\end{array}$ & Base-calling dos cromatogramas \\
\hline $\begin{array}{l}\text { Cross_match } \\
\text { University of Washington (1993-1996) }\end{array}$ & $\begin{array}{l}\text { Alinhamento pareado de cada EST (Expressed } \\
\text { Sequence Tags) com a região de interesse do exon }\end{array}$ \\
\hline $\begin{array}{l}\text { PolyBayes et al } \\
\text { Marth et al. (1999) }\end{array}$ & $\begin{array}{l}\text { Montagem e alinhamento múltiplo ancorado das } \\
\text { ESTs com a região de interesse do exon }\end{array}$ \\
\hline $\begin{array}{l}\text { PolyPhred } \\
\text { Nickerson, Tobe e Taylor (1997) }\end{array}$ & Identificação dos SNPs \\
\hline
\end{tabular}

Ao final, por meio de uma interface web, é possível visualizar e interagir com os resultados. Na Figura 4 é apresentado um alinhamento múltiplo de uma região de interesse do gene e seu respectivo $S N P$.

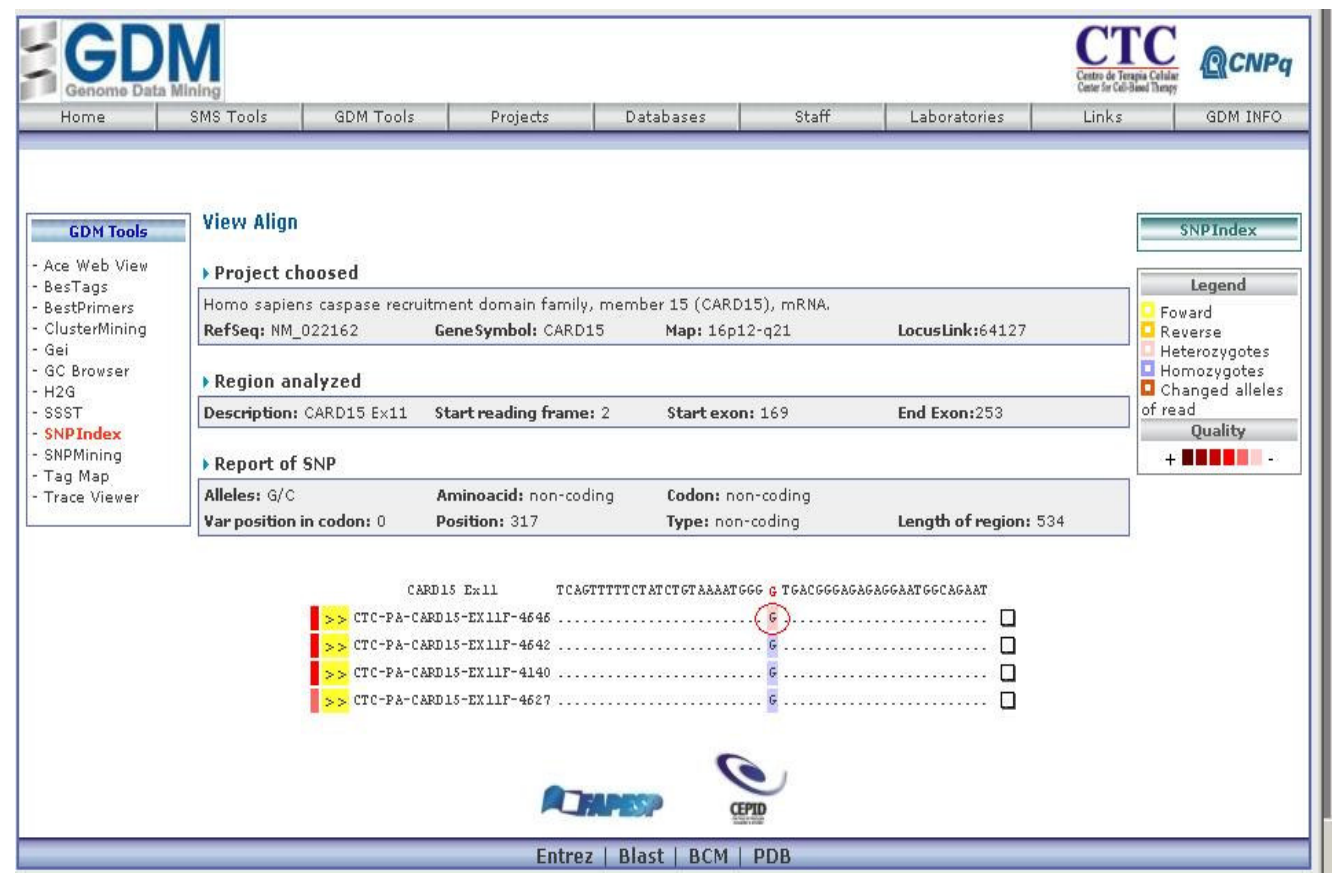

Figura 5. Alinhamento múltiplo da região de interesse com as ESTs e o respectivo SNP sinalizado através do círculo Informações suplementares que incluem a descrição do $S N P$, região do exon analisado e detalhes do $S N P$ encontram-se disponíveis acima do alinhamento em tabelas. 
As mutações encontradas nos pacientes de diferentes macrorregiões do Rio Grande do Sul, foram comparadas com as mutações encontradas na região Sudeste do País, e as descritas em populações européias e asiáticas. 


\section{RESULTADOS}

Utilizando a técnica de seqüenciamento direto do DNA e posterior abordagem computacional, foram identificadas um total de 15 mutações no gene LDLR em 38 pacientes (em 95\% da amostra) pertencentes a 6 grupos étnicos conforme demonstrado na Tabela 6.

Tabela 6 - Mutações encontradas na amostra e sua freqüência relativa (\%) por grupo étnico

\begin{tabular}{|c|c|c|c|c|c|c|c|c|c|c|}
\hline \multirow{3}{*}{ Exon } & & & & \multicolumn{6}{|c|}{ 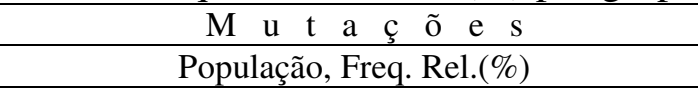 } & \multirow{3}{*}{$\begin{array}{l}\text { Ocor- } \\
\text { rência }\end{array}$} \\
\hline & \multirow[t]{2}{*}{ Nucleotídeo } & \multirow[t]{2}{*}{ Aminoác ${ }^{1}$} & \multirow[t]{2}{*}{ Tipo } & Port & Ital & Alem & Espa & Polo & Leto & \\
\hline & & & & $\mathrm{N}=12$ & $\mathrm{~N}=8$ & $\mathrm{~N}=7$ & $\mathrm{~N}=5$ & $\mathrm{~N}=5$ & $\mathrm{~N}=3$ & \\
\hline 4 & c. $408 \mathrm{C}>\mathrm{T}$ & D115D & $\mathrm{S}$ & & 12 & & & 20 & & 2 \\
\hline 11 & c. $1616 \mathrm{C}>\mathrm{T}$ & P518L & NS & 8 & 25 & & & & & 3 \\
\hline 12 & c. $1773 \mathrm{C}>\mathrm{T}$ & N570N & $\mathrm{S}$ & 33 & 25 & 71 & 20 & 60 & 67 & 17 \\
\hline 15 & c. $2243 \mathrm{~A}>\mathrm{G}$ & D727G & NS & 42 & 37 & 14 & 60 & 40 & & 14 \\
\hline \multicolumn{11}{|c|}{ Introns (InterVening Sequence) ${ }^{1}$} \\
\hline 6 & IVS6+171G $>A$ & & & 16 & 12 & & & & & 3 \\
\hline 6 & IVS6+36G $>A$ & & & 16 & 12 & 14 & & & & 4 \\
\hline 11 & IVS11+56C $>\mathrm{T}$ & & & 33 & 37 & & 60 & 20 & & 11 \\
\hline 11 & IVS11-69G $>T$ & & & 25 & 37 & 14 & 40 & 20 & & 10 \\
\hline 11 & IVS11-55A $>C$ & & & 42 & 25 & 14 & & 20 & & 9 \\
\hline 15 & IVS15-136A>G & & & 83 & 62 & 57 & 60 & 40 & 100 & 27 \\
\hline 16 & IVS16+46C $>\mathrm{T}$ & & & 25 & 25 & 14 & 20 & 20 & & 8 \\
\hline 17 & IVS17-42A $>G$ & & & 58 & 62 & 43 & 40 & 40 & 66 & 21 \\
\hline \multicolumn{11}{|c|}{ 3'UTR (Untranslated Region) ${ }^{2}$} \\
\hline & $* 52 \mathrm{G}>\mathrm{A}$ & & & 42 & 25 & 14 & 40 & 20 & & 11 \\
\hline & $* 105 \mathrm{~T}>\mathrm{G}$ & & & 33 & 37 & 28 & 20 & 40 & 66 & 14 \\
\hline & $* 141 \mathrm{G}>\mathrm{A}$ & & & 16 & 12 & & & & & 3 \\
\hline
\end{tabular}

1 A posição das mutações está de acordo com BIOBASE (2005) (cDNA sequence) (ANEXO D) e a nomenclatura para descrição de codons e aminoácidos (HUMAN GENOME VARIATION SOCIETY, 2002)

${ }^{2}$ A posição das mutações está de acordo com no de acesso AF217403 (GenBank) com a substituição das bases (ANEXO E)

A nomenclatura das mutações obedeceu as regras sugeridas por den Dunnen e

Antonarakis (2001)

$\mathrm{N}=\mathrm{N}^{\mathrm{o}}$ de pacientes. Tipo de mutação: $\mathrm{S}=$ sinônima; $\mathrm{NS}=$ não-sinônima

Nota: Exon 3: pela má qualidade do sequenciamento, não permitiu afirmar sobre as variações encontradas, poderiam ser confundidas com artefato.

Exons 5, 7 e 8: não foram identificadas mutações. 
A relação das mutações do gene LDLR identificadas nos exons, introns e região 3' não traduzida (3'UTR untranslated region) do gene LDLR, são mostradas em homozigose/heterozigose por paciente da amostra e seu componente étnico no Anexo F.

A freqüência de ocorrência dessas 15 mutações nos 38 pacientes (Tabela 6) tiveram uma distribuição em 5 macrorregiões do Estado do Rio Grande do Sul conforme mostra a Figura 5.

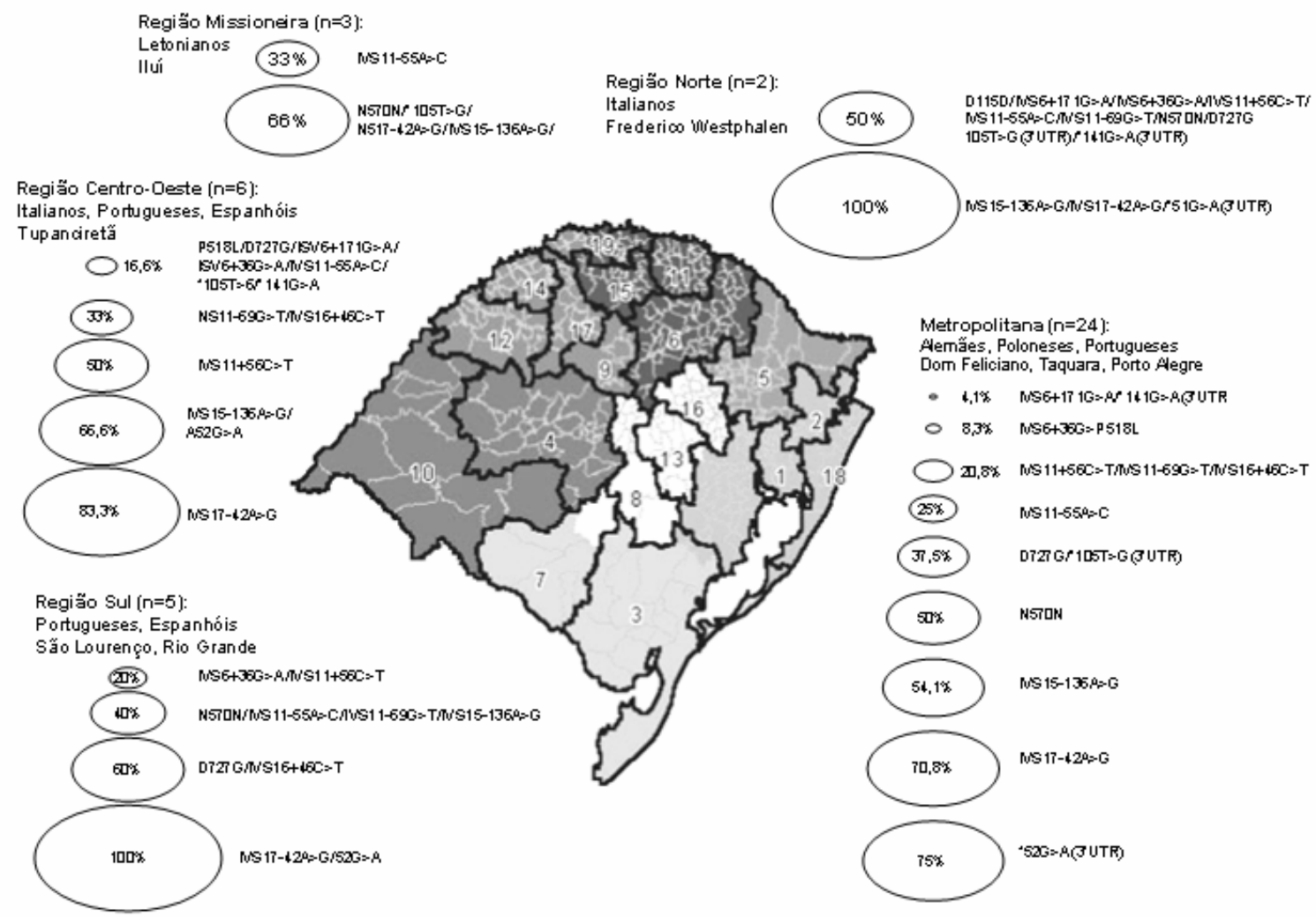

Figura 6. Mutações no gene LDRL: Freqüência relativa (\%) por região do Rio Grande do Sul

As mutações P518L e D727G situadas na região codificadora (exons 11 e 15, respectivamente), são do tipo não-sinônimas, portanto, há substituição de aminoácido. As mutações D115D e N570N (66\% na Região Missioneira) situadas na região codificadora (exons 4 e 12 respectivamente), são do tipo sinônimas não havendo substituição do aminoácido (ANEXO D). 
As mutações situadas nos introns são um total de oito: IVS6+36G $>$ A, IVS6+171G>A, IVS11+56C>T, IVS11-69G>T, IVS11-55A>C, IVS15-136A>G (66\% na Região Missioneira, 100\% na Região Norte), IVS16+46C>T e IVS17-42A>G (66\% na Região Missioneira, 100\% na Região Sul, 83,3\% na Região Centro-Oeste, 100\% na Região Norte) (ANEXO E). Essas mutações podem trazer conseqüências para o RNA mensageiro quando localizadas nos sítios de splicing doador e aceptor, podendo provocar a produção de uma proteína disfuncional. Para tanto, seria necessário realizar estudos funcionais ou de predição, o que não foi realizado nesse trabalho.

Três mutações foram localizadas após o último exon, na região 3' não traduzida (3'UTR untranslated region): *52G>A (75\% na Região Metropolitana, 66\% na Região Missioneira, $100 \%$ na Região Sul, $100 \%$ na Região Norte), *105T>G (66\% na Região Missioneira) e *141G>A (ANEXO E).

Todas as mutações apresentaram freqüência superior a 1\%. A mutação de maior freqüência nos exons, foi a N570N (39\%), e nos introns, a IVS-136A>G (74\%), sugerindo que se trata de sítios polimórficos.

A região promotora e os exons 1 e 2 do gene LDLR não foram seqüenciados. 


\section{DISCUSSÃO}

Este é o primeiro estudo com o propósito de identificar no Rio Grande do Sul, Brasil, as mutações no gene LDLR em pacientes com hipercolesterolemia familiar. Tais mutações são mostradas na Tabela 7 em conjunto com as já identificadas por Alberto et al. (1999), Figueiredo et al. (1992), Inocêncio (2003), Salazar et al. (2002) e van de Kerkhof et al. (2003) e em relação à região Sudeste do Brasil.

Tabela 7 - Mutações identificadas no Brasil

\begin{tabular}{|c|c|c|c|c|c|}
\hline Região do Gene/Ref. & $\begin{array}{c}\text { Mutação } \\
\text { Nucleotídeo }\end{array}$ & $\begin{array}{l}\text { Posição do } \\
\text { Aminoácido }\end{array}$ & $\begin{array}{l}\text { Região do } \\
\text { Brasil }\end{array}$ & População & $\begin{array}{c}\text { Referência } \\
\text { (previamente } \\
\text { mencionado) }\end{array}$ \\
\hline \multicolumn{6}{|l|}{ Exon 1} \\
\hline $\begin{array}{l}\text { Salazar et al.(2002) } \\
\text { Exon } 4\end{array}$ & c. $4 \mathrm{G}>\mathrm{C}$ & $\mathrm{G}(-20) \mathrm{R}$ & Sudeste & caucasiana & nova \\
\hline Salazar et al.(2002) & c. $337 \mathrm{G}>\mathrm{T}$ & E92X & Sudeste & caucasiana & $\begin{array}{l}\text { Hobbs, Brown e } \\
\text { Goldstein (1992) }\end{array}$ \\
\hline Inocêncio (2003) & c. $532 \mathrm{G}>\mathrm{T}$ & D157Y & Sudeste & caucasiana & nova \\
\hline $\begin{array}{l}\text { Presente Estudo } \\
\text { Exon } 5\end{array}$ & c. $408 \mathrm{C}>\mathrm{T}$ & D115D & RS & polonesa\# & \\
\hline$\overline{\text { Salazar et al.(2002) }}$ & c. $769 \mathrm{C}>\mathrm{T}$ & R236W & Sudeste & caucasiana & $\begin{array}{c}\text { Amsellem e } \\
\text { Benlian (2000) }\end{array}$ \\
\hline \multicolumn{6}{|l|}{ Intron 6} \\
\hline Presente Estudo & IVS6+36G>A & & $\mathrm{RS}$ & portuguesa\# & \\
\hline $\begin{array}{l}\text { Presente Estudo } \\
\text { Exon } 7\end{array}$ & IVS6+171G $>A$ & & $\mathrm{RS}$ & portuguesa\# & \\
\hline $\begin{array}{l}\text { van de Kerkhof et } \\
\text { al.(2003) }\end{array}$ & c. $977 \mathrm{C}>\mathrm{G}$ & S305C & Sudeste & $\begin{array}{l}\text { libanesa e } \\
\text { italiana }\end{array}$ & nova \\
\hline Salazar et al.(2002) & c. $1027 \mathrm{G}>\mathrm{A}$ & G322S & Sudeste & caucasiana & $\begin{array}{l}\text { Hobbs, Brown e } \\
\text { Goldstein (1992) }\end{array}$ \\
\hline \multicolumn{6}{|l|}{ Intron 7} \\
\hline Inocêncio (2003) & IVS7+10C>G & & Sudeste & caucasiana & $\begin{array}{l}\text { Dedoussis et al. } \\
\text { (2004) }\end{array}$ \\
\hline \multicolumn{6}{|l|}{ Exon 8} \\
\hline \multirow[t]{3}{*}{$\overline{\text { Salazar et al.(2002) }}$} & c. $1118 \mathrm{G}>\mathrm{A}$ & G352D & Sudeste & caucasiana & $\begin{array}{l}\text { Bertolini et al. } \\
\text { (1999) }\end{array}$ \\
\hline & c. $1171 \mathrm{G}>\mathrm{A}$ & A370T & Sudeste & caucasiana & $\begin{array}{c}\text { Kotze et al. } \\
\text { (1989) }\end{array}$ \\
\hline & c. $1176 \mathrm{C}>\mathrm{A}$ & C371X & Sudeste & caucasiana & $\begin{array}{c}\text { Langenhoven et } \\
\text { al. (1996) }\end{array}$ \\
\hline \multicolumn{6}{|l|}{ Exon 10} \\
\hline Salazar et al.(2002) & $\begin{array}{l}\text { c. } 1489 A>G \\
\text { c. } 1571 T>G\end{array}$ & $\begin{array}{r}\text { T476P } \\
\text { V503G }\end{array}$ & $\begin{array}{l}\text { Sudeste } \\
\text { Sudeste }\end{array}$ & $\begin{array}{l}\text { caucasiana } \\
\text { caucasiana }\end{array}$ & $\begin{array}{l}\text { nova } \\
\text { nova }\end{array}$ \\
\hline Exon 11 & & & & & \\
\hline Presente Estudo & c. $1616 \mathrm{C}>\mathrm{T}$ & P518L & $\mathrm{RS}$ & italiana\# & \\
\hline
\end{tabular}


Tabela 7 (continuação) - Mutações identificadas no Brasil

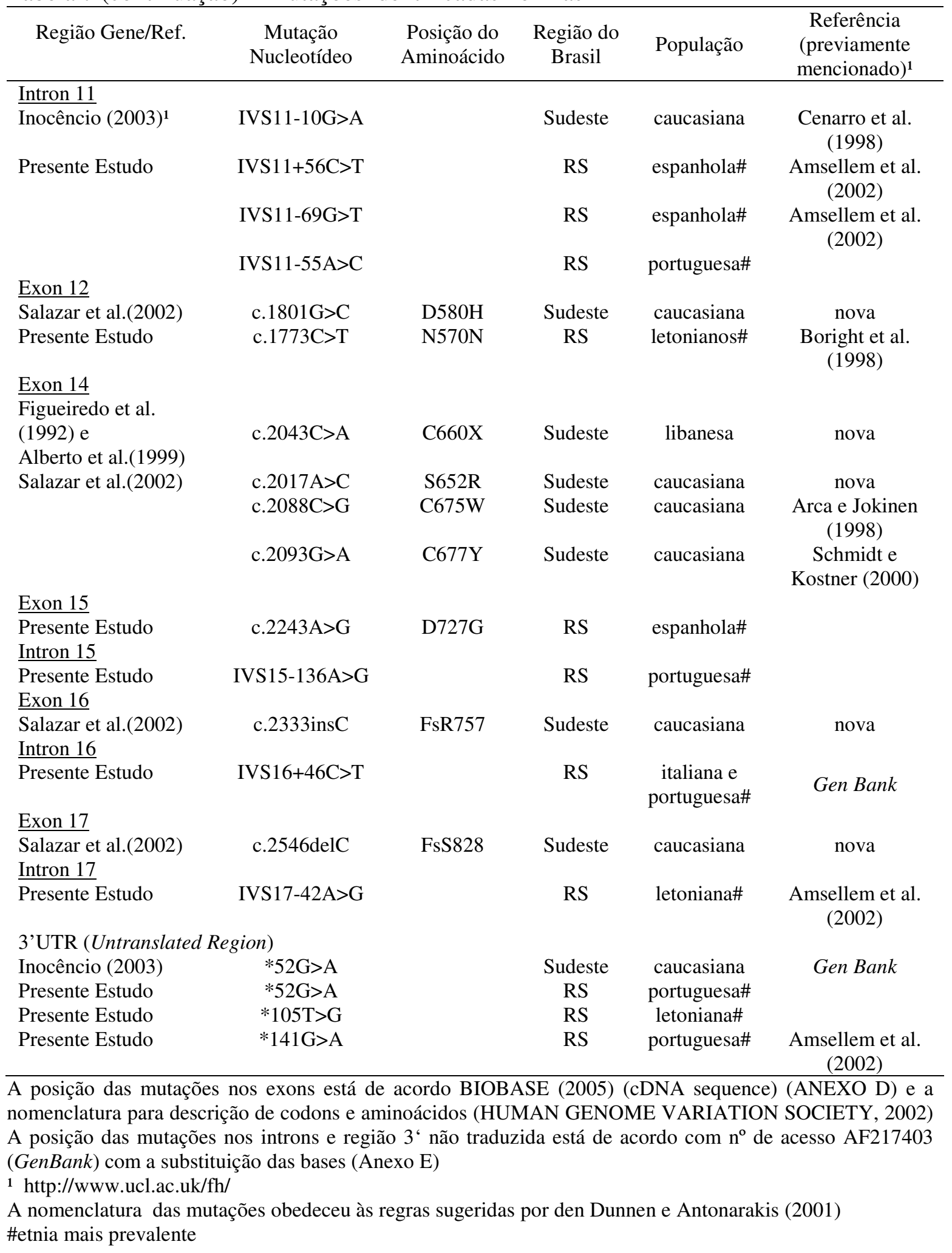

Os primeiros estudos no Brasil (ALBERTO et al., 1999; FIGUEIREDO et al., 1992) utilizando a técnica combinada de PCR (Polymerase Chain Reaction) e Southern blotting, identificaram a mutação libanesa C660X com uma prevalência de 30\% dentre os pacientes 
em tratamento, provavelmente devido ao efeito fundador e à endogamia entre os imigrantes da primeira geração.

Com a técnica de amplificação por meio de PCR seguida da SSCP (Single-Strand Conformation Polymorphism) Salazar et al. (2002) identificaram 15 mutações no gene do LDLR, das quais cinco são do tipo não-sinônimas e duas que deslocam o quadro de leitura (frameshift) alterando a seqüência original de aminoácidos. E, a seguir, utilizando a DGGE (Denaturing Gradient Gel Eletrophoresis), van de Kerkhof et al. (2003) descreveveram pela primeira vez no Brasil a mutação S305C em descendentes de italianos.

Por meio da técnica de SSCP (Single-Strand Conformation Polymorphism), sequienciamento direto do DNA e posterior análise computacional, Inocêncio (2003) identificou outras mutações na região codificadora e intrônica (Tabela 7) que estão associadas à HF, porque alteram o processamento do DNA.

No presente estudo, além do seqüenciamento direto do gene LDLR, foi utilizada uma sequiência de programas de bioinformática (Phred, Cross_match, PolyBayes, PolyPhred) que permititu a melhor visualização de cada região de interesse do gene LDLR, embora essas mutações pontuais devam, a seguir, ser amplificadas e reanalisadas para validação.

A Tabela 8 contém as quatro mutações pontuais na região codificadora do gene do LDLR identificadas no pesente estudo, com as respectivas freqüências encontradas nessa população. Dessas mutações, três ainda não tinham sido descritas (das 481 mutações descritas) (HGMD, 2005), portanto, necessitando reanálise. 
Tabela 8 - Mutações descritas/não descritas em exons no presente estudo por grupo étnico

\begin{tabular}{|c|c|c|c|c|c|c|c|c|}
\hline \multirow{2}{*}{$\begin{array}{l}\text { Região do } \\
\text { Gene }\end{array}$} & \multirow{2}{*}{ Mutação $^{1}$} & \multicolumn{7}{|c|}{ Freq. Rel. \% na População Estudada } \\
\hline & & & Port & Espa & Polo & Alem & Leto & Ital \\
\hline Exon 4 & D115D & ND & & & 20 & & & 12 \\
\hline Exon 11 & P518L & ND & 8 & & & & & 25 \\
\hline Exon 12 & N570N & $\mathrm{D}$ & 33 & 20 & 60 & 71 & 67 & 25 \\
\hline Exon 15 & D727G & ND & 42 & 60 & 40 & 14 & & 37 \\
\hline
\end{tabular}

A mutação N570N no exon 12 foi a mais prevalente encontrada em todos os grupos étnicos, com predominância de heterozigotos (73\%) sobre os homozigotos (27\%) (ANEXO F), o que confirma a heterozigosidade relativamente alta do gene LDLR (1:500) (GOLDSTEIN; HOBBS; BROWN, 1995).

Esta mutação descrita em uma população geneticamente isolada de caucasianos na América do Norte, com taxas elevadas de endogamia, também foi identificada no presente estudo em poloneses e letonianos mais concentrados nos municípios de Dom Feliciano e Ijuí, em populações mais conservadas, e com menores taxas de miscigenação do que os italianos, portugueses, espanhóis e alemães.

As mutações D115D e N570N são do tipo silenciosas, mas podem alterar a função protéica se criarem um novo sítio de splicing ou, ainda, se afetarem a estabilidade do RNAm.

As mutações P518L e N570N por pertencerem à Classe II (acúmulo endoplasmático do LDLR por deficiência no seu transporte) e a mutação D115D por pertencer à Classe III (alelos da ligação deficiente), podem acarretar prejuízo funcional do LDLR.

A mutação D727G no exon 15 foi a mais prevalente encontrada em espanhóis (60\%), com predominância de homozigotos (57\%) sobre heterozigotos (43\%). Essa mutação, 
assim como a P518L encontrada em italianos e portugueses, são do tipo missense ou com maior chance de afetar a funcionalidade do LDLR, ainda dependendo de estudos funcionais para determinar o seu papel no desenvolvimento da HF.

Diferentes mutações no mesmo domínio e mutações iguais em diferentes pacientes podem resultar na variação clínica de fenótipos (UMANS-ECKENHAUSEN et al., 2002).

Estudos com pacientes portadores de HF homozigóticos têm mostrado que diferentes tipos de mutações resultam numa atividade do LDLR residual funcional que varia entre 0 30\% (BERTOLINI et al., 1999; HOBBS; BROWN; GOLDSTEIN, 1992). Essa heterogeneidade mutacional explica a variação fenotípica mostrada nos pacientes com HF homozigotos, em que a forte correlação entre a atividade residual do receptor em cultura de células e a gravidade da doença ocorre (BERTOLINI et al., 1999; GOLDSTEIN; HOBBS; BROWN, 1995; HOBBS; BROWN; GOLDSTEIN, 1992).

Van Gaal et al. (2001) e Descamps et al. (2003) sugeriram que, apesar do fenótipo similar da HF, pacientes que portam mutações sugestivas da doença podem ter maior risco de DAC do que os pacientes sem essas mutações.

Pacientes HF heterozigotos que herdam duas cópias defeituosas do gene LDLR podem se comportar como homozigotos, aumentando até cinco vezes o risco de doença arterial coronariana em estágios precoces da vida (GOLDSTEIN; HOBBS; BROWN, 1995; VAN DE KERKHOF et al., 2003). Pacientes heterozigotos portadores de diferentes mutações no gene LDLR, apresentam correlações genotípicas-fenotípicas como no exemplo de mutações frameshift, que estão mais associadas aos altos níveis de LDLcolesterol do que as mutações tipo missense (GRAHAM et al., 1999).

Nos casos onde não são detectadas mutações em nível de c.DNA, então é sugerida a análise do RNA mensageiro, porque as variações de seqüência ocorridas nas regiões dos introns do gene LDLR podem provocar uma redução da eficiência do splicing do RNA 
mensageiro (AMSELLEM et al., 2002; COOPER; KRAWCZAK, 1993; WEBB et al., 1996) com conseqüências prejudiciais para a sua estabilidade funcional (ROSS, 1988).

A maior parte das novas mutações descritas no presente estudo ocorreram nas regiões intrônicas, devido a dois fatores principais. Primeiro, o seqüenciamento direto do DNA com a utilização de novos conjuntos de primers têm permitido o rastreamento dessas regiões em uma extensão maior. Segundo, espera-se a detecção de um número maior de mutações nas regiões intrônicas, em comparação à região promotora e à região codificadora, já que seriam seletivamente neutras, com exceção daquelas situadas em regiões consenso envolvidas diretamente no processo de splicing. Estima-se que mutações nos sítios de splicing corresponderiam à aproximadamente $15 \%$ das mutações causadoras de doenças em humanos (AMSELLEM et al., 2002).

Amsellem et al. (2002) em um estudo com pacientes franceses com HF observaram que mutações situadas fora das regiões doadoras e aceptoras de splicing podem exercer um efeito regulatório na expressão gênica, como por exemplo, na ativação de sítios crípticos de splicing ou na alteração parcial da eficiência do splicing. Portanto, estas mutações podem se constituir em fatores causadores da HF, mesmo que não localizados nas junções exon-intron.

Na Tabela 9, as oito mutações intrônicas identificadas nesse estudo, foram comparadas com as 58 descritas (HGMD, 2005) em cada um desses introns, quanto à localização e tipo de população. 
Tabela 9 - Mutações descritas/não descritas em introns e região 3' não traduzida (3'UTR) da amostra por população

\begin{tabular}{|c|c|c|c|}
\hline Intron & Mutação & População & Referência/HGMD \\
\hline 6 & IVS6+36G $>A$ & portuguesa\# & Presente estudo \\
\hline 6 & IVS6+171G >A & portuguesa\# & Presente estudo \\
\hline 6 & IVS6-39C>T & espanhola & Mozas et al. (2004) \\
\hline 6 & IVS6-4G>A & sul-africana & Loubser et al. (1999) \\
\hline 6 & IVS6-2A>G & francesa & Amsellem et al. (2002) \\
\hline 11 & IVS $11+56 \mathrm{C}>\mathrm{T}$ & espanhola\# & Presente estudo $^{\mathrm{a}}$ \\
\hline 11 & IVS11-69G $>\mathrm{T}$ & espanhola\# & Presente estudo ${ }^{a}$ \\
\hline 11 & IVS11-55A $>C$ & portuguesa\# & Presente estudo $^{\mathrm{b}}$ \\
\hline 11 & IVS $11+1 \mathrm{G}>\mathrm{C}$ & japonesa & Hattori et al. (2002) \\
\hline 11 & IVS11+1G $>A$ & dinamarquesa & Jenzen et al. (1999) \\
\hline 11 & IVS11+1G>T & norueguesa & Leren et al. (1995) \\
\hline 11 & IVS11-10G $>A$ & espanhola & Cenarro et al. (1998) \\
\hline 11 & IVS11-1G>T & chinesa & Mak et al. (1998) \\
\hline 15 & IVS15+1G >A & italiana & Lelli et al. (1995) \\
\hline 15 & IVS15-136A $>G$ & portuguesa\# & Presente estudo \\
\hline 15 & IVS15+2T>G & francesa & Amsellem et al. (2002) \\
\hline 15 & IVS15-3C>A & italiana(sul) & Liguori et al. (2001) \\
\hline 16 & IVS16+46C>T & italiana e portuguesa\# & Presente estudo $^{\mathrm{a}}$ \\
\hline 16 & IVS16+1G>A & italiana & Bertolini et al. (1999) \\
\hline 16 & IVS16+1G $>\mathrm{T}$ & holandesa & Lombardi et al. 1993) \\
\hline 16 & IVS16+4G $>A$ & espanhola & Mozas et al. (2004) \\
\hline 16 & IVS16-2A>G & holandesa & Lombardi et al. (1993) \\
\hline 16 & IVS16-1G>C & espanhola & Cenarro et al. (1998) \\
\hline 17 & IVS17-42A $>G$ & letoniana\# & Presente estudo $^{a}$ \\
\hline \multirow[t]{4}{*}{17} & IVS17-12A>G & dinamarquesa & Nissen et al. (1996) \\
\hline & 3’UTR(*52G>A) & portuguesa\# & Presente estudo $^{\mathrm{b}}$ \\
\hline & 3’UTR(*105T>G) & letoniana\# & Presente estudo \\
\hline & 3'UTR $(* 141 \mathrm{G}>\mathrm{A})$ & portuguesa\# & Presente estudo $^{\mathrm{a}}$ \\
\hline
\end{tabular}

${ }^{a}$ Previamente descritas em franceses por Amsellem et al. (2002)

b Previamente descritas em http://www.ncbi.nlm.nih.gov/Genbank

\# etnia com maior freqüência da mutação

HGMD (2005)

Os pacientes $\mathrm{n}^{0} 11$ (português) e $\mathrm{n}^{0} 23$ (italiano), individualmente, foram os portadores do maior número de mutações (10), seguidos pelos pacientes $\mathrm{n}^{\mathrm{o}} 3$ (espanhol), $\mathrm{n}^{\mathrm{o}}$ 5 (italiano) e $n^{0} 35$ (italiano) com um número de 7 mutações cada um, perfazendo em relação ao total de mutações identificadas, uma freqüência da ordem de $66 \%$ e $46 \%$ respectivamente (ANEXO F).

Notavelmente, poucas mutações nos introns que estão fora das junções exon-introns de quaisquer genes têm sido descritas como causa de desordens genéticas humanas. Elas ocorrem em sequiências intrônicas altamente conservadas nas proximidades dos locais dos sítios doador e aceptor de splicing (AMSELLEM et al., 2002; COOPER; KRAWCZAK, 1993; KRAWCZAK; REISS; COOPER, 1992). A atual estratégia de screening genômico usando novos primers que franqueiam a seqüência intrônica, melhorou 
significativamente a detecção de mutações causadoras da doença nos pacientes com HF. Em metade dos pacientes estudados por Amsellem et al. (2002), que portavam mutações, elas não foram detectadas usando técnicas com DGGE (Denaturing Gradient Gel Electrophoresis) e seqüenciamento do DNA com primers usuais. Inocêncio (2003), realizou uma análise de predição de criar sítios alternativos nos introns que poderiam afetar o processamento normal do RNA mensageiro, através de programas computacionais específicos para esses sítios (MOLQUEST, 2005-2006). A criação de um local a mais de splicing no segmento central do intron do gene LDLR deveria ser outra causa da doença. Recentemente, tal mutação intrônica resultou na inclusão aberrante de um pseudoexon no gene DMD (Distrofia Muscular de Duchenne) responsável pelos sintomas clínicos da doença (TUFFERY-GIRAUD et al., 2003). Portanto, os procedimentos de screening para a detecção de variações na sequiência do DNA não poderiam omitir as mutações intrônicas. Amsellem et al. (2002), mostraram que as repetições Alu representam 65\% das seqüências intrônicas do gene LDLR, das quais $85 \%$ estão distantes das junções exon-intron. Considerando a hipótese de que esse grande número de repetições Alu favoreceria a ocorrência de muitos crossing-over desiguais e grandes rearranjos no gene do LDRL, é plausível que o surgimento de novas mutações que geram um determinado grau de variabilidade na sua seqüência de DNA podem ser favorecidas, na medida em que “protegem" o gene da ocorrência de novos eventos de recombinação.

Quanto às mutações na região 3'UTR (untranslated region) que foram identificadas após o exon 18 , a *141G $>\mathrm{A}$ e a $* 52 \mathrm{G}>\mathrm{A}$ já foram previamente mencionadas em http://www.ucl.ac.uk/fh, esta última, também por Inocêncio (2003). Estas mutações juntamente com a $* 105 \mathrm{~T}>\mathrm{G}$, ainda não descrita, deverão ser criticamente avaliadas por meio de estudos de alterações do RNA mensageiro. Jensen et al. (1996a, 1996b) e Dedoussis et al. (2003) indicaram a necessidade da avaliação funcional das mutações na 
região 3'UTR (untranslated region) igualmente como as mutações situadas na região promotora e em junções do sítio de splicing.

Cotton e Scriver (1998) sugeriram critérios para definir se uma determinada mutação modifica o fenótipo, levando ao surgimento de uma dada doença, ou se trata de uma variação neutra e comum na população (polimorfismo). De acordo com a utilidade e acessibilidade, poderão ser escolhidos critérios como a análise do tipo de mutação, a região e o tamanho da seqüência analisada, a análise de segregação fenotípica, o aminoácido afetado, a prevalência de tal mutação, a análise de expressão (funcional) e a importância relativa do tipo de mutação. No presente estudo, possíveis erros e ambigüidades foram minimizados pela purificação dos fragmentos amplificados por PCR. A conferência manual das bases identificadas no cromatograma, permitiu excluir o exon 3 pela má qualidade do seqüenciamento, cujas variações poderiam ser confundidas com artefato, assim como nos exons 5,7 e 8 não foram identificadas mutações, porque as bases foram conferidas manualmente uma a uma.

Outra possível causa de erro encontra-se na análise de uma pequena região do gene de interesse para identificar mutações associadas a determinadas doenças (análise de exons específicos). No entanto, um alelo mutante pode não ser o responsável pelo surgimento da doença, mas estar próximo ao alelo de interesse que deixou de ser analisado. Assim, preconiza-se a análise de todo o gene ou a sua maior região possível (COTTON; SCRIVER, 1998). No presente estudo, a maior parte do gene LDLR foi examinada, incluindo a região intrônica (dos exons 3 à região 3'UTR).

O critério da análise de segregação familiar se caracteriza pela comparação dos indivíduos afetados com os familiares não afetados. Como a HF é uma doença autossômica dominante, se uma determinada mutação causa esta doença, ela sempre estará presente nos indivíduos afetados e ausente nos familiares não afetados. 
Além disso, a mutação deve ser analisada em indivíduos normolipêmicos da população de origem dos pacientes com HF. Da mesma forma, se a mutação causa a HF, ou está intimamente relacionada a esta patologia, sua freqüência deve ser nula ou muito inferior àquela observada nos pacientes com HF. Como exemplo, a mutação T705I (FHParis 9) foi primeiramente descrita como uma mutação que causava a HF (HOBBS; BROWN; GOLDSTEIN, 1992). Estudos posteriores demonstraram que esta mutação também ocorre em indivíduos normocolesterolêmicos (LOMBARDI et al., 1997).

Atualmente, dispomos de sessenta e seis amostras de familiares de primeira e segunda gerações dos casos-índices para avaliação das mutações detectadas nos pacientes com $\mathrm{HF}$

Como este é o primeiro estudo das bases moleculares da HF realizado no Rio Grande do Sul, as 15 mutações identificadas requerem, nos próximos trabalhos, a análise de expressão (alteração do fenótipo), a mensuração da atividade biológica e a análise de segregação com a sua prevalência em nomolipêmicos, de acordo com os critérios de Cotton e Scriver (1998).

Para a determinação do fenótipo correspondente, devem estar implicados fatores ambientais e outros genes como o gene CETP (cholesteryl ester transfer protein), o gene LPL (lipoprotein lipase), o gene da apolipoproteína E e, recentemente, o gene PCSK9. As mutações nesses genes poderiam explicar a manifestação clínica da doença em dois dos casos-índices desse estudo, nos quais não foram encontradas mutações no gene LDLR.

Embora tenha sido o primeiro estudo genético das HF no Rio Grande do Sul, o não seqüenciamento da região promotora, exons 1 e 2 do gene LDLR, a falta da análise funcional das mutações encontradas e hábitos de vida desses pacientes, podem ser considerados os fatores da sua limitação. E, ainda, essas mutações preliminarmente 
identificadas no Rio Grande do Sul, nos remetem a questões como a dificuldade de diferenciação entre variantes comuns (polimorfismos) e mutações causadoras da doença.

Assim, diante dessa heterogeneidade de mutações e, provavelmente, também de genes que causam a HF no Brasil, sua base molecular deve continuar sendo investigada para explicar melhor a transmissão de caracteres da HF em mais de $7 \%$ dos brasileiros dislipidêmicos (WHO, 1999) e sua expressão fenotípica no Rio Grande do Sul, que detém uma das mais altas taxas de mortalidade por DAC do Brasil. 
A bases moleculares da HF no Rio Grande do Sul, Brasil, foram caracterizadas em nossa amostra pela identificação de 3 mutações ainda não descritas em regiões codificadoras (exon 4/D115D; exon11/P518L; exon 15/D727G), 4 mutações intrônicas não descritas (IVS6+36G>A, IVS6+171G>A, IVS15-136A>G, IVS17-42A>G) e 1 mutação ainda não descrita na região 3' não traduzida (3'UTR) ( *105T>G).

A análise funcional desses sítios mutantes, bem como sua análise de segregação, permitirão explicar melhor a expressão fenotípica da HF no Rio Grande do Sul. 
1. ABIFADEL, M.; VARRET, M.; RABES, J. P.; ALLARD, D.; OUGUERRAM, K.; DEVILLERS, M.; CRUAUD, C; BENJANNET, S.; WICKHAM, L.; ERLICH, D.; DERRÉ, A.; VILLÉGER, L.; FARNIER, M.; BEUCLER, I.; BRUCKERT, E.; CHAMBAZ, J.; CHANU, B.; LACERF, J-M.; LUC, G.; MOULIN, P.; WEISSENBACH, J.; PRAT, A.; KREMPF, M.; JUNIEN, C.; SEIBAH, NG.; BOILEAU, C. Mutations in PCSK9 cause autosomal dominant hypercholesterolemia. Nat. Genet., New York, v. 34, n. 2, p. 154-6, 2003.

2. AlBERTO, F. L.; FIGUEIREDO, M. S.; ZAGO, M. A.; ARAÚJO, A. G.; DOSSANTOS, J. E. The Lebanese mutation as an important cause of familial hypercholesterolemia in Brazil. Braz. J. Med. Biol. Res., Ribeirão Preto, v. 32, n. 6, p. 739-45, 1999.

3. AMSELLEM, S.; BRIFFAUT, D.; CARRIÉ, A.; RABÈS, J. P.; GIRARDET, J. P.; FREDENRICH, A.; MOULIN, P.; KREMPF, M.; REZNIK, Y.; VIALETTES, B.; DE-GENNES, JL.; BRUKERT, E.; BENLIAN, P. Intronic mutations outside of Alu-repeat-rich domains of the LDL receptor gene are a cause of familial hypercholesterolemia. Hum. Genet., Berlin, v. 111, n. 6, p. 501-10, 2002.

4. ANDERSON, K. M.; CASTELLI, W. P.; LEVY, D. Cholesterol and mortality. 30 years of follow-up from the Framingham study. JAMA, Chicago, v. 257, n. 16, p. 2176-80, 1987.

5. ANITSCHKOW, N. Über die veranderungen der kaninchenaorta bei experimenteller cholesterinsteatose. Beitr. Pathol. Anat. Allg., Stuttgart, v. 56, p. 379-404, 1913.

6. ARCA, M.; JOKINEN, E. Low density lipoprotein receptor mutations in a selected population of individuals with moderate hypercholesterolemia. Atherosclerosis, Amsterdam, v. 136, n. 1, p. 187-94, 1998.

7. BERG, K. Genetics of coronary heart disease. Prog. Med. Genet., New York, v. 5, p. 35-90, 1983.

8. BERTOLINI, S.; CASSANELLI, S.; GARUTI, R.; GHISELLINI, M.; SIMONE, M. L.; ROLLERI, M.; MASTRUSO, P.; CALANDRA, S. Analysis of LDL receptor gene mutations in Italian patients with homozygous familial hypercholesterolemia. Arterioscler. Thromb. Vasc. Biol., Baltimore, v. 19, n. 2, p. 408-18, 1999.

9. BIOBASE. Biological Databases. HGMD® Human Gene Mutation Database. Cardiff: The University/Institute of Medical Genetics, c2005. Available from: http://www.hgmd.cf.ac.uk/ac/gene.php?gene=LDLR. Access: 2006 Jul. 18.

10. BOER, J. M.; FESKENS, E. J.; SCHOUTEN, E. G.; HAVEKES, L. M.; SEIDELL, J. C.; KROMHOUT, D. Lipid profiles reflecting high and low risk for coronary heart disease: contribution of apolipoprotein $\mathrm{E}$ polymorphism and lifestyle. Atherosclerosis, Amsterdam, v. 136, n. 2, p. 395-402, 1998. 
11. BORIGHT, A. P.; CONNELLY, P. W.; BRUNT, J. H.; MORGAN, K.; HEGELE, R. A. Association and linkage of LDLR gene variation with variation in plasma low density lipoprotein cholesterol. J. Hum. Genet., Tokyo, v. 43, n. 3, p. 153-9, 1998.

12. BROWN, M. S.; GOLDSTEIN, J. L. Receptor mediated control of cholesterol metabolism. Science, Washington, v. 191, 4223, p. 150-7, 1976.

13. CENARRO, A.; JENSEN, H. K.; CASAO, E.; CIVEIRA, F.; GONZÁLEZBONILLO, J.; RODRÍGUEZ-REY, J. C.; GREGERSEN, N.; POCOVI, M. Identification of recurrent and novel mutations in the LDL receptor gene in Spanish patients with familial hypercholesterolemia. Hum. Mutat., New York, v. 11, n. 5, p. 413, 1998.

14. COOPER, D. N.; KRAWCZAK, M. Splice site mutations. In: Human gene mutation. Oxford: BIOS, 1993. p. 239-60.

15. COTTON, R. G. H.; SCRIVER, C. R. Proof of "disease causing" mutation. Hum. Mutat., Melbourne, v. 12, p. 1-3, 1998. Special article.

16. DAVIS, C. G.; GOLDSTEIN, J. L.; SÜDHOF, T. C.; ANDERSON, R. G.; BROWN, M. S. Acid-dependent ligand dissociation and recycling of LDL receptor mediated by growth factor homology region. Nature, London, v. 326, n. 6115, p. 760-5, 1987.

17. DE FAIRE, U. Ischaemic heart disease in death discordant twins. A study on 205 male and female pairs. Acta Med. Scand. Suppl., Stockholm, v. 568, p. 1-109, 1974.

18. DEDOUSSIS, G. V.; GENSCHEL, J.; BOCHOW, B.; PITSAVOS, C.; SKOUMAS, J.; PRASSA, M.; LKHAGVASUREN, S.; TOUTOUZAS, P.; VOGT, A.; KASSNER, U.; THOMAS, H-P.; SCHMIDT, H. Molecular characterization of familial hypercholesterolemia in German and Greek patients. Hum. Mutat., New York, v. 23, n. 3, p. 285-6, 2004.

19. DEDOUSSIS, G. V.; PITSAVOS, C.; KELBERMAN, D.; SKOUMAS, J.; PRASSA, M. E.; CHOUMERIANOU, D. M.; STEFANADIS, C.; HUMPHRIES, SE.; TOUTOUZAS, P. FH-Pyrgos: a novel mutation in the promoter $(-45 \mathrm{del} \mathrm{T})$ of the low-density lipoprotein receptor gene associated with familial hypercholesterolemia. Clin. Genet., Copenhagen, v. 64, n. 5, p. 414-9, 2003.

20. DEN DUNNEN, J. T.; ANTONARAKIS, S. E. Nomenclature for the description of human sequence variations. Hum. Genet., Berlin, v. 109, n. 1, p. 121-4, 2001.

21. DESCAMPS, O. S.; GILBEAU, J. P.; LUWAERT, R.; HELLER, F. R. Impact of genetic defects on coronary atherosclerosis in patients suspected of having familial hypercholesterolaemia. Eur. J. Clin. Invest., Berlin, v. 33, n. 1, p. 1-9, 2003.

22. ENCICLOPÉDIA Rio-Grandense: Alemã. Canoas: Regional, 1958a. v. 1, p. 77-108.

23. ENCICLOPÉDIA Rio-Grandense: Espanhola. Canoas: Regional, 1958b. v. 5, p. 21040.

24. ENCICLOPÉDIA Rio-Grandense: Italiana. Canoas: Regional, 1958c. v. 1, p. $127-$ 40.

25. ENCICLOPÉDIA Rio-Grandense: Letoniana. Canoas: Regional, 1958d. v. 5, p. $283-$ 92.

26. ENCICLOPÉDIA Rio-Grandense: Polonesa. Canoas: Regional, 1958e. v. 5, p. 3103. 
27. ENCICLOPÉDIA Rio-Grandense: Portuguesa. Canoas: Regional, 1958f. v. 5, p. $117-25$.

28. EWING, B.; GREEN, P. Base-calling of automated sequencer traces using phred. II. Error probabilities. Genome Res., Cold Spring Harbor, v. 8, n. 3, p. 186-94, 1998.

29. EWING, B.; HILLER, L.; WENDL, M. C.; GREEN, P. Base-calling of automated sequencer traces using phred. I. Accuracy assessment. Genome Res., Cold Spring Harbor, v. 8, n. 3, p. 175-85, 1998.

30. FIGUEIREDO, M. S.; DOS SANTOS, J. E.; ALBERTO, F. L.; ZAGO, M. A. High frequency of the Lebanese allele of the LDLr gene among Brazilian patients with familial hypercholesterolemia. J. Med. Genet., London, v. 29, n. 11, p. 813-5, 1992.

31. FRANCKE, U.; BROWN, M. S.; GOLDSTEIN, J. L. Assignment of the human gene for the low density lipoprotein receptor to chromosome 19: synteny of a receptor, a ligand, and a genetic disease. Proc. Natl. Acad. Sci. U S A, Washington, v. 81, n. 9, p. 2826-30, 1984.

32. GENEST, J. J. JR; MARTIN-MUNLEY, S. S.; MCNAMARA, J. R.; ORDOVAS, J. M.; JENNER, J.; MYERS, R. H.; SILBERMAN, SR.; WILSON, PW.; SALEM, DN.; SCHAEFER, EJ. Familial lipoprotein disorders in patients with premature coronary artery disease. Circulation, Hagerstown, v. 85, n. 6, p. 2025-33, 1992.

33. GENOME DATA MINING (GMD). Ribeirão Preto: USP/Faculdade de Medicina, $2006 . \quad$ Disponível em: http://gdm.fmrp.usp.br/cgibin/snpi/index.pl?template_file=index. Acesso em: 19 jul. 2006.

34. GILBERT, W. Genes-in-pieces revisited. Science, Washington, v. 228, n. 4701, p. 823-4, 1985.

35. GOLDSTEIN, J. L.; BROWN, M. S.; ANDERSON, R. G.; RUSSEL, D. W.; SCHNEIDER, W. J. Receptor-mediated endocytosis: concepts emerging from the LDL receptor system. Annu. Rev. Cell. Biol., Palo Alto, v. 1, p. 1-39, 1985.

36. GOLDSTEIN, J. L.; BROWN, M. S. Molecular medicine. The cholesterol quartet. Science, Washington, v. 292, n. 5520, p. 1310-2, 2001.

37. GOLDSTEIN, J. L.; BROWN, M. S. Progress in understanding the LDL receptor and HMG-CoA reductase, two membrane proteins that regulate the plasma cholesterol. J. Lipid Res., Memphis, v. 25, n. 13, p. 1450-61, 1984.

38. GOLDSTEIN, J. L.; HOBBS, H.; BROWN, M. S. Familial hypercholesterolemia. In: SCRIVER, C. R.; SLY, W. S.; BEAUDET, A. L.; VALLE, D. (Eds.). The metabolic and molecular bases of inherited disease. $7^{\text {th }}$ ed. New York: McGrawHill, 1995. p. 1981-2030.

39. GRAHAM, C. A.; MCCLEAN, E.; WARD, A. J.; BEATTIE, E. D.; MARTIN, S.; O'KANE, M.; YOUNG, IS.; NICHOLLS, DP. Mutation screening and genotype:phenotype correlation in familial hypercholesterolemia. Atherosclerosis, Amsterdam, v. 147, n. 2, p. 309-16, 1999.

40. GUIMARÃES, A. C.; LIMA, M.; MOTA, E.; LIMA, J. C.; MARTINEZ, T.; CONTI FILHO, A.; PAES, J. N.; BERTOLAMI, M.; LION, M. F.; MARANHÃO, M.; DASILVA, O. F.; BODANEZE, L. C.; DIAS, G. C.; MACEDO, V.; ALFIUME NETO, A. The cholesterol level of a selected level of a selected brazilian salaried population: biological and socioeconomic influences. Cardiovasc. Dis. Prev., v. 1, p. 306-17, 1998. 
41. HARVALD, B.; HAUGE, M. Hereditary factors elucidated by twins studies. In: NEEL, J. V.; SHAW, M. W.; SCHULL, W. J. (Eds.). Genetics and epidemiology of chronic disease. Washington: US Department of Health, Education and Welfare, 1965. p. 61-7.

42. HATTORI, H.; HIRAYAMA, T.; NOBE, Y.; NAGANO, M.; KUJIRAOKA, T.; EGASHIRA, T.; ISHII, J.; TSUJI, M.; EMI, M. Eight novel mutations and functional impairments of the LDL receptor in familial hypercholesterolemia in the north of Japan. J. Hum. Genet., Tokyo, v. 47, n. 2, p. 80-7, 2002.

43. HOBBS, H. H.; BROWN, M. S.; GOLDSTEIN, J. L. Molecular genetics of the LDL receptor gene in familial hypercholesterolemia. Hum. Mutat., New York, v. 1, n. 6, p. 445-66, 1992.

44. HOBBS, H. H.; LEITERSDORF, E.; GOLDSTEIN, J. L.; BROWN, M. S.; RUSSEL, D. W. Multiple crm-mutations in familial hypercholesterolemia. Evidence for 13 alleles, incluing four deletions. J. Clin. Invest., Ann Arbor, v. 81, n. 3, p. 90917, 1988.

45. HUMAN GENOME VARIATION SOCIETY. Nomenclature for the description of sequence variations. Melbourne: The Society, c2002. Available from: http://www.hgvs.org/mutnomen/codon.html\#aalist. Access: 2006 Jul 18.

46. INOCÊNCIO, M. T. Análise de mutações associadas ao gene do receptor de LDL em pacientes com hipercolesterolemia familiar. 2003. 65 f. Dissertação (Mestrado) - Faculdade de Medicina de Ribeirão Preto, Universidade de São Paulo, Ribeirão Preto, 2003.

47. INSTITUTO BRASILEIRO DE GOEGRAFIA E ESTATíSTICA (IBGE). Séries estatísticas retrospectivas. Rio de Janeiro: IBGE, 1986. v. 1.

48. JENSEN, H. K.; JENSEN, L. G.; MEINERTZ, H.; HANSEN, P. S.; GREGERSEN, N.; FAERGEMAN, O. Spectrum of LDL receptor gene mutations in Denmark: implications for molecular diagnostic strategy in heterozygous familial hypercholesterolemia. Atherosclerosis, Amsterdam, v. 146, n. 2, p. 337-44, 1999.

49. JENSEN, L. G.; JENSEN, H. K.; HEATH, F.; EIBERG, H.; KJELDSEN, M.; FAERGEMAN, O.; KOLVRAA, S.; BOLUND, L.; GREGERSEN, N. Allelespecific measurement of low-density lipoprotein receptor transcript levels. Hum. Mutat., New York, v. 8, n. 2, p. 126-33, 1996c..

50. JENSEN, L. G.; JENSEN, H. K.; NISSEN, H.; KRISTIANSEN, K.; FAERGEMAN, O.; BOLUND, L.; GREGERSEN, N. An LDL receptor promoter mutation in a heterozygous $\mathrm{FH}$ patient with dramatically skewed ratio between the two allelic mRNA variants. Hum. Mutat., New York, v. 7, n. 1, p. 82-4, 1996d..

51. KANNEL, W. B.; CASTELli, W. P.; GORDON, T.; MCNAMARA, P. M. Serum cholesterol, lipoproteins, and the risk of coronary heart disease. The Framingham Study. Ann. Intern. Med., Philadelphia, v. 74, n. 1, p. 1-12, 1971.

52. KASTELEIN, J. J.; ORDOVAS, J. M.; WITTEKOEK, M. E.; PIMSTONE, S. N.; WILSON, W. F.; GAGNE, S. E.; LARSON, MG.; SCHAEFER, EJ.; BOER, JM.; GERDES, C.; HAYDEN, MR. Two common mutations (D9N, N291S) in lipoprotein lipase: a cumulative analysis of their influence on plasma lipids and lipoprotein in men and women. Clin. Genet., Copenhagen, v. 56, n. 4, p. 297-305, 1999.

53. KEYS, A.; ARAVANIS, C.; BLACKBURN, H. W.; VAN BUCHEM, F. S.; BUZINA, R.; DJORDJEVIC, B. D.; DONTAS, AS, FIDANZA, F.; KARVONEN, 
MJ.; KIMURA, N.; LEKOS, D.; MONTI, M.; PUDDU, V.; TAYLOR, HL. Epidemiological studies related to coronary heart disease: characteristics of men aged 40-59 in seven countries. Acta Med. Scand. Suppl., Stockholm, v. 460, p. 1-392, 1966.

54. KHACHADURIAN, A. K.; UTHMAN, S. M. Experiences with the homozygous cases of familial hypercholesterolemia. A report of 52 patients. Nutr. Metab., Basel, v. 15 , n. 1, p. 132-40, 1973.

55. KIM, S. J.; KIM, J. E.; MOON, I. S. Paraquat induces apoptosis of cultured rat cortical cells. Mol. Cells., Seoul, v. 17, n. 1, p. 102-7, 2004.

56. KOTZE, M. J.; LANGENHOVEN, E.; WARNICH, L.; DU PLESSIS, L.; MARX, M. P.; OOSTHUIZEN, C. J.; RETIEF, AE. The identification of two low-density lipoprotein receptor gene mutations in South African familial hypercholesterolaemia. S. Afr. Med. J., Cape Town, v. 76, n. 8, p. 399-401, 1989.

57. KRAWCZAK, M.; REISS, J.; COOPER, D. N. The mutational spectrum of single base-pair substitutions in mRNA splice junctions of human genes: causes and consequences. Hum. Genet., Berlin, v. 90, n. 1-2, p. 41-54, 1992.

58. KUIVENHOVEN, J. A.; JUKEMA, J. W.; ZWINDERMAN, A. H.; DE KNIJFF, P.; MCPHERSON, R.; BRUSCHKE, A. V.; LIE, KI.; KASTELEIN, JJ. The role of a common variant of the cholesteryl ester transfer protein gene in the progression of coronary atherosclerosis. The Regression Growth Evaluation Statin Study Group. N. Engl. J. Med., Boston, v. 338, n. 2, p. 86-93, 1998.

59. LANGENHOVEN, E.; WARNICH, L.; THIART, R.; RUBINSZTEIN, D. C.; VAN DER WESTHUYZEN, D. R.; MARAIS, A. D.; KOTZE, M. Two novel point mutations causing receptor-negative familial hypercholesterolemia in South African Indian homozygote. Atherosclerosis, Amsterdam, v. 125, n. 1, p. 111-9, 1996.

60. LAROSA, J. C.; HUNNINGHAKE, D.; BUSH, D.; CRIQUI, M. H.; GETZ, G. S.; GOTTO, A. M. JR.; GRUNDY, SM.; RAKITA, L.; ROBERTSON, RM.; WEISFELDT, ML.; CLEEMAN, JI. The cholesterol facts. A summary of the evidence relating dietary fats, serum cholesterol, and coronary heart disease. A joint statement by the American Heart Association and the National Heart, Lung, and Blood Institute. The Task Force on Cholesterol Issues, American Heart Association. Circulation, Texas, v. 81, n. 5, p. 1721-33, 1990.

61. LEHNINGER, A. L. Princípios de bioquímica. $2^{\text {a }}$ ed. São Paulo: Sarvier, 1995. 839 p.

62. LELLI, N.; GARUTI, R.; GHISELLINI, M.; TIOZZO, R.; ROLLERI, M.; AIMALE, V.; GINOCCHIO, E.; NASELLI, A.; BERTOLINI, S.; CALANDRA, S. Occurrence of multiple aberrantly spliced mRNAs of the LDL-receptor gene upon a donor splice site mutation that causes familial hypercholesterolemia (FHBenevento). J. Lipid. Res., Memphis, v. 36, n. 6, p. 1315-24, 1995.

63. LEREN, T. P.; SOLBERG, K.; RODNINGEN, O. K.; TONSTAD, S.; OSE, L. Two novel point mutations in the EGF precursor homology domain of the LDL receptor gene causing familial hypercholesterolemia. Hum. Genet., Berlin, v. 96, n. 2, p. 2412,1995 .

64. LIGUORI, R.; BIANCO, A. M.; ARGIRIOU, A.; PAUCIULlO, P.; GIANNINO, A.; RUBBA, P.; SIMONE, V-D. LDL receptor cDNA sequence analysis in familial hypercholesterolemia patients: 5 novel mutations with high prevalence in families originating from southern Italy. Hum. Mutat., New York, v. 17, n. 5, p. 433, 2001. 
65. LILJEFORS, I. Coronary heart disease in male twins. Hereditary and environmental factors in concordant and discordant pairs. Acta Med. Scand. Suppl., Stockholm, v. 511, p. 1-90, 1970.

66. LINDGREN, V.; LUSKEY, K. L.; RUSSEL, D. W.; FRANCKE, U. Human genes involved in cholesterol metabolism: chromosomal mapping of the loci for the low density lipoprotein receptor and 3-hydroxy-3-methylglutaryl-coenzyme A reductase with cDNA probes. Proc. Natl. Acad. Sci. U S A, Washington, v. 82, n. 24, p. 856771, 1985.

67. LOMBARDI, P.; HOFFER, M. J.; TOP, B.; DE WIT, E.; GEVERS LEUVEN, J. A.; FRANTS, R. R.; HAVEKES, LM. An acceptor splice site mutation in intron 16 of the low density lipoprotein receptor gene leads to an elongated, internalization defective receptor. Atherosclerosis, Amsterdam, v. 104, n. 1-2, p. 117-28, 1993.

68. LOMBARDI, P.; SIJBRANDS, E. J. G.; KAMERLING, S.; LEUVEN, J. A. G.; HAVEKES, L. M. The T705I mutation of the low density lipoprotein receptor gene (FH Paris-9) does not cause familial hypercholesterolemia. Hum. Genet., Leiden, v. 99, p. 106-9, 1997.

69. LOUBSER, O.; MARAIS, A. D.; KOTZE, M. J.; GODENIR, N.; THIART, R.; SCHOLTZ, C. L.; DE VILLIERS, JN.; HILLERMANN, R.; FIRTH, JC.; WEICH, HF.; MARITZ, F.; JONES, S.; VAN DER WESTHUYZEN, DR. Founder mutations in the LDL receptor gene contribute significantly to the familial hypercholesterolemia phenotype in the indigenous South Africa population of mixed ancestry. Clin. Genet., Copenhagen, v. 55, n. 5, p. 340-5, 1999.

70. MAK, Y. T.; PANG, C. P.; TOMLINSON, B.; ZHANG, J.; CHAN, Y. S.; MAK, T. W.; MASAREI, JR. Mutations in the low-density lipoprotein receptor gene in Chinese familial hypercholesterolemia patients. Arterioscler. Thromb. Vasc. Biol., Baltimore, v. 18, n. 10, p. 1600-5, 1998.

71. MARTH, G. T.; KORF, I.; YANDELL, M. D.; YEH, R. T.; GU, Z.; ZAKERI, H. A.; STIZIEL, NO.; HILLIER, L.; KWOK, PY.; GISH, WR. A general approach to single-nucleotide polymorphism discovery. Nat. Genet., New York, v. 23, n. 4, p. 452-6, 1999.

72. MARTINEZ, T. L.; SANTOS, R. D.; ARMAGANIJAN, D.; TORRES, K. P.; LOURES-VALE, A.; MAGALHÃES, M. E.; LIMA, JC.; MORIGUCHI, E.; AMODEO, C.; ORTIZ, J. National alert campaign about increased cholesterol: determination of cholesterol levels in 81,262 Brazilians. Arq. Bras. Cardiol., São Paulo, v. 80, n. 6, p. 635-8, 2003.

73. MENOTTI, A.; LANTI, M.; PUDDU, P. E.; KROMHOUT, D. Coronary heart disease incidence in northern and southern European populations: a reanalysis of the seven countries study for a European coronary risk chart. Heart, London, v. 84, n. 3, p. 238-44, 2000.

74. MOHRENWEISER, H. W.; TSUJIMOTO, S.; GORDON, L.; OLSEN, A. S. Regions of sex-specific hypo- and hyper-recombination identified through integration of 180 genetic markers into the metric physical map of human chromosome 19. Genomics, San Diego, v. 47, n. 2, p. 153-62, 1998.

75. MOLQUEST. Bioinformatics toolbox for analysis of biomedical data. Mount Kisko: Softberry, c2005-2006. Available from: http://www.molquest.com/molquest.phtml. Access: 2006 Jul. 19.

76. MOZAS, P.; CASTILLO, S.; TEJEDOR, D.; REYES, G.; ALONSO, R.; FRANCO, M.; SAENZ, P.; FUENTES, F.; ALMAGRO, F.; MATA, P.; POCOVÍ, M. 
Molecular characterization of familial hypercholesterolemia in Spain: identification of 39 novel and 77 recurrent mutations in LDLR. Hum. Mutat., New York, v. 24, n. 2, p. 187, 2004.

77. MULTIPLE RISK FACTOR INTERVENTION TRIAL RESEARCH GROUP. Risk factor changes and mortality results. JAMA, Chicago, v. 248, n. 12, p. 1465-77, 1982.

78. NABEL, E. G. Cardiovascular disease. N. Engl. J. Med., Boston, v. 349, n. 1, p. 60$72,2003$.

79. NAPOLI, C.; D’ARMIENTO, F. P.; MANCINI, F. P.; POSTIGLIONE, A.; WITZTUM, J. L.; PALUMBO, G.; PALINSKI W. Fatty streak formation occurs in human fetal aortas and is greatly enchanced by maternal hypercholesterolemia. Intimal accumulation of low density lipoprotein and its oxidation precede monocyte recruitment into early atherosclerotic lesions. J. Clin. Invest., Ann Arbor, v. 100, n. 11, p. 2680-90, 1997.

80. NATIONAL CHOLESTEROL EDUCATION PROGRAM (NCEP). Executive summary of the third report of expert panel on detection, evaluation, and treatment of high blood cholesterol in adults (adult treatment panel III). JAMA, Chicago, v. 285, n. 19, p. 2486-97, 2001.

81. NICKERSON, D. A.; TOBE, V. O.; TAYLOR, S. L. PolyPhred: automating the detection and genotyping of single nucleotide substitutions using fluorescence-based resequencing. Nucleic Acids Res., Oxford, v. 25, n. 14, p. 2745-51, 1997.

82. NISSEN, H.; GULDBERG, P.; HANSEN, A. B.; PETERSEN, N. E.; HORDER, M. Clinically applicable mutation screening in familial hypercholesterolemia. Hum. Mutat., New York, v. 8, n. 2, p. 168-77, 1996.

83. NORA, J. J.; LORTSCHER, R. H.; SPANGLER, R. D.; NORA, A. H.; KIMBERLING, W. J. Genetic: epidemiologic study of early-onset ischemic heart disease. Circulation, Dallas, v. 61, n. 3, p. 503-8, 1980.

84. NUSSBAUM, R. L. Thompson \& Thompson genética médica. $6^{\mathrm{a}}$ ed. Rio de Janeiro: Guanabara Koogan, 2002. 387 p.

85. OMIM Online Mendelian Inheritance in Man. Bethesda: The National Center for Biotechnology Information (NCBI). 2005. LDLR gene mutations. Available from: http://www.ncbi.nlm.nih.gov/omim. Access: 2005 Aug 12.

86. RIFAI, N.; BACHORIK, P. S.; ALBERS, J. J. Lipids, lipoproteins, and apolipoproteins. In: BURTIS, C. A.; ASHWOOD, E. R. (Eds.). Tietz textbook of clinical chemistry. $3^{\text {rd }}$ ed. Philadelphia: Saunders, 1999. p. 809-61.

87. RIO GRANDE DO SUL. Secretaria da Saúde. Prevalência de fatores de risco para a doença arterial coronariana no estado do Rio Grande do Sul. Porto Alegre: A Secretaria, 2003. Disponível em: http://www.saude.rs.gov/cronicos_degenerativos/documentos/pesquisa.pdf. Acesso em: 18 jul. 2006.

88. RIO GRANDE DO SUL. Secretaria da Saúde. Evolução da mortalidade proporcional por principais grupos de causas Rio Grande do Sul, 1998 a 2002. Porto Alegre: A Secretaria, 2006. Disponível em: http://www.saude.rs.gov.br/documentos/evolucao_mortalidade12.pdf. Acesso em: 19 jul. 2006.

89. ROBBINS, S. L.; CONTRAN, R. S.; KUMAR, V.; COLlINS, T. Patologia estrutural e funcional. $5^{\mathrm{a}}$ ed. Rio de Janeiro: Guanabara Koogan, 1996. 1277 p. 
90. ROSS, J. Messenger RNA turnover in eukaryotic cells. Mol. Biol. Med., London, v. 5, n. 1, p. 1-14, 1988.

91. SALAZAR, L. A.; CAVALLI, S. A.; HIRATA, M. H.; DIAMENT, J.; FORTI, N.; GIANNINI, S. D.; NAKANDAKARE, ER.; BERTOLAMI, MC.; HIRATA, RDC. Polymorphisms of the low-density lipoprotein receptor gene in brazilian individuals with heterozygous familial hypercholesterolemia. Braz. J. Med. Biol. Res., Ribeirão Preto, v. 33, n. 11, p. 1301-4, 2000.

92. SALAZAR, L. A.; HIRATA, M. H.; CAVALLI, S. A.; NAKANDAKARE, E. R.; FORTI, N.; DIAMENT, J.; GIANNINI, SD.; BETOLAMI, MC.; HIRATA, RD. Molecular basis of familial hypercholesterolemia in Brazil: identification of seven novel LDLR gene mutations. Hum. Mutat., New York, v. 19, n. 4, p. 462-3, 2002.

93. SCHMIDT, H.; KOSTNER, G. M. Familial hypercholesterolemia in Austria reflects the multi-ethnic origin of our country. Atherosclerosis, Amsterdam, v. 148, n. 2, p. 431-2, 2000.

94. STRONG, J. P.; MALCOM, G. T.; MCMAHAN, C. A.; TRACY, R. E.; NEWMAN, W. P. 3RD.; HERDERICK, E. E.; CORNHILL, JF. Prevalence and extend of atherosclerosis in adolescents and young adults: implications for prevention from the Pathobiological Determinants of Atherosclerosis in Youth Study. JAMA, Chicago, v. 281, n. 8 , p. $727-35,1999$.

95. SÜDHOF, T. C.; GOLDSTEIN, J. L.; BROWN, M. S.; RUSSEL, D. W. The LDL receptor gene: a mosaic of exons shared with different proteins. Science, Washington, v. 228, n. 4701, p. 815-22, 1985.

96. THOMPSON, G. R. Screening relatives of patients with premature coronary heart disease. Heart, London, v. 87, n. 4, p. 390-4, 2002.

97. TOlLESHAUG, H.; GOLDSTEIN, J. L.; SCHNEIDER, W. J.; BROWN, M. S. Posttranslational processing of the LDL receptor and its genetic disruption in familial hypercholesterolemia. Cell, Cambridge, v. 30, n. 3, p. 715-24, 1982.

98. TOLLESHAUG, H.; HOBGOOD, K. K.; BROWN, M. S.; GOLDSTEIN, J. L. The LDL receptor locus in familial hypercholesterolemia: multiple mutations disrupt transport and processing of a membrane receptor. Cell, Cambridge, v. 32, n. 3, p. 941-51, 1983.

99. TONSTAD, S.; JOAKIMSEN, O.; STENSLAND-BUGGE, E.; LEREN, T. P.; OSE, L.; RUSSELL D.; BONAA, KH. Risk factors related to carotid intima-media thickness and plaque in children with familial hypercholesterolemia and control subjects. Arterioscler. Thromb. Vasc. Biol., Baltimore, v. 16, n. 8, p. 984-91, 1996.

100. TUFFERY-GIRAUD, S.; SAQUET, C.; CHAMBERT, S.; CLAUSTRES, M. Pseudoexon activation in the DMD gene as a novel mechanism for Becker muscular dystrophy. Hum. Mutat., New York, v. 21, n. 6, p. 608-14, 2003.

101. UMANS-ECKENHAUSEN, M. A.; SIJBRANDS, E. J.; KASTELEIN, J. J.; DEFESCHE, J. C. Low-density lipoprotein receptor gene mutations and cardiovascular risk in a large genetic cascade screening population. Circulation, Dallas, v. 106, n. 24, p. 3031-6, 2002.

102. UNIVERSITY OF WASHINGTON. Genome Science Department. Laboratory of Phil Green. Phred, phrap, consed. Washington: The University, 1993-1996. Available from: http://www.phrap.org/. Access: 2006 Jul. 19. 
103. VAN DALEN, D. B.; MEYER, W. J. Estrategia de la investigación descriptiva. In: 1979. p. 226-66.

Manual de técnica de la investigación educacional. Buenos Aires: Paidós,

104. VAN DE KERKHOF, L.; VAN EIJK, S. J.; DEFESCHE, J. C.; DOS SANTOS, J. E. Identification of a new mutation, $\mathrm{S} 305 \mathrm{C}$, in exon 7 of the low-density lipoprotein receptor gene in a Brazilian family with homozygous familial hypercholesterolemia. Genet. Test., Larchmont, v. 7, n. 1, p. 77-9, 2003.

105. VAN GAAL, L. F.; PEETERS, A. V.; DE BLOCK, C. E.; DE LEEUW, I. H.; THIART, R.; KOTZE, M. J. Low-density lipoprotein receptor gene mutation analysis and clinical correlation in Belgian hypercholesterolemics. Mol. Cell. Probes., London, v. 15, n. 6, p. 329-36, 2001.

106. WEBB, J. C.; PATEL, D. D.; SHOULDERS, C. C.; KNIGHT, B. L.; SOUTAR, A. $\mathrm{K}$. Genetic variation at a splicing branch point in intron 9 of the low density lipoprotein (LDL)-receptor gene: a rare mutation that disrupts mRNA splicing in a patient with familial hypercholesterolemia and a commom polymorphism. Hum. Mol. Genet., Oxford, v. 5, n. 9, p. 1325-31, 1996.

107. WENDELHAG, I.; WIKLUND, O.; WIKSTRAND, J. Arterial wall thickness in familial hypercholesterolemia: ultrasound measurement of intima-media thickness in the common carotid artery. Arterioscler. Thromb., Dallas, v. 12, n. 1, p. 70-7, 1992.

108. WILLIAMS, R. R.; HUNT, S. C.; HEISS, G.; PROVINCE, M. A.; BENSEN, J. T.; HIGGINS, M.; CHAMBERLAIN, RM.; WARE, J.; HOPKINS, PN. Usefulness of cardiovascular family history data for population-based preventive medicine and medical research (the Health Family Tree Study and the NHLBI Family Heart Study). Am. J. Cardiol., New York, v. 87, n. 2, p. 129-35, 2001.

109. WORLD HEALTH ORGANIZATION. Raised lipids. Geneva: The Organization, 2006.

http://www.who.int/ncd_surveillance/infobase/web/surf2/html_files/PAHO/Brazil.pd f. Access: 2006 Jul 19.

110. WORLD HEALTH ORGANIZATION. Familial hypercholesterolaemia (FH). Report of a second WHO consultation. Geneva, 4 September 1998. Geneva: The Organization, $1999 . \quad$ Available from: http://whqlibdoc.who.int/hq/1999/WHO_HGN_FH_CONS_99.2.pdf. Access: 2006 Jul. 19.

111. YAMAMOTO, T.; DAVIS, C. G.; BROWN, M. S.; SCHNEIDER, W. J.; CASEY, M. L.; GOLDSTEIN, J. L.; RUSSELL, DW. The human LDL receptor: a cysteinerich protein with multiple Alu sequences in its mRNA. Cell, Cambridge, v. 39, n. 1, p. 27-38, 1984. 


\section{APÊNDICE A: Extração de DNA}

Kit: Super Quik-Gene-DNA Isolation Kit

Componentes do Kit

$>160 \mathrm{ml}$ de 10x RBC Lysis Buffer

$>150 \mathrm{ml}$ WBC Lysis Buffer

$>20 \mathrm{ml} \mathrm{10 \%} \mathrm{SDS}$

$>50 \mathrm{ml}$ Protein Precipitating Reagent

Procedimentos:

1- Descongelar bem o sangue que já deverá estar em tubo cônico (Falcon - $15 \mathrm{ml}$ ), caso o sangue ainda esteja em tubo de coleta, centrifugá-lo à 2.000 rpm por 10 minutos;

2- Acrescentar $10 \mathrm{ml}$ do tampão de lise de glóbulos [1X] (O RBC Lysis Buffer-deve ser diluído e preparado no momento do uso, em seguida manter em gelo);

Obs.: o volume do tampão pode variar de 0,7 a $10,0 \mathrm{ml}$ de acordo com o volume de sangue total.

3- Homogeneizar durante 15 minutos;

4- Centrifugar a $2.500 \mathrm{rpm} / 20$ minutos;

5- Desprezar o sobrenadante;

6- Acrescentar novamente o tampão de lise de glóbulos vermelhos (podendo variar de 7,0 a 10,0 ml do tampão);

7- Homogeneizar durante 15 minutos;

8- Centrifugar a $2.500 \mathrm{rpm} / 20$ minutos;

9- Desprezar o sobrenadante, tomando cuidado de limpar a borda com papel absorvente (um para cada amostra);

Obs.: se necessário, fazer mais lavagens com o tampão de lise de glóbulos vermelhos antes de prosseguir com a técnica.

10- Adicionar 1,5 ml do tampão de lise de glóbulos brancos (WBC Lysis Buffer);

11- Misturar bem no Vórtex;

12- Colocar em banho-maria a $55^{\circ} \mathrm{C}$ durante 30 minutos;

13- Acrescentar 200 microlitros de SDS 10\%;

14- Acrescentar 500 microlitros de Reagente Prescipitante de Proteínas;

15- Agitar vigorosamente por 30 segundos;

16- Incubar em banho-maria a $55^{\circ} \mathrm{C}$ durante 25 minutos;

17- Centrifugar a $2.500 \mathrm{rpm} / 20$ minutos;

18- Transferir todo o sobrenadante límpido para um tubo cônico Falcon de $15 \mathrm{ml}$ com o auxílio de uma pipeta de Pasteur;

19- Adicionar Etanol Absoluto, na proporção de duas vezes o volume do sobrenadante;

20- Misturar por inversões delicadas o tubo cônico onde está o DNA (prescipitação);

21- "Pescar" o DNA e colocá-lo em um Eppendorf estéril de 1,5 ml devidamente identificado;

22- Fazer a diluição com água Milli-Q estéril. Aguardar a diluição total do DNA. Se necessário, deixar em geladeira overnight.

23-Estocar em freezer para a quantificação que, em tempo oportuno, será realizada em tubos de Eppendorf estéreis pipetando 1,0 ml de água deionizada com 5 microlitros de DNA. 
APÊNDICE B: Reagentes utilizados para o $1^{\circ}$ PCR

\section{Reagentes}

H2O Milli Q autoclavada

Buffer PCR 10X Invitrogen

DNTPs $1,25 \mathrm{Mm}$

$\mathrm{MgCl} 250 \mathrm{mM}$ Invitrogen

Primer R ${ }^{1}$ 3,2 pmoles/microL

Primer $\mathrm{R}^{2}$ 3,2 pmoles/microL

$\mathrm{Taq}^{3}$ Invitrogen 5 pmoles/microL

\section{Volume por Reação Volume por Placa}

9,19 microL

1,50 microL

1,50 microL

0,45 microL

0,63 microL

0,63 microL

0,20 microL
900,62 microL

147,00 microL

147,00 microL

44,10 microL

61,74 microL

61,74 microL

19,60 microL

Colocar 168 microL do mix nos 8 primeiros poços e distribuir 14 microL para os demais poços. Colocar 1 microL da cultura de bactérias.

\section{Ciclo:}

$95{ }^{\circ} \mathrm{C}-3 \min$

$95^{\circ} \mathrm{C}-40 \mathrm{seg}>$

$60{ }^{\circ} \mathrm{C}-40 \mathrm{seg}>35$ ciclos

$72{ }^{\circ} \mathrm{C}-55 \operatorname{seg}>$

$72{ }^{\circ} \mathrm{C}-5 \min$

$4{ }^{\circ} \mathrm{C}$ - infinito

1 Primer Reverse (R)

2 Primer Flanking $(\mathrm{F})$

3 Taq (Thermus aquaticus) microorganismos com habitat em fontes quentes, do qual é obtida uma DNApolimerase termoestável entre $94{ }^{\circ} \mathrm{C}$ e $80{ }^{\circ} \mathrm{C}$. 
APÊNDICE C: Preparação da Placa para Eletroforese no Rol de Capilares do Sistema MegaBACE

$\mathrm{H} 2 \mathrm{O}$

921,2 micro 1

Premix ET

784,0 micro 1

Primer R

156,8 micro 1

Colocar 228 micro 1 do mix nos primeiros poços (dos 96 da placa) da $1^{a}$ fileira

Distribuir 19 micro 1 para os poços restantes da placa

Colocar 1 micro 1 do produto de $1^{\circ} \mathrm{PCR}$
Condições:
$\left.95^{\circ} \mathrm{C}-2 \operatorname{seg}\right\} \quad 1 \mathrm{vez}$
$95{ }^{\circ} \mathrm{C}-10$ seg \} 35 vezes
$51{ }^{\circ} \mathrm{C}-15$ seg $\} 35$ vezes
$\left.60{ }^{\circ} \mathrm{C}-1 \mathrm{seg}\right\} 35$ vezes 
APÊNDICE D: Conjunto do equipamento MegaBACE e Rol de capilares.

A - Conjunto do equipamento MegaBACE

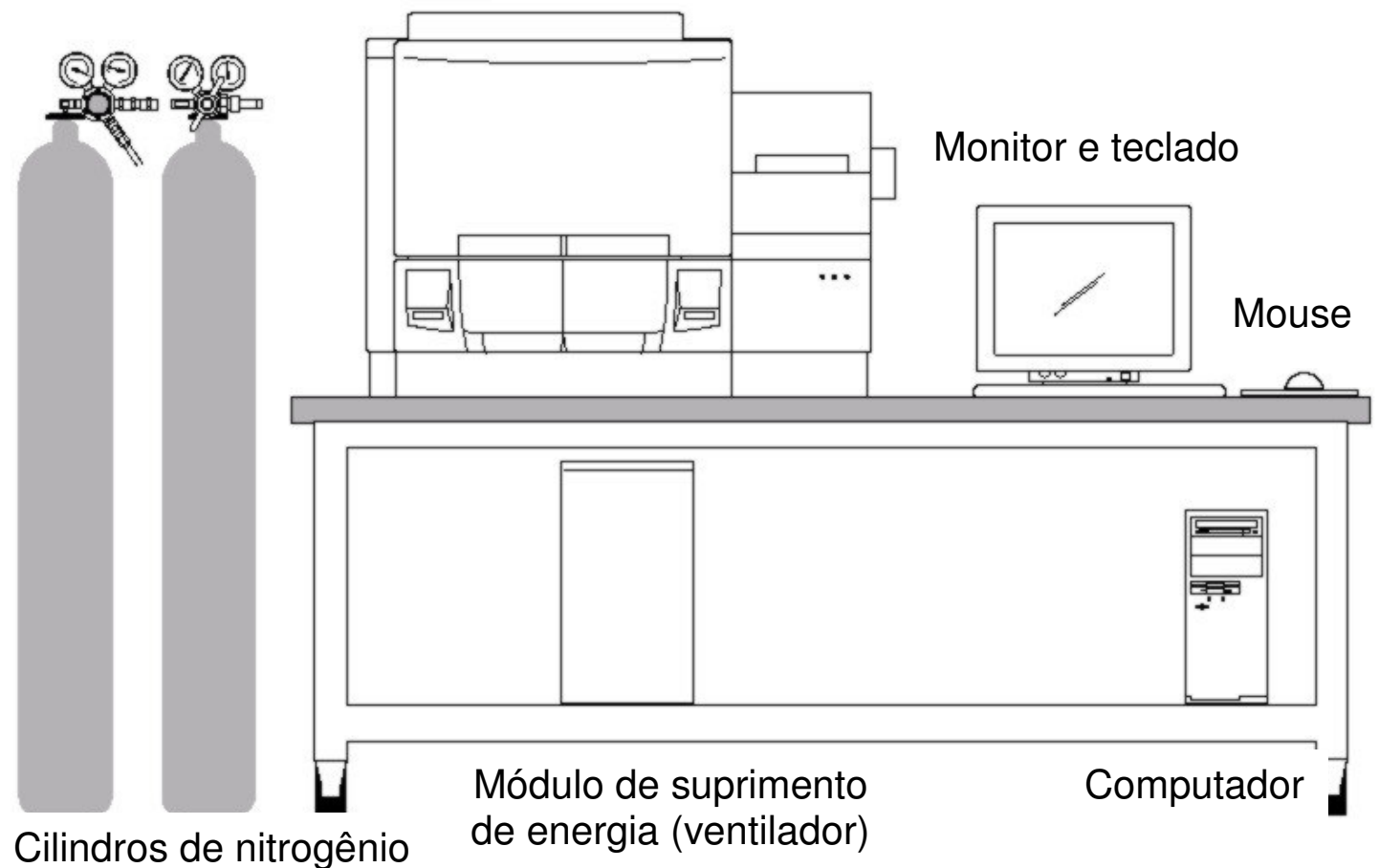

B) Rol de capilares

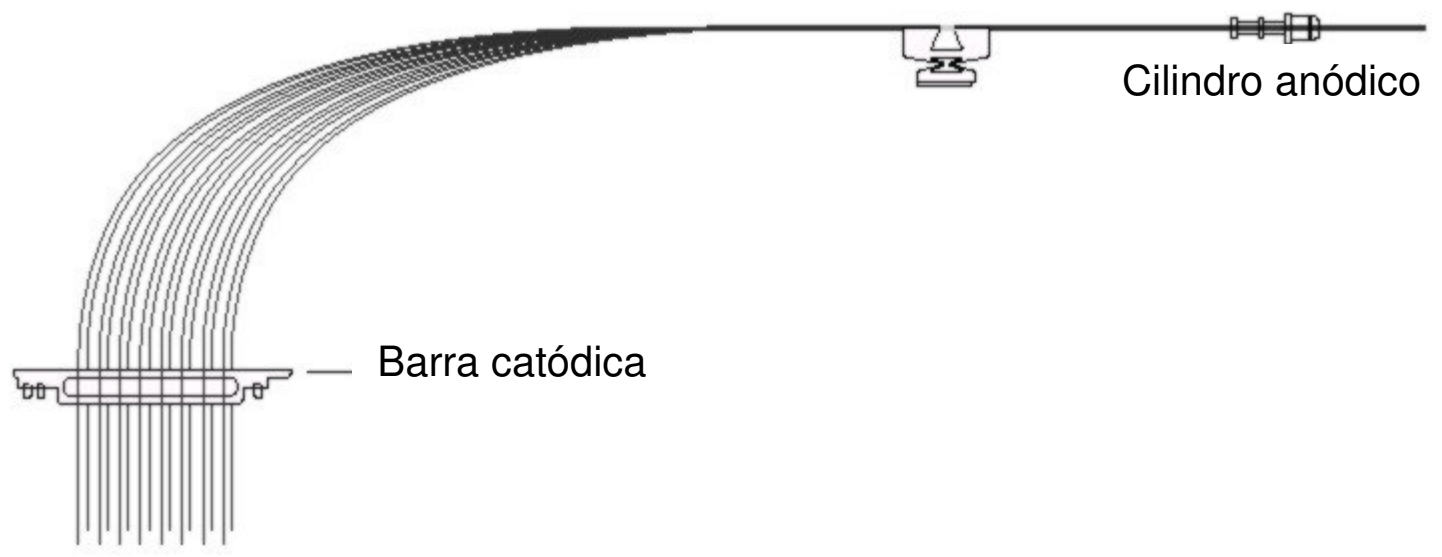


ANEXO A: Modelo de Identificação
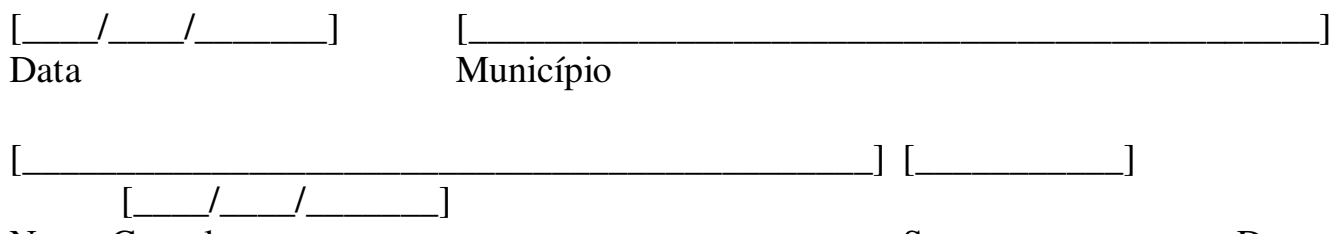

Nome Completo

Sexo

Data

Nascimento
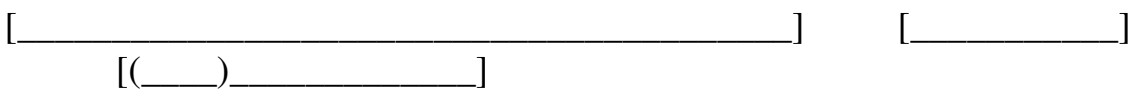

Endereço

CEP

Telefone

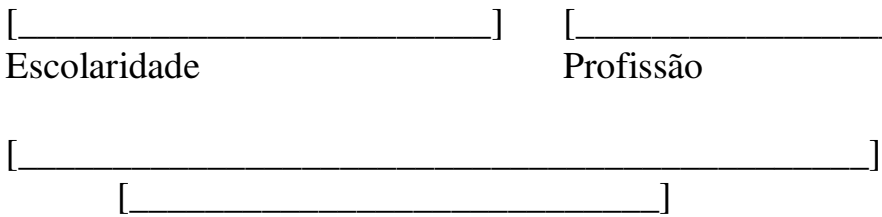

Nome do Doente da Família

Grau de Parentesco

\section{HISTÓRIA DA DOENCA}

$\left[\_\mathrm{mg} / \mathrm{dl}\right]$

Taxa Máxima Colesterol Medicação em Uso para o Colesterol

Em Qual Parente?

[__ Verrugas nas pálpebras (olhos)

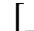

[__ _ "Caroços" nos tendões dos músculos (mãos, braços, pernas)

\begin{tabular}{|c|c|}
\hline [__ Infarto & Idade [__ \\
\hline$[\ldots]$ Safena/Angioplastia & Idade [_ \\
\hline [__ Doença. Isquêmica Coração & Idade [_ $]$ \\
\hline [_] AVC ("derrame") & Idade [_ $]$ \\
\hline
\end{tabular}

\section{ETNIA AUTO-RELATADA}

\begin{tabular}{|c|c|c|}
\hline [___ Portuguesa (brasileira) & [__ ] Polonesa & [__ Espanhola \\
\hline [__ Açoriana & [__ [ Letoniana & [___] Uruguaia \\
\hline [__ Indígena & [___ Austríaca & [__ Síria \\
\hline [__ ] Afriana & [__ ] Romena & [__ [ Libanesa \\
\hline
\end{tabular}


ANEXO B: Termo de Consentimento Informado e Esclarecido

UNIVERSIDADE DE SÃO PAULO

FACULDADE DE MEDICINA DE RIBEIRÃO PRETO

Termo de Consentimento Informado e Esclarecido

Autorizo o Médico Carlos Alberto Werutsky, doutorando do Curso de Clínica Médica dessa Faculdade, incluir-me na Pesquisa, cujos objetivos são de identificar o tipo de "traço" genético que desenvolve a doença familiar do colesterol.

Estou ciente que, para tanto, é necessário que cada participante:

1- responda aos questionários de identificação e de hábitos de vida;

2- doe 10 mililitros de sangue da veia do braço-antebraço, por técnica apropriada e idêntica ao exame de sangue (laboratorial) de rotina;

3- autorize a medida do colesterol total e suas frações, bem como a análise genética; e

4- fique disponível para a repetição dos mesmos se, eventualmente, for solicitado.

Nesta avaliação, os participantes não devem sentir nenhum desconforto, dor ou constrangimento, e devo ter a garantia de resposta a qualquer pergunta.

Os resultados dos exames de cada participante, onde consta a medida do colesterol total e suas frações e o tipo de "traço" genético da doença familiar do colesterol, serão entregues confidencialmente, sem nemhum custo (serão absorvidos pelo orçamento da Pesquisa), seguindo-se a orientação médica elucidativa para cada caso.

Caso tiver ainda mais perguntas sobre esta Pesquisa, posso chamar o pesquisador responsável no telefone (051)3342-0742 e, para qualquer pergunta sobre os meus direitos como participante desta Pesquisa ou se penso que fui prejudicado pela minha participação, posso chamar o orientador no telefone (016)602-2366.

Se por qualquer motivo pessoal, de saúde ou de não adequação, o participante tem a liberdade de abandonar a Pesquisa, sem prejuízo para si, bastando informar ao pesquisador.

Portanto, concordo que as informações provenientes de todos os testes a que fui submetido(a), sem minha identificação, possam ser usadas para esta Pesquisa científica, bem como sua publicação.

Declaro que recebi cópia do presente Termo de Compromisso.

Assinatura do Paciente

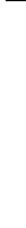
enquanto eu estava presente.

\begin{tabular}{ll}
${ } }$ & Nome \\
Este Termo foi lido para & (nome do participante) em \\
\hline
\end{tabular}

\begin{tabular}{ll}
${ } }$ & Nome \\
Este Termo foi lido para & (nome do participante) em \\
\hline
\end{tabular}

Nome

\begin{tabular}{ll}
${ } }$ & Nome \\
Este Termo foi lido para & (nome do participante) em \\
\hline
\end{tabular}

\section{Data}

Assinatura da testemunha

Nome

Data 
ANEXO C: Carta de Aprovação do Comitê de Ética

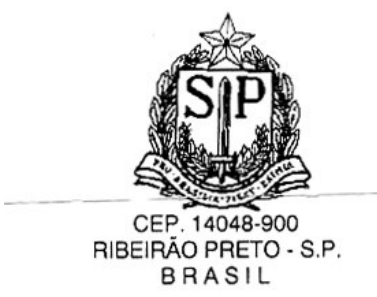

HOSPITAL DAS CLÍNICAS DA FACULDADE DE MEDICINA DE RIBEIRÃO PRETO DA UNIVERSIDADE DE SAOO PAULOO

CAMPUS UNIVERSITÁRIO - MONTE ALEGRE FONE: 602-1000 - FAX (016) 633-1144

Ribeirão Preto, 08 de agosto de 2003

Oficio $n^{\circ} 2238 / 2003$

$\mathrm{CEP} / \mathrm{SPC}$

\section{PROCESSO HCRP $\mathrm{n}^{\circ} 10303 / 2002$}

Prezado Senhor:

O Comitê de Ética em Pesquisa, em sua $160^{a}$ Reunião Ordinária realizada em 04/08/2003, analisou e aprovou a recomendação solicitada pela CONEP em Parecer $\mathrm{n}^{\circ}$ 636/2003, referente ao Projeto de Pesquisa intitulado: “AS BASES MOLECULARES DAS HIPERCOLESTEROLEMIAS FAMILIARES (HF) NO BRASIL: A REGIÃO SUL".

Aproveito a oportunidade para apresentar a Vossa Senhoria protestos de estima e consideração:

PROF. DR. SÉRGIO PEREIRA DA CUNHA

Coordenador do Comitê de Ética

em Pesquisa do HCFMRP-USP e da FMRP-USP

Ilustríssimo Senhor

CARLOS ALBERTO WERUTSKY

PROF. DR. JOSÉ ERNESTO DOS SANTOS (Orientador)

Depto. de Clínica Médica

Em mãos 


\section{Anexo D: Posição das Mutações nos Exons}

-21 ATG GGg CCC TGG GGC TGG AAA TTG CGC TGG ACC GTC GCC TTG CTC CTC GCC GCG GCG GGG ACT GCA GTG//GGC GAC AGA TGT GAA AGA AAC GAG TTC CAG TGC CAA GAC GGG AAA TGC ATC TCC TAC AAG TGG GTC TGC GAT GGC AGC GCT GAG TGC CAG GAT GGC TCT GAT GAG TCC CAG GAG ACG TGC TTG//TCT GTC ACC TGC AAA TCC GGG GAC TTC AGC TGT GGG GGC CGT GTC AAC CGC TGC ATT CCT CAG TTC TGG AGG TGC GAT GGC CAA GTG GAC TGC GAC AAC GGC TCA GAC GAG CAA GGC TGT CCC // 84 CCC AAG ACG TGC TCC CAG GAC GAG TTT CGC TGC CAC GAT GGG AAG 99

TGC ATC TCT CGG CAG TTC GTC TGT GAC TCA GAC CGG GAC TGC TTG 114 GAC GGC TCA GAC GAG GCC TCC TGC CCG GTG CTC ACC TGT GGT CCC 129 GCX AGC TTC CAG TGC AAC AGC TCC ACC TGC ATC CCC CAG CTG TGG 144 GCC GC GAC AAC GAC CCC GAC TGC GAA GAT GGC TCG GAT GAG TGG 159 c.408C>T TGT AGG GGT CTT TAC GTG TTC CAA GGG GAC AGT AGC 174 D115D GCC TTC GAG TTC CAC TGC CTA AGT GGC GAG TGC ATC 189 TCT GAC GAG GAA AAC TGC GCT//GTG GCC ACC TGT CGC CCT GAC GAA TTC CAG TGC TCT GAT GGA AAC TGC ATC CAT GGC AGC CGG CAG TGT GAC CGG GAA TAT GAC TGC AAG GAC ATG AGC GAT GAA GTT GGC TGC GTT AAT GTG//ACA CTC TGC GAG GGA CCC AAC AAG TTC AAG TGT CAC AGC GGC GAA TGC ATC ACC CTG GAC AAA GTC TGC AAC ATG GCT AGA GAC TGC CGG GAC TGG TCA GAT GAA CCC ATC AAA GAG TGC GGG//ACC AAC GAA TGC TTG GAC AAC AAC GGC GGC TGT TCC CAC GTC TGC AAT GAC CTT AAG ATC GGC TAC GAG TGC CTG TGC CCC GAC GGC TTC CAG CTG GTG GCC CAG CGA AGA TGC GAA GAT//ATC GAT GAG TGT CAG GAT CCC GAC ACC TGC AGC CAG CTC TGC GTG AAC CTG GAG GGT GGC TAC AAG TGC CAG TGT GAG GAA GGC TTC CAG CTG GAC CCC CAC ACG AAG GCC TGC AAG GCT GTG GGC//TCC ATC GCC TAC CTC TTC TTC ACC AAC CGG CAC GAG GTC AGG AAG ATG ACG CTG GAC CGG AGC GAG TAC ACC AGC CTC ATC CCC AAC CTG AGG AAC GTG GTC GCT CTG GAC ACG GAG GTG GCC AGC AAT AGA ATC TAC TGG TCT GAC CTG TCC CAG AGA ATG ATC TGC AGC//ACC CAG CTT GAC AGA GCC CAC GGC GTC TCT TCC TAT GAC ACC GTC ATC AGC AGG GAC ATC CAG GCC CCC GAC GGG CTG GCT GTG GAC TGG ATC CAC AGC AAC ATC TAC TGG ACC GAC TCT GTC CTG GGC ACT GTC TCT GTT GCG GAT ACC AAG GGC GTG AAG AGG AAA ACG TTA TTC AGg GAG AAC GGC TCC AAG CCA AGg GCC ATC GTG GTG GAT CCT GTT CAT GGC//TTC ATG TAC TGG ACT GAC TGG GGA ACT CCC GCC AAG ATC AAG AAA GGG GGC CTG AAT GGT GTG GAC ATC TAC TEG CTG GTG ACT GAA AAC ATT CAG TGG CCC AAT GGC ATC ACC CTA \&AT//CTC CTC AGT GGC CGC CTC TAC TGG GTT GAC TCC AAA CTT CAC TCC ATC TCA AGC ATC GAT GTC AAT GGG GGC AAC CGG AAG ACC AZC TTG GAG

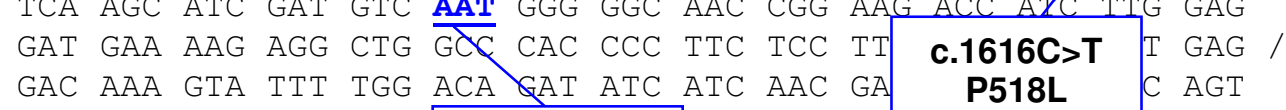
GCC AAC CGC CTC ACA CTA CTG TCC CCA GAG

\section{c.1773C>T} N570N CTC TTC CAC AAC CTC ACC CAG CCA AGA GGA//GTG AAC GGC TGC CAG TAT CTG TGC CTC CCT GCC CCG CAG ATC AAC CCC CAC TCG CCC AAG TTT ACC TGC GCC TGC CCG GAC GGC ATG CTG CTG GCC AGG GAC ATG AGG AGC TGC CTC ACA GAG//GCT GAG GCT GCA GTG GCC ACC CAG GAG ACA TCC ACC GTC AGG CTA AAG GTC AGC TCC ACA GCC GTA AGG ACA CAG CAC ACA ACC ACC CGG CCT GTT CCC GAC ACC TCC CGG CTG CCT GGG GCC ACC CCT GGG CTC ACC ACG GTG GA ATA GTG ACA ATG TCT CAC CAA GCT//CTG GGC GAC GTT GCT GGC AGA GGA AAT GAG AAG AAG CCC AGT AGC GTG AGG GCT CTG TCC ATT ATC GTG//CTC CTC GTC TTC CTT TGC CTG GGG GTC TTC AAG AAC TGG CGG CTT AAG AAC ATC AAC AGC ATC AAC CCC GTC TAT CAG AAG ACC ACA GAG GAT GAG GTC CAC ATT TGC CAC AAC CAG GAC GGC TAC AGC TAC CCC TCG//AGA CAG ATG GTC AGT CTG GAG GAT GAC GTG GCG TGA
$-7$

24

39

54

69 9

74

204

219

234

249

264

279 Exon 6

294

309

324 Exon 7 339

354

369 Exon 8

384

399

414

429

444

459

474

489

504

519

534 549

564

579

/ 594

609

624

639

654

669

684

699

714

729

744 Exon 15

759

774

789

804

819 834
Exon 2

Exon 3

Exon 4

Exon 9

Exon 10

Exon 11

Exon 12

Exon 13

Exon 14

Exon 16

Exon 17

Exon 18 


\section{ANEXO E: Posição das Mutações nos Íntrons e Região 3' Não Traduzida}

1

61

121

181

241

301

361

421

481

541

601

661

721

781

841

901

1

961

1021

1081

1141

1201

1261

1321

1381

1441

1501

1561

1621

1681

1741

1801

1861

1921

1981

2041

2101

2161

2221

2281

2341

2401

2461

2521

2581

2641

2701

2761

2821

2881

2941

3001

3061

3121

3181

3241

3301

3361

3421

3481

3541

3601

3661

3721

3781 gtttccctaaaatcctgctgagaggttagcactgcctgccaaagtcagtttgcaaalcc cagagaaatccagcttattcctgggggaaccgccaagactgcccagccctgtgtggggtt caggcaagtttctcacatgtgccttttggcaagaggcctctggcaaccccatgagtccc caaagagactcaattctaaagttggtctccaccagctctctgtggcttaggggttcaag ttcaactgtgaaagccctgttttgttttgattttgctttgagggagaggaaaccgccctt ctgtttgttcaactccttctcctaaggggagaaatcaatatttacgtccagactccaggt atccgtacaattgattttcagatgtttatactcagccaaaggcgggatcccacaaaca aaaatatttttttggctgtacttttgtgaagattttatttaaattcctgattgatcagt gtctattaggtgatttggaataacaatgtaaaacaatatacaacgaaaggaagctaaa atctatacacaattcctagaaaggaaaggrcaatatagaaagtggcggaagttcccaac atttttagtgttttcctttgaggcagagaggacaatggcattaggctattggaggatct tgaaaggctgttgttatccttctgtggacaacaacagcaaaatgttaacagttaaacatc gagaaatttcaggaggatctttcagaagatgcgtttccaattttgagggggcgtcagctc ttcaccggagacccaatacaacaatcaagtcgcctgccctggcgacactttcgaagga ctggagtgggaatcagagcttcacgggttaaaagccgatgtcacatcggccgttcgaaa ctcctcctcttgcagtgaggtgaagacatttgaaaatcaccccactgcaaactcctcccc

$$
M \quad G \quad P \quad W \quad G \quad W \quad K
$$

ctgctagaaacctcacattgaaatgctgtaaatgacgtggATGGGGCCCTGGGGCTGGAA

$$
\begin{array}{llllllllllllllll}
L & R & W & T & A & L & L & A & A & A & G & T & A & V
\end{array}
$$

ATTGCGCTGGACCGTCGCCTTGCTCCTCGCCGCGGCGGGGACTGCAGgtaaggettgctC caggcgccagaataggttgagagggagcccccggggggeccttgggaatt attttttg ggtacaataatcactccatccctgggagacttgtggggtaatggcacggggtccttccc aaacggctggagggggcgctggaggggggcgctgaggggagcgcgagggtcgggaggagt ctgagggatttaagggaaacggggcaccgctgtcccccaagtctccacagggtgagggac cgcatcttctt gagacggagtctagctctgtcgcccaggatggagtgcagtggcacgat ctcagctcactgcaacctccgcctcccgggtttaagcgagtctcctctctcagcctcccg aatagctgggattacaggcgcccaaccaccacgcccgcctaattttgtattttagtag agacgggttttcaccattttggccaggctggtctcgaaccccgacctcaggtgatctgcc caaaagtgctgggattacaggcgtcagccaccgcgcccggccgggaccctctct ctaac tcggagctgggtgtggggacctccagtcctaaaacaagggatcactcccacccccgcctt aagtccttctgggggcgagggcgactggagacccggatgtccagcctggaggtcaccgcg ggctcaggggtcccgatccgctttgcgcgaccccagggcgccactgccatcctgagttgg gtgcagtccegggattccgcegcgtgctccgggacgggggccaccccctcccgccectgc ccccgcccctttggcccgccccccgaattccattgggtgtagtccaacaggccaccctcg agccactccccttgtccaatgtgaggcggtggaggcggaggcgggcgtcgggaggacggo gcttgtgtacgagcggggcggggctggcgcggaagtctgagcctcaccttgtccggggcg aggcggatgcaggggaggcctggcgttcctccgcggttcctgtcacaaaggcgacgacaa gtcccgggtccccggagccgcctccgcgacatacacgagtcgccetccgttatcctgggc cctcctggcgaagtccccggtttccgctgtgctctgtggcgacacctccgtccccacctt

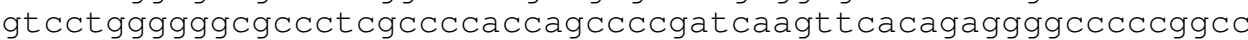
accctcaaggcctcggttccttacgaggttgaaacgttgcctcagaatctccccgcccct ccttggtctgcagccgagatcttcagccacggtggggcagctat $\mathrm{Ccccgggaccgaccc}$ cctggggtggcctcgcttcttcagaggctgtgaatggcttcggttcagctgtccaagcgg cgattttcctctgggtgaaatggattagattttagatttccacaagaggctggttagtg catgatcctgagttagagctttttaggtggctttaattagttgcagagagacagcctcg ccctagacaacagctacatggcccttccctcctgagaaccagcctagcctagaaagga ttgggattgcctgatgaacacaaggattgcaggaaacttttttttaattggcaaggggg ttggctttgactggatggagagctttgaactgccttgaaattcacgctgtaactaacaca ccagtttcctctgggaggccagagagggagggagggtgtaatgaaatacggatgattgtt ctttattttatt acttatt atttttaacttttgtagagatgaggtctcocttgg ttgctcaggctggtcttgaactcctggcctcaagcgatcctcctacctcagcctcccaaa gtgttgggattacaggagtgagccaccgcgccccaccggggatgatgatgattgcaaaca ttctgccactcagttttacaaagaaagagaggcactggattaatgtgtatctcactcac caatcaacctcttccttaagagaaatgttaaggaagtcttaggcaaggccttgtttgtt catcactttagtttctctctcccgggatggctgagaatgtgatgtttcctctgttgtcaa ggagactacacccctgatgttttcctccagacttctgagagctggtgtgtgtttctagca cttctagctgcaccacctcacgctgtagctggcttcaaggcatatccaggggggagttt cttgtccatttcctttacaagggaagttgttggaatctgaaccgcaagccttcacttag accaaatcaggcaacagcggtgagcgcagctccaaacgtgtcaatgactcacccaatt tgagtaagggagttggctgctttaacgagccgcagggtgattcccttgtcatttccggaa atacctatcttccagggaacactgggaaaaacagggagacctttgttgagacagaaac ctgtaggggaattctgttcctcattcctgctcttatctgtagact cctccctgataaga tccaattctagatgggtcggttgctccttgctttgatgggtgctttgatgggctttatta ttattattattattattattattattttgatgggctttttgatgtcccttttccttccac actctgtcccaactgtcaagcaaatagccttttgttgctaagagactgcagatgtaaccg accagcagcaaacagtgagtcaggctctctcttccggaagcaaatcaattgctgagatc
60

120

180

240

300

360

420

480

540

600

660

720

780

840

900

960

1020

Exon 1

1080

1140

1200

1260

1320

1380

1440

1500

1560

1620

1680

1740

1800

1860

1920

1980

2040

2100

2160

2220

2280

2340

2400

2460

2520

2580

2640

2700

2760

2820

2880

2940

3000

3060

3120

3180

3240

3300

3360

3420

3480

3540

3600

3660

3720

3780

3840 
3841

3901

3961

4021

4081

4141

4201

4261

4321

4381

4441

4501

4561

4621

4681

4741

4801

4861

4921

4981

5041

5101

5161

5221

5281

5341

5401

5461

5521

5581

5641

5701

5761

5821

5881

5941

6001

6061

6121

6181

6241

6301

6361

6421

6481

6541

6601

6661

6721

6781

6841

6901

6961

7021

7081

7141

7201

7261

7321

7381

7441

7501

7561

7621

7681

7741

7801

7861

7921 actctggggaaaatacccaccttatttggaaagaagcactgatcaattgatgtctatttt tttttttttgagttggagtctcgccctgtcacccaggctggagtgcaatggcataatct cgcctcactgcaatccccgcctcccgggttccagcaattctcctgcctcagcctcctgag tagctggaattataggcgcctgccacaacacccggctaatttttgtatttgtagtagaga tggggtttcaccacgttggccaggctggtctcgaactcctgacctcgtgatccacccgcc tcagcctcccaaagtccaaggattgcaggcgtgacccactgtgccagccaatcaattgat ttctcattcattttcagctggctctgttcccttaagccaggggattttcgtttgtttgtt tccccttcaaggaaatgattctagctacagttttgatttccttgtacaactgttttcagt agcacagggaaagaaaacatcgaaagcattcaccacctcatttgtgtgctgggggaaaaa gcagaaatgtgtattctcttttttgtttcgatgaccttgttcctgacttgttactcotg acttgagagatcagagggctagaggactagaatttatagaggtgttttttttgtttgttt atttttgttcgagttgcccaggctggagtgcagtggcgcaatctcggctcactgcaacct ctgcctcccaggttcaagcgattcttcggcctcagcctcctgagtagctggaactacagg cgcccgccaccacacccagctaatttttgtattttcagtagagatgggatttcaccata ttggtcaagctggcctcgaactcctgacctcgtgatccacccgcctcagtttcccaaagt gctgggagtacaggcgtgagccgccgtgcccggcctttttgtgtttttgtgtttttgaga ggagctcattgcttttaggcttccctagcgtgagaaaatctggggatccatgctctagt ttacttccttttttttttttttgagatggagtctcgcttagattgcctaatctcagc tcattgcaacttctgcctccggggttcaagggattctcgtgtctcagcctcctgggtagc taggatacgggcacccgctaccatgcctggctaattttgtacttttagtagagacagggt ttcgccacgttggccaggctggtctcgaactcctgacctcaggtgagccgcctgccttgg cctcccaagtgctgagattacaggcgtgagccaccgcgcttggcctaatttgcttttcc tgaaattcaaatggtctaatatgaaaacgccaaccttgcttgaaagaataagaaagagg tgcggtttcgttgggccgttgatgtttggaacaggactggttttgtccccttgctcggaa agggcagcaactgtgaggacagctccctgacgtgctctcactcagcactgttccottcct gagcactgtccccactagctaggccaagggagctcatttggcaggcaactgctgtctggc tgcgcctgtggcagtaaatctgcctttattttttggaggcagggtcttgccctgtcgct caggctgaagtgtgcagttatagctcactgcagcctccagcttctgtactcaactgatcc tcctctctcagcctcctgagtagctgggactatacgcacgtgttaccactcccacctcag tttgtttgtttatttatttatttatttatttattgagatggagttttgctcttgctgccc aggctggagtgcaatggcgcgatctcggctcaccgcaacctccacctcctggttcaagcg attctcctgcctcagcctcctgagtagctgggattacaggcatgcaccaccacgcccggc taattttgtatttttcgtagagatggggtttctccacattggttcaggctgttctcgaac tcccaacctcaggtgatccacccgcctcagcctcccaaagtgctgggattataggcgtga gcccccgaacccggccactcccagctaagtttaaattttttgtttgtttgttcgtttgtt tttattttttgagacagagtctcccgcccaggctggagcgcagatcactgcatccttgac ctcccaggcttaagccatcctccccactcagcctcccaagtagctgggattacaggtgtg tgccactatgcttggctaagttgtgtattttttgtagagatggggttcaagggattctcg ctttgttgcctcggttggtctcaaactcctgggctcaagcagtcctccctcctcagcctc ccaaggtgctggggaaatccacttttgaaacattgtctggagagttgcccaggtggtaga tcacagaataggtcatcgtggggtccttcccatgggtgcagtcttgagccacctgtggc cagcaaatatttggagaataatagtcaggggagagcttgaggtccagggaaaggttttgt ttttcttcagggaagggttttattgttctttatccctccttaaaggaccttcaggtgtt actgacattcccggtctacccagtggcacatttagtttgtaagctgggccctcgtacaga ggtagggaggtgagagcattggattagtggtcaccaaagctgcggtcacctagtggggtg atcagaggctcctccettaagatcttgattgccaacgcctctggcciactt ccettt atttatcgcaagcctcctggaatctcaattgctttttgcccacccggtgtgtcagcacaa gaaatgagtcatttcctcctttaagcacagttgaaattgagctgtgagtcagtgaggtgt gtacgatattgtcaaagcggggtgtgtacagtattgacagatctgtagttgggcaagaga attatcagagtttgtgaccacagcagattccaaagctcgactcatttettctctcttcc ttccctttttctttcttttttttttttttgacagagtctcgctctgttgcccagg ctggagtgcagtggcacaatctgggctcactgcagcccetgcctcctgggt tcaatgat tctcatgtttcagcctcccgagtagctgcaattacaggcattcgggttcaagtgattctc ctgcctcagccacctgagcagctgggattacaggcgcccgccaccacgcccogctaatt ttgtatttttagtagagacggggtttcaccatgttggccaggctggtctcgaactcctga actcaggtgatccgcccacttcggcctcccaagtgctgagattacagacgtgagtcacc gcgcccagcctgttctgttctt aattctcaaacaccctctaggaagtagagactgcca ttctcccccattttacagatcaggaaactgagtcccagaaggatttagtcagttacccaa gttgttctagttaaatggcctggaaagccagtgaagcccaggattgtctatctaaccccc ttactactctaactttcagggaatccacatgaatgtgctgggtcaaccatcaaagttgaa atggataaagggggctggatgcggtggctgatgcctgtaatcctagcactttgggaggcc gagatgggtgggtggattgcttgagcccaagagtttgagaccagcctgggcaacatagtg agacacctgtctctgcaaaaataaataaaagttagctgagtgtgatggtgcacccctc tagtcacagctgttgagttaggcttaggcaggaggatcgcatgaacctgggaggtggagg cggccgtgagcctcagtcatgccactgcactccaacctgggcaacagagtgaaagccggt gtccgaaagagaaagaaaaaagacatagatacatcttttaaagttaggttgtatgttaa ttacctacaactcagtttcaactgtgcttaaaggaggaaatgactcatttcttgctacat atcaattagcccaaatgtagtggcttaaacaacacatttatgatttctcagtttttg cgtgtcaggaatttggaagcagcacagctagacggttccagctcagggtctctcatgaag
3900

3960

4020

4080

4140

4200

4260

4320

4380

4440

4500

4560

4620

4680

4740

4800

4860

4920

4980

5040

5100

5160

5220

5280

5340

5400

5460

5520

5580

5640

5700

5760

5820

5880

5940

6000

6060

6120

6180

6240

6300

6360

6420

6480

6540

6600

6660

6720

6780

6840

6900

6960

7020

7080

7140

7200

7260

7320

7380

7440

7500

7560

7620

7680

7740

7800

7860

7920

7980 
7981

8041

8101

8161

8221

8281

8341

8401

8461

8521

8581

8641

8701

8761

8821

8881

8941

9001

9061

9121

9181

9241

9301

9361

9421

9481

9541

9601

9661

9721

9781

9841

9901

9961

10021

10081

10141

10201

10261

10321

10381

10441

10501

10561

10621

10681

10741

10801

10861

10921

10981

11041

11101

11161

11221

11281

11341

11401

11461

11521

11581

24

11641

32

11701

52

11761

11821

11881 ttgcaatcaaatattggcaggagagaaaacatattttcagaagctgcaggcataggaa gacttggctggggttgaaggatccacttccaagatggcgcactcagtggctcttggctgg aggcctcagttccctgctgcgtggagctctccctccagctgcttgagtggactcatgaca tgcagctggcctcccctggagcagtcgatccaacaatgagcatggccatgaactaggctc agaagccactccctgtcgtctctacattttcctatcagaagcaagtcattaaaagtccag tgccactccaggggagacgaattaggctctgccttctgaaaggattatcacagaagatgc ggtcctatattcttttttaaattattctttttttattttgtagagatggggtcttgg tatgttgcctaggccagtctggaattcctgggctcaaacaatcctgtctctgcctcccaa agtgttgggattacaggcatgagccactgcacctggtcatgtggtcatattttctttttc ttttttttttttttgagacagagtctctgtcocccaggctggagtatggtggcotgat ctcagttcactgcagcctccgcctcccgggttcaagcgattctcctgcctcagcctcctg agtagctgggattacaggcgcccgccaacatgcccagctaattttttagtagagatggg gtttcaccatgttagccaggatggtctcgatctcctgatttggtgatccgcccaccttgg cctcccaagtttcaaccatcgatcagaacttattgatgtacttatgtagctaggcacgg tggcgcgtgcctgtaatcccagctacttggaagggttaaggcaggagaatcgcttgaacc tgggaggcagaggttacagtgagtcaagatcataccattgcactccagtctgggcaacag aatgagactctgtctcaaaacaaaaacaaacccttgtatgtgattttcctggatagca tctgttacatcttcacaaagataaaagtcagacttggctgggcatggtggctcacacct gtaatcccagcactgagaggctgaggcaggcagatcacttgaggtcaggaatttgagacc aggctgggcagcatggtgaaaccccgtctctacaaaaatacaaaattagccgggtgtg gtgtcacgcacctgtattcccaagctactcaggaagctaaggcaggagaatcacttgaac ccagaggtggaggtttgcagtgagttgagattgtgccattgcactccagcctgggcgaca gagtgagactctgtgtcaaaataaaataaataaattttaaaaaggcagattttttt ttcttcttggtattgttaccttattatagtaataataagtgcatagtgcatgctgagata agcaatcataatttgttattgcggccgggcatggtggctccagcctataatcccagcact ttggtcaggagttcaaggccagcctggccaatatagtgaaactccatctctactaaata caagaaattacctgggcatggtggcagttgctggtgatccccagctacttgggaggctga ggcaggagaatcgcttgaacctgggaagcagaggttgcagtgagccaagattgcaccact gcactccagcctgggtgacagagtgagactctgtctgaaaataataataataataatttg ttattgcttttattgccttagtttacatagggaatcaagtttatactttgatttataaa agttgctttgattctagttcacagaaccagaatctttcatataaaggtattagagggccc agtgtggtggctcatgcctgtaatcccagcatattgggaggctgaggagggaggatcact ttaggagtttgaggccagcctaggcaacatagtgagaccttgtctctacaaaaattcca acattagctgggcatggtggcatgtgcctgtagtcccatttatttggggggctgaggcag gaggatcacttgagcccacgaggttcaatccaggttgcagtaagccatgatcctgccact gcactccagtttgggtaacagagcgaagctatgtctcaaaaaagaaaaaaaagtattc taatccaatttaatatataaactaatgcaggccaagtgtggtggcatatacctata atcacaacactttgggaggctgaggtgggaggattgcttgagcccaagagttcaagacca gcctaggtaacacagtaagaccccatctctacaaaagtagaaaattagcctggcatgg tggtgagtgcttt aatcccaactacttagggggctgagatgggaagattgcttgagcct cagagtttgaggctgcagtgggccgtgatcgctccactgatcgctctaaagtgagaccct gtctcaaaaaaagaaatagaagaaactaaatacattcaataagactttgatctct ttccaaggtgtaaatatattttgggaaattttccagttactttgttctcattttaatgta ataatctaagtcttggtttctaaggaaagtttctcttattatatctttgttaatgt ttctctcccatttcttttgatctgatcttcagatacatgattatcttcactgctaaattt gtgttctctggcctctacatt ataattctcataattcttatctaagtattctecco tacctactgaagaaaactcaagttttcttccaccttaatgattatgctgtgtctgtgagt tttcttcatgactctttacagtacaagttttttgtttttgttttttaatggtcagatgg atagaacaacacaggttttgtttgttttgttttaacttttaaaaaattataatagataa agggtctcactacgttgtccaggctgatctcatactcctgggctcaagcaatccacccac ctctgcctcccaaagtgctgggattacagtcatgagccaacatgcctgggcagtacaggt ttttttgagacggagttttgttcttgttgccgaggctggagtgcaatggcacaatcttg gctcaccacaaagtctgcctcccaggttcaagtgattctcctgcctcagcctcctgagta gctgggattacaggcatgtgccaccacgcccagctaattttgtatttttagtagagacgg ggtttcaccatgttggccaggctggtttcgaactgctgacctcaggtgatctgcccacct cggcctcccaagtgctgggattacaggcatgagccaccatgcccagctgtagtacaggt tttaatatgctaatactcttcctttcttattaatgtgcatggaagttctaatatttt ttcccataccccagagagtccatattttggaatcaacaacactagcctttgttgacaagt gtctctcttgggttccttctttgtgtcctccactgaattttggggttcataaaatttcat ttgttgtgcttgcttaattccctgggaatcagactgttcctgatcggatgacatttctgg ttaattctttagttggcaggaaatagacacaggaaacgtggtcagtttctgattctggcg

$$
\begin{array}{llllllllllll}
G & D & R & C & E & R & N & E
\end{array}
$$

ttgagagaccetttctcctttcctctctctcagTGGGCGACAGATGCGAAAGAAACGAG $\begin{array}{llllllllllllllllllll}F & Q & C & Q & D & G & K & C & I & S & Y & K & W & V & C & D & G & S & A & E\end{array}$ TTCCAGTGCCAAGACGGGAAATGCATCTCCTACAAGTGGGTCTGCGATGGCAGCGCTGAG $\begin{array}{llllllllllllll}C & Q & D & G & S & D & E & S & Q & E & T & C & L\end{array}$

TGCCAGGATGGCTCTGATGAGTCCCAGGAGACGTGCTgtgagtcCcctttgggcatgata tgcatttatttttgtaatagagacagggtctcgccatgttggccaggctggtcttgaatt tctggtctcaagtgatccgctggcetcggcetcccaaagtgctgggattacaggcaccac
8040

8100

8160

8220

8280

8340

8400

8460

8520

8580

8640

8700

8760

8820

8880

8940

9000

9060

9120

9180

9240

9300

9360

9420

9480

9540

9600

9660

9720

9780

9840

9900

9960

10020

10080

10140

10200

10260

10320

10380

10440

10500

10560

10620

10680

10740

10800

10860

10920

10980

11040

11100

11160

11220

11280

11340

11400

11460

11520

11580

11640

11700

11760

11820

11880

11940 
11941

12001

12061

12121

12181

12241

12301

12361

12421

12481

12541

12601

12661

12721

12781

12841

12901

12961

13021

13081

13141

13201

13261

13321

13381

13441

13501

13561

13621

13681

13741

13801

13861

13921

13981

14041

65

14101

80

14161

100

14221

14281

14341

14401

14461

14521

14581

14641

14701

14761

14821

14881

14941

15001

15061

15121

15181

15241

15301

15361

15421

15481

15541

15601

15661

15721

15781

15841 gcctggcctgtgacacgattcttaaccccttttgatgatggcggctggaaaagtggcca gtggattttgatgtattcaatcatgaattaggaggtggggagagaatgaattattggagc tttccttaaagccattaalggctctattgtttttcaattgatgtgaatttcacataac atgaattaaccagctcagtggcattaatacatctgcaatgctgtgtggccaccacctct atcttgttccaaactttgcataacctaatgtctttttttttttttttttgagacgga gtctcgttccatcacccaggctggagtgcagtggtgtgatctcagctcactgcaacctcc gcctcccaggttcacgccatcctcctgcctcagcctcccgagtagctgggactacaggca ccctccaccacatccggctaattttttgtatctttagtagagatggggtttcaccatgtt agccgggatggtctcgatctcctgacctcgtgatccacctgcctccgcctcccaaagtgc tggcattacaggcgtgagccaccatgcccggcctattttttttttaagagatggagtct aattctgttgcccaggctggagtccagtggtaccatcatacttcactgcagccttgacct cttgggctcaagtgattctcttgcctcgaactcccaaagtattgggattacaggtgtgag ccaccgcactcagcctaatgtccagtttttaacaagctccatttaatgccctccgtttt gacccataaaggggtaggcttggccgggcacaatggcttgtgtctgtagtcccagctact tgggaggctgaggcagaaaggcagaaagattgctttataaagcccaggagtttgagggcc acctgggtggcatagctagacctcatctctaaaaataagtaataaataaatatttgttt ttgttttttctttttctttctttttttttttttttgagacggagtcttgctctgttg cccaggctggagtgcagtggcgcgatctcagctcactgcaagctgtgcctcctgggttca tgccattctcctgcctcagcctcccgagtagctgggactacaggcgccictaccacgcc cagctaatttttgtattttagtagagatggggtttcaccacgttagccaggatggtct caatctcctgacctcgtgatccgccagctttggcctcccaagtgttgggattacaggcg tgagccactgagcccgccccatatgtatgtatatatatattttttaaatgggagacca ggcatggtggctcatgcctagaatcccagcactttgggaagctgaggtaggcggatcact tgaggccatgagtttgagaccagcctgctcaacatgatgaaacttctatctctactaaa aaaaagtgggattaggtcaggcacggtggctcacacctgtaatcccagcactttcagag gccgaggcaggaggatcatgaggtcaggagatcgagaccatcctggctaacacggtgaaa ccccgtctctactaaaaaatacaaaaattagccaggcgtggtggcgggtgcctgtagt cccagctactcaggaggctgaggcaggagaatggcgtgaacccgggaggcggagcttgca gtgagccaagatcgtgccactgtactccagcctgggcgacagagcaagactctgtctcaa aaaaaaaaaaagtgggattgacattctcttcaaagttctggggttttcctttgcaaa gacaggattggcaaggccagtgggtcttttttgtgtgtgtgtgtgtgacggagtctcact ctgccacccaggctggagtgcaatggcaggatctcggctcaccgcaacctcctcctccca ggttaaagtgattctcctgcctcagcctcccgagtagctgggactacaggtgcccgccac cacacccaactaatttttgtattttagtagagacagggtttcactatattggccaggct ggtcttgaacccctgacctcacgtgatccacccgccttggcctcccaaagtgctgggatt acaggcgtgagccactgtgctcggcctcagtgggtctttcctttgagtgacagttcaatc

$$
\begin{array}{llllllllllllllll}
S & V & T & C & K & S & G & D & F & S & C & G & G & R & V
\end{array}
$$
ctgtctcttctgtagTGTCTGTCACCTGCAAATCCGGGGACTTCAGCTGTGGGGGCCGTG $\begin{array}{llllllllllllllllllll}N & R & C & I & P & Q & F & W & R & C & D & G & Q & V & D & C & D & N & G & S\end{array}$ TCAACCGCTGCATTCCTCAGTTCTGGAGGTGCGATGGCCAAGTGGACTGCGACAACGGCT D $E$ \& $\quad G \quad C \quad P$

CAGACGAGCAAGGCTGTCgtaagtgtggccctgcctttgctattgagcctatctgagtcC tggggagtggtctgactttgtctctacggggtcctgctcgagctgcaaggcagctgcccc gaactgggctccatctcttgggggctcataccaagcctcttccgccettcaaatcccccc ttgaccaggaggcattacaaagtggggatggtgctacctcttcgggtttgtcacgcacag tcagggaggctgtccctgccgagggctagccacctggcacacacactggcaagccgctgt gattcccgctggtcgtgatccccgtgatcctgtgatccccgccccgtgaggctgaacaca tagtgacgcttgctagccaagcctcaatgacccacgtaacatgaagggggaaaagccaga aagttctgccaaggagcaaggccaagaatcccgaagggaaatggactttgaagctgggcg tcttcttggctgtcttaatacaagtggcacatccaaatccaaa ccccgaaattcaaagt cttgagcacccgaaattctgaaacgtcttgagcactgacctttagaaggaaatgcttatt ggagcattttggatttcggatttttaccactgagtgtggagtcctaattaggaaaaaac caggctgaccgaaccaaaggaaagcaataaaagaaggcagatagggtcaggcacggtggc tcacccctgtaatcccagccttttgagaggctgaggcgggtggatcacttgaggtcagga gttcgagagcagcctggccaacacggtgaaaccccatctctactgaaatacaaaacta gccaggtatggtggcgtctgcctgtaatcccagctactcgggaggctgagacaggagaat cacttgaacctgggaggcagaggttgcagtgagccaatatcacgccattgcactccagcc tgggggacaagagcgaaattctgtctcaaaaaaaagaagaagaaggccgacaaactatg taactctgccttctccatggtccagaacacacagccctcctgcgtaataactccttat cttcctgctcccagctatcatcagacacctcggctgatagaaattgcaagttagctcac tgcaacctcggcattataagtactgcacaaagccetcttcagcgcacagcacaagcacca ttctataaatctccagcaagcggccaggtgcagtggctcatacctgtaatcccagcatt ttgggagactgaggcgggcggatcacctgaggtcaggagtttgagaccagcctggccaac atggtgaaaccccgtctctattaaaatacaaaaaattagccaggcgtggtggcaggtg cctgtaatcccagctacttggaaggctgaggcaggagaatcgcttgaacccgggaggtgg aagttgcagtgagccgagatcttgccatcgcactccagcctgggggacaagagtgagact tcgtctcaaaaaaaaaaaaaaattcccagcaagcctttgtcttctggcagtcagctcc tctcttgctgacctgctcattgcttccttgcaaggtattttcctacctactttctggaat aatctgtcttctgtacttacaactacctttttaaatttcttetttttgagatgg
12000

12060

12120

12180

12240

12300

12360

12420

12480

12540

12600

12660

12720

12780

12840

12900

12960

13020

13080

13140

13200

13260

13320

13380

13440

13500

13560

13620

13680

13740

13800

13860

13920

13980

14040

14100

14160

Exon 3

14220

14280

14340

14400

14460

14520

14580

14640

14700

14760

14820

14880

14940

15000

15060

15120

15180

15240

15300

15360

15420

15480

15540

15600

15660

15720

15780

15840

15900 
15901

15961

16021

16081

16141

16201

16261

16321

16381

16441

16501

16561

106

16621

109

16681

129

16741

149

16801

169

16861

189

16921

209

16981

229

17041

17101

17161

17221

17281

17341

17401

17461

17521

17581

17641

17701

17761

17821

17881

17941

233

18001

247

18061

267

18121

18181

18241

18301

18361

18421

18481

18541

18601

18661

18721

18781

274

18841

293

18901

313

18961

19021

19081

19141 agtctcactctgtttgcccaggctggagttcagtggtgcaatctcagctcactgcaacct ctacctactgggttcaagcgattctcctgcctcagcttcccgagtagctgggattacagg cgtgcaccagcacgcaggctaatttttgtatttttagtagagacggggtttcaccatgtt ggccaaggtggtcttgaactcctgacctcaagtgatcctcccacctcagcctcccaaagc gctaggattacggccatgagccactgaggccggctgcacctacaactgtcttgataatt cttacccccacaccactggtccagatagtcagtgctcacccacaacattaaggatattcc aatttgaacattccaaatcagaaaatattccaactctgaaatattccaaatcca aaaaattcaaatccaaaacacttctggtcccaagcattttagagaagggatactcaac ccaaataaggacagcaattctataaattgtgctaccatcttgcaggtctcagtttaaca gctttacacctattagcgcaccagtgctcatagcagtgctgggaaatgtgtacagatgag gaaactgaggcaccgagagggcagtggttcagagtccatggcccctgactgctccccagc ccgcctttccaggggcctggcetcactgcggcagcgtccccggctatagaatgggctggt $P \quad K \quad T$

gttgggagacttcacacggtgatggtggtctcggcccatccatcCctgcagCCCCCAAGA $\begin{array}{llllllllllllllllllllllllllll}C & S & Q & D & E & F & R & C & H & D & G & K & C & I & S & R & Q & F & V & C\end{array}$ CGTGCTCCCAGGACGAGTTTCGCTGCCACGATGGGAAGTGCATCTCTCGGCAGTTCGTCT $\begin{array}{llllllllllllllllllll}D & S & D & R & D & C & L & D & G & S & D & E & A & S & C & P & V & L & T & C\end{array}$ GTGACTCAGACCGGGACTGCTTGGA- GGCTCAGACGAGGCCTCCTGCCCGGTGCTCACCT $\begin{array}{lllllllllllllllllllll}G & P & A & S & F & Q & C & N & S & S & T & C & I & P & Q & L & W & A & C & D\end{array}$ GTGGTCCCGCCAGCTTCCAGTGCAACAGCTCCACCTGCATCCCCCAGCTGTGGGCCTGCG $\begin{array}{llllllllllllllllllll}N & D & P & D & C & E & D & G & S & D & E & W & P & Q & R & C & R & G & L & Y\end{array}$ ACAACGACCCCGACTGCGAAGATGGCTCGGATGAGTGGCCGCAGCGCTGTAGGGGTCTTT $\begin{array}{lllllllllllllllllllll}V & F & Q & G & D & S & S & P & C & S & A & F & E & F & H & C & L & S & G & E\end{array}$ ACGTGTTCCAAGGGGACAGTAGCCCCTGCTCGGCCTTCGAGTTCCACTGCCTAAGTGGCG

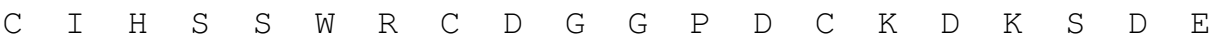
AGTGCATCCACTCCAGCTGGCGCTGTGATGGTGGCCCCGACTGCAAGGACAAATCTGACG E $\quad \mathrm{N} \quad \mathrm{C} \quad \mathrm{A}$

AGGAAAACTGCGgtatgggcggggccagggtgggggcggggcgtcctatcacctgtccet gggctcccccaggtgtgggacatgcagtgatttaggtgccgaagtggatttccaacaaca tgccaagaagtattcccatttcatgtttgtttctttttttcttttctttctttatttt gttttgagatggagtctcactctgtgattttttcatctctaaatttcctacatccata tggccaccatgaggccccaggctggccgatggttgctgttagcttattgggaaatcactg tttggaaggtgctggttgtttttgttgtttgttgtttttgtttttgtttttgttttgag acggagtctcgctctgtcgccagggtggagtgcagtggcgcgatcagctcactgcaacct ccgcttcctgggttcaagccattctcctgcctcagcctcccaagtagcgcggattacagg catgtgccaccacctccggctattttttttctatttagtagagatggggtttcaccatg ttagtcaggctggtcatgaactcttgacctcaggtgatccacccgcctcggcctcccaa gtgctgggattacaggcgtgcactgctgcacccagcctttttttgtttttttgagacagg gtcttgctgtcacccaggttgaagtaaggtggcacgattatggctcactgcggccttgat ctccttggctcaagcgatcctctcacttcagcctctcaagcagttggaaccacaggctgt accaccaagcctggccaatttttttgtacagacacaggctggtcttgaactcctgggctc aagcaatcctcctgccttggcctcccaaagtgctgggattccaggcatgagccgctgcac ccggcaaaggccetgcttcttttctctggttgtctcttcttgagaaaatcaacacact

$$
\begin{array}{llllllllllllllllll}
V & A & T & C & R & P & D & E & F & Q & C & S & D & G
\end{array}
$$

ctgtcctgttttccagCTGTGGCCACCTGTCGCCCTGACGAATTCCAGTGCTCTGATGGA $\begin{array}{llllllllllllllllllllllllll}N & C & I & H & G & S & R & Q & C & D & R & E & Y & D & C & K & D & M & S & D\end{array}$ AACTGCATCCATGGCAGCCGGCAGTGTGACCGGGAATATGACTGCAAGGACATGAGCGAT $\mathrm{E} \quad \mathrm{V} \quad \mathrm{G}$ C $\mathrm{V}$ N V

GAAGTTGGCTGCGTTAATGgtgagcgctggccatctggttttccatcccccattctctgt gccttgctgcttgcaaatgatttgtgaagccagagggcgcttccctggtcagctctgcac cagctgtgcgtctgtgggcaagtgacttgacttctcagagcctcacttccttttgttttg agacggagtctcgctctgacacccaggctggagtgctgtggcacaatcacagctcacggc agcctctgcctctgatgtccagtgattctcctgcctcagcctcccgagtagctgagatta aaggcgtataccaccacgcccggctaattttttgtatttttattagagacagggtttctc catgttggccaggctggtcttgaactcctggtctcaggtgatccacccgcctcggcetcc caaagtgctaggattacaggtgtgagccactgcgccaggcctaatttttt gtatttta gtagagatgcggttttgccatattgcccaggctggtctcgaactcctgggctcaagcgat ctgcctgccttggcctcccaaagtgctgggattacaggcacaaaccaccgtgcccgacgc gtttcttaatgaatccatttgcatgcgttcttatgtgaataaactattatatgaatgag tgccaagcaaactgaggctcagacacacctgaccttcctccttcctctctctggctctca

$$
\begin{array}{lllllllllllllllllllll}
T & \mathrm{~L} & \mathrm{C} & \mathrm{E} & \mathrm{G} & \mathrm{P} & \mathrm{N} & \mathrm{K} & \mathrm{F} & \mathrm{K} & \mathrm{C} & \mathrm{H} & \mathrm{S} & \mathrm{G} & \mathrm{E} & \mathrm{C} & \mathrm{I} & \mathrm{T} & \mathrm{L}
\end{array}
$$
cagTGACACTCTGCGAGGGACCCAACAAGTTCAAGTGTCACAGCGGCGAATGCATCACCC

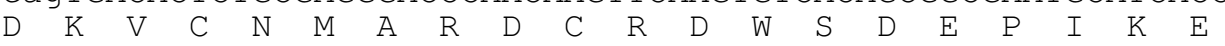
TGGACAAAGTCTGCAACATGGCTAGAGACTGCCGGGACTGGTCAGATGAACCCATCAAAG C G

AGTGCGgtgagtctcggtgcaggcggcttgcagagtttgtggggarecagaagggact gagacatgagtgctgtagggttttgggaactccactctgcccaccctgtgcaaagggctc ctttttcattttgagacagtctcgcacggtcgcccaggctggagcgcaatggcgcgatc tcggctcactgcaacctctgcctcccaggttcaagtgattctcctgcctcagcctcctga
15960

16020

16080

16140

16200

16260

16320

16380

16440

16500

16560

16620

16680

Exon 4

16740

16800

16860

16920

16980

17040

17100

17160

17220

17280

17340

17400

17460

17520

17580

17640

17700

17760

17820

17880

17940

18000

18060

Exon 5

18120

18180

18240

18300

18360

18420

18480

18540

18600

18660

18720

18780

18840

18900

Exon 6

IVS6+36G $>A$

19020

19080

19140

19200 
19201

19261

19321

19381

19441

19501

19561

19621

19681

19741

19801

19861

19921

19981

20041

20101

20161

20221

20281

20341

20401

20461

20521

20581

20641

20701

20761

20821

20881

20941

21001

21061

21121

21181

21241

21301

21361

21421

21481

21541

21601

21661

21721

21781

21841

21901

21961

22021

315

22081

327

22141

347

22201

22261

22321

22381

22441

22501

22561

22621

22681

22741

22801

22861

355

22921

360

22981 gtagctgggattacaggcgcccaccaccaagccegggtaatttttgtatgtttagtaga gatggggtttcactatgttggccaggctggtgttgaactcctgacctcatgatccgccca cctcggcctcccaaagtgctgggattacaggcgtgacccaccccatgaaaaaaattaaa aaatgaagcgatgctgggcgcggtggatcacgcctgtaatcccagcactttgggaagctg aggcaggcagatcacgagggcaggagattgagaccatcctggctaatacggtgaaacccc atctctactaaactacaaaaattagccgggtgtggtggcaggcacctgtgatcccagc tactcaggaggctgaggcaggagaatcgcttgaacccaggaggtggaggttgcagtgagc cgggatcacaccattgcactccagcctgggtgacagagtgagactctgtctcaaaaaaa aaaaaaaaaaaagcgaattctgaaatacatgaattcttttccttagatgcctgcttct gtcttgaggtttgttgttgttatttcgaaacagagtcttgctctgtcgctcaggctggag tgcagtggcatgatcttggctcaccacaacctccggctcccaggttcaagcgattcttct gcctcagcctcctgagtagctgggattacagctgaatgccaccttgctgggctaattttt gtattttagtagagatggggtttcaccatgttggccaggctggcctcgaactcctgacc tcgagtgatctgcccgcctcctgaagtgctgggattacaggcgtgagccacctcgtcctg gtgagggttttttttttccccaaccctctgtggtggatactgaaagaccatattaggat aactgtacagtatagagaaggcagtggcaagttttctctgtcatataccagagtgggctt gggcatggtggcatactcctgtagtctcagctaatcaggaggctgaggaaggaggatcgc ttgggcccaggagttggagactgtagtgagctgtgatcacaccaccacacttcaatctgg gcaacagagcaagagaccctatctctaaaaaaagtaagtatttcggacactgtgggcca tacggtctctggtgcagtttctcaacatggctgttgggtgaacacaaccacgcacagaac gcaaaccaatacacgtggctgtgggcccagaaatgttatttatggacacaaaattgga atttcatataactgttttgtgtcatgaaaatgatttccctttttatttttatttttcttc tcaagtatttaaatatgtaaaagccatttttaggcctggcaggatggttcacagctgtaa tcccagcactttgggaggtcgaggcgggaggatcacgaggtcaggagatcgagaccatcc tggccaacacagtgaaaccccgtctctactaaaatacaaaaattaaccaggcttggtg gcgcgcgtctgtagtcccagctgctcaggaggctgaggcaggagaatcgcttgaatgcag gaggcggaggttgtagtgagccgaggttgcaccactgcactccagcctgagcgacagagt gagagtccgcctcaaacaaaaaatgtttgcccatgctggtcttgaactcctgggctcaa gctatctgcctgccttggtctcccaaagttctgggattacaggcatgagctacagcgccc ggacttttgttgttttatatctatatatctatatataacttgttttatgtatatatataa cttgttt atatatatacataaactgcagtaaaaacatgtaacataaatttaccttct caaccttattaagtgcacagttctgtgccattagcaaattcacactgttgtacaacatc acaaccaccatctccagaacttttttttttttttattctttttgagacagagtctcac tcgtcgcacgggctggagtgcagtggtgcgatctcggttcactgcaacctccacctacca ggttcaagcaattctcctgcctcagccccctcagtagctgggattacaggtgcccgtcct accacgcccagctaatttttgtattttcagtagagactgactgggtttcaccatgttggc caggctggtctcgaactcctgacctcaagtgatcctcccacctcagcctcccaaagtgct gggaatacaggcatgagccactgcgcccggccccagaactcttttatcttcccaaactga agctctgtccccatgaaacactcactctccatcccctccccaactcctggcacccaccat tctactttctgtccctatgaatgtgatggctctagggacctcctctgagtggaatcagac agcattttcctttttgactggcttatttcactgagccaagtgcggtggcacacgcctgt aatcccaaactttgggagaccgaggcgggcgcatcacctgaggtcaggagttcgagacc agcccggccaacatggtgaaaccccatctctagtaaaatacaaaaattagcctgtcat ggtcgtgggtgcctgtaatcccagctaagtgggaggctgaggcaggagaatcgcttgtac ccaggaggcggaggtcgcagtgagccgagatcgtgccattacactccagcctgggcaaca agagtgaaactccgtctctcctaaaatacaaaaaattagctgggcatggtggcacatg cctgtagtcccagctacttgggaggctgaggcaggagaatcacttgaacccgggaggtgg aggttgtaatgagccaaggttggcggcgaagggatgggtaggggcccgagagtgaccagt ctgcatccectggcectgcgcagGGACCAACGAATGCTTGGACAACAACGGCGGCTGTTC $\begin{array}{lllllllllllllllllllll}\mathrm{H} & \mathrm{V} & \mathrm{C} & \mathrm{N} & \mathrm{D} & \mathrm{L} & \mathrm{K} & \mathrm{I} & \mathrm{G} & \mathrm{Y} & \mathrm{E} & \mathrm{C} & \mathrm{L} & \mathrm{C} & \mathrm{P} & \mathrm{D} & \mathrm{G} & \mathrm{F} & \mathrm{Q} & \mathrm{L}\end{array}$ CCACGTCTGCAATGACCTTAAGATCGGCTACGAGTGCCTGTGCCCCGACGGCTTCCAGCT $\begin{array}{lllllllll}V & A & Q & R & R & C & E & D\end{array}$

GGTGGCCCAGCGAAGATGCGAAGgtgatt ccgggtgggactgagccctgggeccectct gcgcttcctgacatggcaaccaaacccctcatgcctcagtttccccatctgttaagtgtg cttgaaagcagttaggagggtttcatgagattccacctgcatggaaactatcattggct ggccagagtttcttgcctctggggattagtaattaagaaatttcaggccgggtgcgtaat ccctgtaatcccaacaccttgggacgccgaggcgggcagatcacctgaggtcgggagttc cagaccagcctgaccaacatggagaaaccccgtctctactaaaatacaaattagccgg gcttggtggtgcatgcctataatcccagctactcaggaggctgaggcaggagaatcact gaacctgggaggtggaggttgtggtgagccaagatcgtgccattgcactccagcctgggc a caagagtgaaactccatccaaaaaaaagaaagaaagaaaaaaagaaagaat ttcagctgacacagcttcacactcttggttgggttcccgtggtgaatgatgaggtcaggt gatgactggggatgacacctggctgtttccttgattacatctcccgagaggctgggctgt ctcctggctgccttcgaaggtgtgggttttggcetgggccccatcgctccgtctctagcc I $D$ E $C$ C attggggaagagcctccCCaccaagcctctttctctctcttccagATATCGATGAGTGTC $\begin{array}{lllllllllllllllllllll}D & P & D & T & C & S & Q & L & C & V & N & L & E & G & G & Y & K & C & Q & C\end{array}$ AGGATCCCGACACCTGCAGCCAGCTCTGCGTGAACCTGGAGGGTGGCTACAAGTGCCAGT

\section{0 \\ IVS $6+171 \mathrm{G}>\mathrm{A}$}

19440

19500

19560

19620

19680

19740

19800

19860

19920

19980

20040

20100

20160

20220

20280

20340

20400

20460

20520

20580

20640

20700

20760

20820

20880

20940

21000

21060

21120

21180

21240

21300

21360

21420

21480

21540

21600

21660

21720

21780

21840

21900

21960

22020

22080

22140

Exon 7

22200

22260

22320

22380

22440

22500

22560

22620

22680

22740

22800

22860

22920

22980

Exon 8

23040 
380

23041

23101

23161

23221

23281

23341

23401

23461

23521

23581

23641

23701

23761

23821

23881

23941

24001

24061

24121

24181

24241

24301

24361

24421

24481

24541

24601

24661

397

24721

414

24781

434

24841

454

24901

454

24961

465

25021

485

25081

505

25141

525

25201

25261

25321

25381

25441

25501

25561

25621

25681

25741

25801

25861

25921

25981

26041

26101

26161

26221

26281

26341

26401

26461

26521

\section{$\begin{array}{llllllllllllllllll}E & E & G & F & Q & L & D & P & H & T & K & A & C & K & A & V & G\end{array}$}

GTGAGGAAGGCTTCCAGCTGGACCCCCACACGAAGGCCTGCAAGGCTGTGGgtgagcacg ggaaggcggcgggtgggggcggcctcaccccttgcaggcagcagtggtgggggagtttca tcctctgaactttgcacagactcatatcccetgaccgggaggctgtttgctcctgagggc tctggcaggggagtctgccgccctgttaggacttgggcttgccagggggatgcctgcata tgtcctagtttttgggaatatccagttaacggaaccctcagccctactggtggaacagga accggctttcctttcagggacaacctggggagtgacttcaaggggttaaagaaaaaaat tagctgggcatggtgccacacacctgtggtcccagctactcagaaggctgaggcgggagg attgcttgagggcaggaggattggttgatcctcccacctcagcctccggagtagctggga cctcaggtgcatgccactatgcctggctaattttctttttcttttttttttttcoga gacggagtctcgctctgttgcccaggctggagtgcagtggcaggatctcggctcactgca agctccgcctcccgggttcacgccattctcctgcctcagcctccccagtagctgggacta caggagcccgccactgcaccaggccaattttttgtatttttagtagagacggggtttca ctgtgttagccaggatggtctcgatctcctgacttcgtgatccgcccacctcggccttcc aaagtgctcggattacaggcgtgagccactgcgcccagccgctaattttcatatttttag taaaacagggtttcaccatgttggccaggctagtcttgaactcctgaacccaagtgatc ctcctgccttggcctcccaaagtgctgggattacagacaccacacctggctattattatt ttttagagacagggtgctgctctatcttccagcctgtagtgcagtgcagcctccatcata gctcgctgcagccttgacctcctgggttcacgtgatcgtcccgcctaagcctctggagga gctgggagtactggcatgtgccaccatgcctggttaattttttttttttttttgaga cagagtctcattctgtcacccaggctggagtgcggtggtgcgatcttggcttactgaaac ctccacctcccaggttccagcaattctcctgcctcacccttctgagtagctgggattaca ggttccggctaccaaacctggctagtttttgtatgtttagtagagacagggtttcaccat gttggtgaggctggtctcgattctcccgcctcagcctcccaaagtgctgggattacaggc ttgagccaccgtgcctggctttttttttttttttttttgtggcaataaggtctcatt gtcttgcccaggctagccttatgctcctagcctcaagtgatcctcctccctcagcctccc aaagtgctgggattacaggtgggcgccactgtgcctgttcccgttgggaggtcttttcca ccctcttttctgggtgcctcctctggctcagccgcaccctgcaggatgacacaagggga tggggaggcactcttggttccatcgacgggtccectctgaccccetgacctcgctecccg $\begin{array}{lllllllllllllllll}S & I & A & Y & L & F & F & T & N & R & H & E & V & R & K & M & T\end{array}$ gacCCCCagGCTCCATCGCCTACCTCTTCTTCACCAACCGGCACGAGGTCAGGAAGATGA

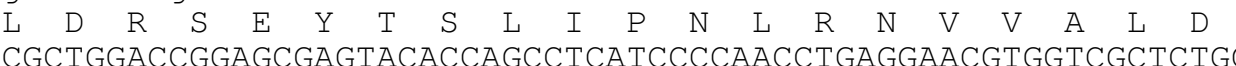
$\begin{array}{llllllllllllllllllll}T & E & V & A & S & N & R & I & Y & W & S & D & L & S & Q & R & M & I & C & S\end{array}$ ACACGGAGGTGGCCAGCAATAGAATCTACTGGTCTGACCTGTCCCAGAGAATGATCTGCA

Ggtgagcgtcgeccetgectgcagecttggeccgcaggtgagatgaggget cetggeget $\mathrm{T} Q \mathrm{~L}$ D R A H G V S S

gatgccettctctcctcctgcctcagCACCCAGCTTGACAGAGCCCACGGCGTCTCTTCC $\begin{array}{llllllllllllllllllllllllllllllllll}Y & D & T & V & I & S & R & D & I & Q & A & P & D & G & L & A & V & D & W & I\end{array}$ TATGACACCGTCATCAGCAGAGACATCCAGGCCCCCGACGGGCTGGCTGTGGACTGGATC $\begin{array}{llllllllllllllllllll}\mathrm{H} & \mathrm{S} & \mathrm{N} & \mathrm{I} & \mathrm{Y} & \mathrm{W} & \mathrm{T} & \mathrm{D} & \mathrm{S} & \mathrm{V} & \mathrm{L} & \mathrm{G} & \mathrm{T} & \mathrm{V} & \mathrm{S} & \mathrm{V} & \mathrm{A} & \mathrm{D} & \mathrm{T} & \mathrm{K}\end{array}$ CACAGCAACATCTACTGGACCGACTCTGTCCTGGGCACTGTCTCTGTTGCGGATACCAAG $\begin{array}{llllllllllllllllllll}G & V & K & R & K & T & L & F & R & E & N & G & S & K & P & R & A & I & V & V\end{array}$ GGCGTGAAGAGGAAAACGTTATTCAGGGAGAACGGCTCCAAGCCAAGGGCCATCGTGGTG D P V H G

GATCCTGTTCATGGgtgcgtatccacgacgctgagggctgcagagggaatggagggagca ggaaggagcttcaggaactggttagtgggctgggcatggtggctcaaagcacctgtaatc ccagcactttgggaggccaaggtgggtggatcatcaagaccagcctgaccaacatggtga aacctcgtctctactaaaatacaaaattagccgggtgtggtggtgggcacctgtaatc ccagctgctcgggaggctgaggcaggagaatcacttgaacctgggagatggaggttgcag tgagccaagacagccccactgcactccagcctgggtgacagagtgagactccgtctcaaa aaaaaaaaaaaactaaacaaaaactggttagtggctagacaacaggatggtatcttc caagcccatggctgactcagcagctcctgggtcaagacactgtgacctgtgtcccctggc aggaagcatcgcccctgccacctgcccggtgtactctgtacctgtcaggtgacatctgct acctaagcacgtgagaggtggcatttcacagtttcagtgtggtgctgacaacccgggacg cacactgtccttgcagctacaatcaggaggtgaatgttgggtttccagcagagaacactg gagaaggcacacttggtgtctggaagggaaaagcagggaagagagcatcatcagatgcct gcgggtgaaggtgggcccgctatggccagcgtcccttttattttatttatttatttat ttgagatggaatctcgctctgtcgcccagactgtagtgcagtggtgcgatcacggctcac tgcaagctccgcctcacaggttcacgccattctcctgcctcagcctcccgagtagctggg actacaggcacccgccaccacgcccggttaattttttgcatttttattagagacggggtt tcaccgcgttagccaggatggtctaatctcctgaccctgtgatccacccgcctcggcct ccctaagtgcttggattacaagcgtgagccaccacgcccggcccccttttatttttat tttttgagacggagtctcgctctgtcgcccaggctagattgcagtggcgtgatctcggct cactgcagcctccgcctcccaggttcaagtgattctcctgcctcaacctcccaactaatt aggattacaagcatgtaccaccatgcctgactaatttttgtattttagtagagactgg gtttcaccatgttggctaggctggtctcgaacccttagcctcaagtaatctgcctgcctc agcctcccaaacagcggggattacaggcatgagccactgtgcccaacccaaccctggatc
23100

23160

23220

23280

23340

23400

23460

23520

23580

23640

23700

23760

23820

23880

23940

24000

24060

24120

24180

24240

24300

24360

24420

24480

24540

24600

24660

24720

24780

Exon 9

24840

24900

24960

25020

Exon 10

25080

25140

25200

25260

25320

25380

25440

25500

25560

25620

25680

25740

25800

25860

25920

25980

26040

26100

26160

26220

26280

26340

26400

26460

26520

26580 
26581

26641

26701

26761

26821

26881

26941

27001

27061

27121

27181

27241

27301

27361

27421

27481

530

27541

548

27601

568

27661

27721

27781

27841

27901

27961

28021

28081

28141

28201

570

28261

573

28321

593

28381

613

28441

28501

28561

28621

28681

28741

28801

28861

28921

28981

29041

29101

29161

29221

29281

29341

29401

29461

29521

29581

29641

29701

29761

29821

29881

29941

30001

30061

30121

30181

30241 tcttttaaacaagacaatgctcgctgttgccacagaacaatgggtggggtacatgtggcc cagtgtgtttggccacataactgccaggccagagggaaagagactctcagactgtctcca ctcagatacaaatgtgtgtgttgtgtgcgtgtgttctggtctcatatttgtttgttttga gacagggtgtcgctctgtcactgagtctggagtgcagtggcgcaatcagagttcactgca gcctcaactcttgggctcagttgattctcccacttcagcctcccaagtagctggaacta caggtgaacaccactgtgcccagctaatttattttatttttagtagagatgaggtctcac tatgttgcccaggctggtcttgacctcctagcctcaagcaatcctcctgccttggtctcc caaagtgctgggattacacgtgcgagccattgcgcatggcttgtgttcttgtgtttcttc cttttctttcgagatggcgtctcagtctgccacccaggctggagtgcagtggtgtgatc atagctcactgtagcctcaacttcctgggctcaagcaatcctcttgatttcagcctcccg ggcctggccagcatggtgaaaccccgtctctactaaaatacaaaatgtagccaggcgt ggtggtgggcgcctgtaatcccagctacaccagaggctgaggcaggagaatcgcttgagc ctggaaggtggaggttgcagcaagccaagatcgtgccactgcactccagcctgggcaaca gagacagactctgtctcaaaaaaaaaaaaaaacccaaacaagccacatttggagttt ggggttcccagcaggactatttcccaagcctgagcctggctgtttcttccagaattcgtt gcacgcattggctgggatcctcccccgccctccagcctcacagctattctctgtcctccc $\begin{array}{lllllllllllllllllll} & \mathrm{M} & M & \mathrm{Y} & \mathrm{W} & \mathrm{T} & \mathrm{D} & \mathrm{W} & \mathrm{G} & \mathrm{T} & \mathrm{P} & \mathrm{A} & \mathrm{K} & \mathrm{I} & \mathrm{K} & \mathrm{K} & \mathrm{G} & \mathrm{G} & \mathrm{L}\end{array}$ accagCTTCATGTACTGGACTGACTGGGGAACTCECCGCCAAGATCAAGAAAGGGGGCCTG $\begin{array}{lllllllllllllllllllll}N & G & V & D & I & Y & S & L & V & T & E & N & I & Q & W & P & N & G & I & T\end{array}$ AATGGTGTGGACATCTACTCGCTGGTGACTGAAAACATTCAGTGGCCCAATGGCATCACC L $\quad$ D

CTAGgtatgttcgcaggacagccgtcccagccagggccgggcacaggctggaggacagac gggggttgccaggtggctctgggacaagcccaagctgctccctgaaggtttccctct ttttctttgttttttcttttttgagatgaggtcttggtctgtcacccaggctgragtgc actggcgcaatcgtagctcactgcagcctccacctcccacoctcaacoratect cctgcc tcaccctcctgagtagctgagattacagacacgtgcca IVS11+56C>T ttttatt IVS11-55A>C 20

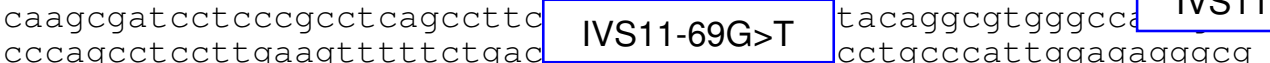
tcacaggggaggggttcaggctcacatgtggttggagckcctctccaggtgcttttcto ctaggtccetggcagggggtcttcctgcciggagcagcgtogccaggccetcaggaccet

$$
\text { L L } \mathrm{S}
$$

ctgggactggcatcagcacgtgacctctccttatccacttgtgtgtctagATCTCCTCAG $\begin{array}{lllllllllllllllllllll}G & R & L & Y & W & V & D & S & K & L & H & S & I & S & S & I & D & V & N & G\end{array}$ TGGCCGCCTCTACTGGGTTGACTCCAAACTTCACTCCATCTCAAGCATCGATGTCAACGG $\begin{array}{llllllllllllllllllllllllll}G & N & R & K & T & I & L & E & D & E & K & R & L & A & H & P & F & S & L & \bar{A}\end{array}$ GGGCAACCGGAAGACCATCTTGGAGGATGAAAAGAGGCTGGCCCACCCCTTCTCCTTGGC $\begin{array}{llll}\mathrm{F} & \mathrm{E}\end{array}$

CGTCTTTGAGgtgtggcttacgtacgagatgcaagcacttaggtggcggatagacacaga ctatagatcactcaagccaagatgaacgcagaaactggttgtgactaggaggaggtct agacctgagttatttctattttcttcttctttttttttttttttgagacagagttt gctctcgtt cccaggctggagggcaatggcatgatctcggctcaccgcaacctccacct cccaggttcaagtgattctcctgtctcaggctccccagtagctgggattacaggcatgca ccaccaccatgcccggctaattttgtatttttagtagagacggagtttctccatgttggt caggctggtctcgaactcccgacctcaggtgatctgcctgcctcggcctcccaaagtgct gggattacagacttgagccaccgcgcccagctatttctgttt ctttctt cttctett ctttttttttctaagagacaggatctcactctgtccccaggcaggagtgcagtgctgt gatcatagctcactgcagccttaacctcctgggctcaagtgatct cccacctcagcctc ccaagtagctggaactacaggtgcacaccaccatgcccagctcatttttgtattttttt ttttttgagacagtctcgttctgtcaccccggctggagtgcagtggtacaatcttggctc actgcaacctctgcctcccaggttcaagcgattctcctgcctcagcctcctgagtagttg agattacaggcatgtgtgccatcatacctggctgatttttgtattttttttagagatgg ggtctcagtatgttgaccaggcttgtcttaaactcccggcctcaagtgatcctcccact cagtctcccaaagtgctgggattacaggcatgagccactgcggccggtttgttttcttt tttttcgtttttggagacggaatttcacctttgttgcccaggatggagtgcaatggca cgatatcgcctcaccacaacctctgcctcctgggttcaaaccattttcctgcctcagcct tcttagtagctgggattacaagcatgtgccaccacgcccggctgattttgtatttttagt agagatggggtttctccatgttggccaggctggtctcgaactcctgacctcaggtcattc gcccacctctgcctcccaaagtgctgggattacaggcgtgagccaccgtgcccggtggtt tgtattcttttactgagagtcgtgaaaggcagtgatcctctgtcacatgtgatcttggc tctcaggggacatttggcaatttctagagattttttggttgtcacaagtcaatggggaag actgttggcatttagtgggtagaggctggtgacgctgctgaacacccagaacagggaagt agcaggccctagatagagccatcgtggggaaaccctgctctaaggaaatggcgctattt ataaccccacgttcctggcatgattaccaacagccaaagtggagtccccccaagtgtgt tcgtccatttgcattgcagtaaaggaatagctgaggccgggtaatttataaagaaagag atttaaactgggtatggcagtttatgcctataatcccagaactttgggaggctgaggcag gaggatcgcttgagtccaggagtgtgagaccgagaccagcctggccaacatgacgaact ctgtctctacaaaaatacaaaagtaggccaggcacggtggttcacgcctgtaatccca gcactttgggaggccgaggcgggcggatcacgaggtcaggagatcgagaccatcctggct
26640

26700

26760

26820

26880

26940

27000

27060

27120

27180

27240

27300

27360

27420

27480

27540

27600

27660

27720

27780

27840

27900

27960

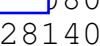

28200

28260

28320

28380

28440

28500

28560

28620

28680

28740

28800

28860

28920

28980

29040

29100

29160

29220

29280

29340

29400

29460

29520

29580

29640

29700

29760

29820

29880

29940

30000

30060

30120

30180

30240

30300
Exon 11

\section{Exon 12}


30301

30361

30421

30481

30541

30601

30661

30721

30781

30841

30901

30961

31021

31081

31141

31201

31261

31321

31381

31441

616

31501

622

31561

642

31621

662

31681

31741

664

31801

677

31861

697

31921

31981

32041

32101

32161

32221

32281

32341

32401

32461

32521

32581

32641

32701

32761

32821

32881

32941

33001

33061

33121

33181

33241

33301

33361

33421

33481

33541

33601

33661

33721

33781

33841

33901

33961 aacacggtgaaaccccgtctctactaaaatacaaaacaaattagccgggtgtggtgg caggcgcctgtagtcccagctactcgggaggctgaggcgggagaatggcgtgaacccggo aggcggagcttgcagtgagccaagatcgcgccactgcactccagcctgggtgaccgagtt gagactccgtctcaaaaaaaaaaaaaaaaaaatacaaaagtagccaggtgtggtg gcaggcacctgtaatcctgggttctcgagaccgaggcatgagaattgcctgaccccagga ggtggaggctgcagtgagccaagatcatgccactgcactccagcctgggcgacagagtgg gactctgtctcaaaaacaacaaaaaaaagttctggaaatggatggtggtgatggtgat acttccacaacagcgtgaatctgcttaaggccaccgaactgtgcactcacaaatagtcga gatggtacattttatgttatgtgtatttcaccacaattaaaactagttgtgggccaggt gtggtggttcatgcctgtaatcccagcactttgggaggtcagagggaggtggatcatgag gtcagcagttcgagaccagccaggccaacatggtgaaaccccatctctactaaaataca aaattagccaggcgtggtggcacatgcctgtagtcccagctacttgagaggctgaagca ggagaatcgcttgaacctgggaggctaagattgcagtgagccgagatcgtgccactgcac tccagcctggacgacagagtgagacttcgtctcaaaaaaaaaccaaaaaaaaattagc tgtgggtcaggcactgtggctcacgcctgtaatcccagcactttgggagaccgaggtagg tggatggcctgaggtcaggagttcgaatccagcctggccaacatggtgaaagcccgtctc tactaaaatacaaaaattagtcaggtatgttggcacacctgtaatcccagctactcgg gaggctgaagcaagagaatcgtttgaacccaggaggtggacgttgcagtgagccgagatt gggccactgtactccagcctgggcaacaaaagtgaaactctgtctgaaacaaacaaacaa acaaacaaacagacaaacaaaaaactagttgtggagagagggtggcctgtgtctcatcc

$$
\text { D K V F W T }
$$

cagtgtttaacgggatttgtcatcttccttgctgcctgtttagGACAAAGTATTTTGGAC

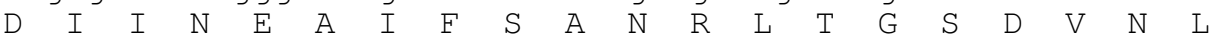
AgATATCATCAACGAAGCCATTTTCAGTGCCAACCGCCTCACAGGTTCCGATGTCAACTT $\begin{array}{lllllllllllllllllllllllllll}L & A & E & N & L & L & S & P & E & D & M & V & L & F & H & N & L & T & Q & P\end{array}$ GTTGGCTGAAAACCTACTGTCCCCAGAGGATATGGTTCTCTTCCACAACCTCACCCAGCC R G

AAGAGgtaagggtgggtcagccccacccccccaaccttgaaacctccttgtggaaactct ggaatgttctggaaatttctggaatcttctggtatagctgatgatctcgttcctgccctg

$$
\begin{array}{lllllllllllll}
V & N & W & C & E & R & T & T & L & S & N & G & G
\end{array}
$$
actccgct cttctgecCcagGAGTGAACTGGTGTGAGAGGACCACCCTGAGCAATGGCG $\begin{array}{llllllllllllllllllll}C & Q & Y & L & C & L & P & A & P & Q & I & N & P & H & S & P & K & F & T & C\end{array}$ GCTGCCAGTATCTGTGCCTCCCTGCCCCGCAGATCAACCCCCACTCGCCCAAGTTTACCT $\begin{array}{llllllllllllllllll}A & C & P & D & G & M & L & L & A & R & D & M & R & S & C & L & T & E\end{array}$ GCGCCTGCCCGGACGGCATGCTGCTGGCCAGGGACATGAGGAGCTGCCTCACAGgtgtgg cacacgccttgtttctgcgtcctgtgtcctccaactgccccctcctgagcctctctctgc tcatctgtcaatgggtacctcaaggtcgttgtaaggactcatgagtcgggataaccata cttttcttggatggacacatcagcaccgggcttgacatttacccagttcccctttgatgc ctggtttcctctttcccggccccctgaagaggtgatctgatttctgacaggagccctgag ggaggaaatggtccccttgttgacttttcttttctttattttttcttttgagatttg ctgtcacccagcctggaatgcagtggtgccatcttggctcactgctacctctcccactgg gttcaagcaattctcctgcctcagcctcccaagtagctgggattacaagcatgcgccacc atgcctggctaagttttgtattttagtacagacagggtttctccatggtggccaggctg gtcttgaactcctgacctcaggtgatcctcccacctctgcctcccgaagtgctacgatta caggcatgagccaccgcgcccatccccctttgttgacttttctcatcctctgagaaagtc tcagttgaggccagcacctccctcaagtgaattgaatctcccttttgaacaacaacaaat aacalatgacccagacgtggtggctcacacctgtggtcccagctactcgggaggctgag gtgtgaggattgcttgagcccaggaggtcaaggctacagagagctataatcacaccact cactccagcctgggggacaaagtgaaaccctgtctgaaaaaacaaaaaagaaaagga aaagaaacaatacgatcacaaagtagatattcatagtgtttattttcagtactctttt ttttttttttttttttgagacggagtcttgctctgttgcccaggctggagtgcagtg gcacgatcttggctcactgcagcctctgcctcccaggttcaagcgcttggctcactgcaa cctccgcctcctgggttcaagcgcttcttctgcctcagcctccccagtagctgggactat aggcacgtcccactacgcccagctaattttttgtattttttagtagagatggggtttcac tatgttagccaggatggtctcgatctcctgacctcgtgatctgcctgccttgggctccca aagtgttgggattatgggcatgagccactgcacctggcctttttttttttttttttgag atggagtttcgctcttgttgcccaggctggagtgcaatggtgtgatctcggctcactgca acctctgcctcctgggttcaagcaattctcctgcctcagcctcccgagtagctgggatta caggcacctgccaccacgcctggctaatttttgtacttttagtagagacggggtttctcc atgttggtcaggctggtctcaaactcctgacctcaggtgatccacccacctcggcctccc aaagttctgggattacagacatgagccaccgcgcctggccgtgtctggcettttttagtt atttcttttttttttttttttttttgagacagagtcttactccgtcgcccaggctgga gtgcagcggtgcgatgtctgcgcactgcaagctccgccccctgggttcatgccattctcc tgcctcagccttctgagtagctgggactgcaggcgcctgccactacgcccggctactttt ttgtatatttagtagagatggagtttcactgtgttagccaggatggtctcgatctcctga ctttgtgatccgcccgcctcggcctcccaaagtgctgggattacaggcgtgagccaccat gccaggctttttttttttttttttgagacggagtcttgctctgtcgcccaggctg gagtgcagtgccatgatctcagctcactgcaagctccacttcccaggctcacgccattct ccagcctcagcctcccaagtagctgagactacaggggcccgccaccacactcggctaatt
30360

30420

30480

30540

30600

30660

30720

30780

30840

30900

30960

31020

31080

31140

31200

31260

31320

31380

31440

31500

31560

31620

31680

31740

31800

31860

31920

31980

32040

32100

32160

32220

32280

32340

32400

32460

32520

32580

32640

32700

32760

32820

32880

32940

33000

33060

33120

33180

33240

33300

33360

33420

33480

33540

33600

33660

33720

33780

33840

33900

33960

34020

\section{$13 \mathrm{~F}$ \\ Exons \\ 13-14}

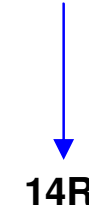


34021

34081

34141

34201

34261

34321

34381

34441

34501

34561

715

34621

733

34681

753

34741

34801

34861

34921

34981

35041

35101

35161

35221

35281

35341

35401

35461

35521

35581

35641

35701

35761

35821

35881

35941

36001

36061

36121

36181

36241

36301

36361

36421

36481

36541

36601

36661

36721

36781

36841

36901

36961

37021

37081

37141

37201

37261

37321

37381

37441

37501

37561

37621

37681

37741

37801

37861

37921 tttttgtattttagtagagacggggtttcaccatgttagccaggctggtcttgaactcc taacctcaggcgattcacctgcctcggcctcccaaagtgctgggattaaaggtatgagcc acctcgcctggtgtgagccacctcgcccagcctgagccacctcacccagcctaagccact gtgcctggcctgattttggacttttaaaattttattaataattatttttgggtttctt tttttgagacagggtcttactctgtcatccaggccatcctgtctgtctgtcatcccagt gatgggatcataccttgctgcagcctctacctcctgggctcaagcgatcctcccccctca gcctcctgagtagctgggagtacaggtgtgcaccaccacacctggctaattttttttt tttttgtatatagagatggtattttgccatgttgaccaggctagtcttaaactcctgga ctcactcaagagatcctcctgccttggcctcccaaggtcatttgagactttcgtcattag gcgcacacctatgagaagggcctgcaggcacgtggcactcagaagacgtttatttattct

$$
\begin{array}{llllllllllllllllll}
A & E & A & A & V & A & T & Q & E & T & S & T & V & R & L & K & V & S
\end{array}
$$

ttcagAGGCTGAGGCTGCAGTGGCCACCCAGGAGACATCCACCGTCAGGCTAAAGGTCAG $\begin{array}{llllllllllllllllllll}\mathrm{S} & \mathrm{T} & \mathrm{A} & \mathrm{V} & \mathrm{R} & \mathrm{T} & \mathrm{Q} & \mathrm{H} & \mathrm{T} & \mathrm{T} & \mathrm{T} & \mathrm{R} & \mathrm{P} & \mathrm{V} & \mathrm{P} & \mathrm{D} & \mathrm{T} & \mathrm{S} & \mathrm{R} & \mathrm{L}\end{array}$ CTCCACAGCCGTAAGGACACAGCACACAACCACCCGACCTGTTCCCGACACCTCCCGGCT $\begin{array}{lllllllllllllllllllllllll}P & G & A & T & P & G & L & T & T & V & E & I & V & T & M & S & H & Q & A\end{array}$ GCCTGGGGCCACCCCTGGGCTCACCACGGTGGAGATAGTGACAATGTCTCACCAAGgtaa agactgggccctccctaggcccctcttcacccagagacgggtcccttcagtggccacgaa cattttggtcacgagatggagtccaggtgtcgtcctcactcccttgctgaccttctctca cttgggccgtgtgtctctgggccctcagtttccctatctgtaaagtgggtctaataacag ttcttgccctctttgcaaggattaaatgggccaatcatatgaggggccaggtccttcag gctcctggttcccaaagtcagccacgcaccgtgtgggtcccaaattttatcaaggcaca ttcgttgcctcagcttcaggcatctgcccaaaaggccaggactaaggcaaggagaggga gggattcctcagtactcagcttt cacagaggctccaaaaggctaaggaatccagtaacg ttttaacacaattttacaattttttttttgagacggagttttgctcttgttgcccaggc tggagtgcagtggcacgatctcggctcactgcaacctctggctcccgggttcaagcgatt ctcctgcctcagtctcccgagtagctgggattacaggcatgcgccaccacgctcggctaa ttttgtatttttagtacagaaggggcttctctgttggtcaggctggtcgtgaactctcaa cctcaggtgagccacccgcctgagcctcccaaagtgctgggattacaggtgtgagccacc acgcctggcctttttttgagacagagtctcgctctcgcccatgctgtactgcagtgacg cagtctgggctcactgtaacctccgcttcccaggttcaagtgattcttctgccgcagcct cccatgtagagtagctgggattacaggcacccgccaccatgcctggctaattcttgcatt tttagtagagatggggtttcacagtgttggccaggctggtctcaaacttctgacctcaag tcatctgcctgccttggccctgccaaagtgctgggattatagatgtgagccaccgcgcct ggcctacagtttattctttggtggctcacacctgtaatctcagcactttgggaggccaag gtgggagaatggcttgagcccaggagttcaagtccagcctgggcaacatagcaagaccct atctctactacaaataaataataaataactaattttttttcttttaaacccaactat tcaacatggcaatgcaatatattaaaaaattttttttttctttgaaacggagtctctca ctgtcacccgggctggagtgcagtgtcgccatcttggctcactgcaacctccgcctccca ggtccaagtgattctcctgcttcagcctcccgagtagctgggattacaggcacccaccac catacccagctaatatttttgtatttttagtagagatggggtttcactatgttgggcagg ctggtctggaactcctgacctcgtgatctgcccgaggatcggcggcctcccaaagtgctg gggattgcaggcatgagccaccgtgcccagccaaactttttattttattttttggg acacggtctcactgtgtaccccagactggagtgatagagtgctgtcatggctcactgcag cctcaacctccctgggctcaggtgatcttcctgcttcagtctcccaggtagctgggacta caggcatgagccaccacacccagctaatttttgaatttttttgtagagacagggtttcac cttgtggcccagacttgtctctaactccagggctcaagcgatctgcccaccttggcctcc caaagtgctgagattaatgcaatttaaaaattttttggccaggcctggtggctcatgcc tgtattcacaacaccttgggaggcaaaggtgggcagatcacttgaggtcaggagttcgag actagcctggccaacatggtgaaaccccctgtctactaaaaaatacaaaattacctgg gcacagtggtgggtgcctgtaatcccagctacttgggatgctgagggtggagaattgctt gaacctgggaggcagaagttgcagtaagccaagatcatgccactggactccagcctcagt gacagagcaaaactctgtctccaaaaaattgttttttttttttttttcaaatcatca cactacagccaaggcctggccacttacttttgtaataaagttttattggagccagtgga ccagtgaggccgaatcttgcaggtgtaagatcacagtctatccttgaaattttgatatt ttgttcattgggtggttttcattaatttaaattttaaaaataacatattaaaggctgg tgtggaggtgcacgcctgcagtcctagctactcccagaggctgaggcgggagacttgctt gagcccaagagttgaagtccagcctgggcaacatagcgagacccccatctctaaaataa aataatgcattagaatattattggattcctgggcagggcacagtggctcacacctgtaa tcccagcactttgggaggctgaggtgggtggatcacctgaggtcaggagtttgagaccag cctggccaacatggtgaaaccccgtctctactaaaatacaaaattagccaggcgtggt ggcaggtgcctgtaatcccagctactcgggaggctgaagcacgagaatcgcttgaatcca ggaggcggaggttgcagtgagctgagattgcgccattgcactccagcctggaggacaaga gtgaaactccattcccctctgcaaagaaaaggaatattatcagattcctaagctttttgg ctccccctttagtttgggggctggggtggtgagtgtctgacctggcctcactgtcctccc tggatgtgatgagacccaggtgtgggtcaggatgtcattcgtttgtccaccagagggcgc ccaaactgctttgagctgctgggaaatggtgctcctagacttttagcaaacaaacaaaa aaatggcacatcggcaatttcagaccattcttttttttttttttttggttccagagt agctgaatctttgttcagttacaagcaggataaatggaaactgcctgggagaggctga gaaacctcttgcttgggggaggtggggcactgctagaattaatcgcttcacagaccagc
34080

34140

34200

34260

34320

34380

34440

34500

34560

34620

34680

Exon 15

34740

34800

34860

34920

34980

35040

35100

35160

35220

35280

35340

35400

35460

35520

35580

35640

35700

35760

35820

35880

35940

36000

36060

36120

36180

36240

36300

36360

36420

36480

36540

36600

36660

36720

36780

36840

36900

36960

37020

37080

37140

37200

37260

37320

37380

37440

37500

37560

37620

37680

37740

37800

37860

37920

37980 
37981

38041

38101

38161

38221

38281

38341

38401

38461

38521

38581

38641

38701

38761

38821

38881

38941

39001

39061

39121

39181

39241

39301

39361

772

39421

779

39481

39541

39601

39661

39721

39781

9841

39901

39961

40021

40081

40141

40201

40261

40321

40381

40441

40501

40561

40621

40681

40741

40801

40861

798

40921

803

40981

823

41041

843

41101

41161

41221

41281

41341

41401

41461

41521

41581

41641

41701 ccatccaggactcctcaaatttggcaaaaagccattcattcattcattcatttatgtag agacgagggggatctggctatattgcctagattggtctcaaattcctggcctcaagtgat cctcctgccttggtctactaatgtgctgcgattacaggcatgagccaccgtgcctagctc tagtggacttgaaatgttgccttgcccagggcccttatgttgaatggcccaggtccactt gtatggttctgtaccaaggttaaccccatcccataatgcctgggacagttgatgcaggac aatcagcttctgtgccattcaacctcaggactgagcatgctgggcattgtggggtccgaa ggtggctcccctgtcccctcaaataccctcttttctttcttcttttttttttt tttttttgagacgaagtcttgctctgttgccccagctagagtgcagtggtgcgatctca gctccccgcaacctctgcttcccgggttcaggcgattctcctgcctcagcctcctgagta gctgggattacaggtgcccaccgccacagctggctaatttttgtatttttagtagagaca gggtttcaccgtgttggccaggctggtcttgaactcctgacctcaggcaacctgcccacc tcagcctcccaaagtgctgggattacaggtttgagccactgggcctggccttttttttt ttttttgagagggagtctcactctgttgcccaggctggagtgcaatggcgcgatcttgac tcactgcaactccatttcccgggttcaagtgattctcctccctcagcctcccaagtagct gggattacaggtgcatgccaccacggccagctaattttgtattttagtagagacagggt ttcactatgttgatcatgctggtctcaaactcctgaccttaggtgatctgcccgccttag cctcccaagtgttgggattacaggtgtgagccaccgcgcccagaccaaatatgctcat tttaataaatgcacaagtaggttgacaagaatttcacctgcaaccttgtcaaccaccta gaataaagcctctgcagccctcccC Itgaggctcaagaaccttc ttaggctgggctcggtggctcattc $\quad$ IVS15-136A>G tggaagetgaggcagga ggatctcttgaggccaggagttcaagacaagcctgggcaacatagccagacctctgtttc tatcccccacaaaagaaccttcttaazcoggattgagtcctacaacctcgataactca caataagcccgtgtggcctctcalagacttgggaagttctccaagtgtccagggagatg tgccaggcgctttcctgccgtgaccaccgtcctctgcctgctccatttcttggtggcctt L $\quad G \quad D \quad V \quad A \quad G \quad R$ cctttagacctgggcetcactcttgcttctctcctgcagCTCTGGGCGACGTTGCTGGCA $\begin{array}{lllllllllllllllllll}G & N & E & K & K & P & S & S & V & R & A & L & S & I & V & L & P & I & V\end{array}$

GAGGAAATGAGAAGAAGCCCAGTAGCGTGAGGGCTCTGTCCATTGTCCTCCCCATCGgta agcgcgggccggtcccccagcgtcccccaggtcacagcctcccgctatgtgacctcgtgc ctggctggttgggcctgttcactttttctcctggacagggaacagcccactggtgtcct ttatcacccccacggcctctcctggcttggggctgacagtgacaagatragacagctaag gggtcagatggaggatgtggagctgggtcccgtgctgtggaat agtgccttctggggaactggttcccttgcagggggctgtgtgg IVS16+46C>T gcctcacccatgctcatcctaactcggttaccatcacatctct aattttaagaaaaagaaatttaatttttttgagagacagagtcttgctctgtcacccag gctggagtgcagtggcaccatcatgcctcgctgcagcctcaatgtctgggctcaagcgat cctcccacctcagcctcctgagtagctggtgcaagccactataccccacttcctatttct taaaagtcacagccctgtgtgtggctaatcctggacagaaatctagaagaagtcagcta cttctggggcgtggctcacccagtgggcttcaggttagatatttcttatacttatgaggc tgggtgtggtggcttatgcctgtaatcccagcactttgggaggctgaagtgggtggattg cttgggctcaggagttcgagaccaacctgggcaacatggcgaaaccctgtttctagaaaa ggtacaaaattagctgggcaggtggcacgtgcctgtggtaccagctacttgagggcctg aggcaggaggatcgcttgaacctgggaggtcgaggttgcagtgaactgagatcatgtcac tgcactccagcctggtgacagagcaagaccccgtctcaaaaaaaaaagaaagaaaa aattcttatgcatagatttgcctctttctgtttgtttgttttgagatggagtctcgctc tgtcgcccaggctggagtacagtggctcaacctcggctcactgcaacctctgcctcccgg gttcaagcaattctcctgcctcagcctcctgagtagctgggactacaggcgcccgccacc atgcccagctaatttttgtatttt agtagagactgactgggtttcatcatgttggccag gctggtctcgaactcttgacctcatgatccgcccgcctcagcctcccaaatgctgggat tacaggcgtgagccaccaggcccaggccgcaaggcgatctctaaacaaacataaaagacc aggagtcaaggttatggtacgatgcccgtgttttcactccagccacggagctgggtctct L L V F L

ggtctcgggggcagctgtgtgacagagcgtgcctctccctacagTGCTCCTCGTCTTCCT

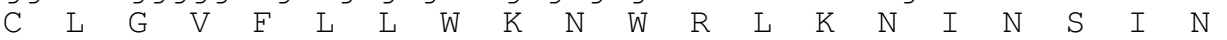
TTGCCTGGGGGTCTTCCTTCTATGGAAGAACTGGCGGCTTAAGAACATCAACAGCATCAA

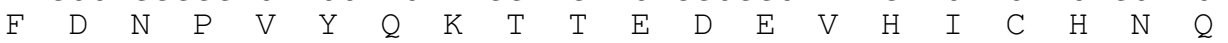
CTTTGACAACCCCGTCTATCAGAAGACCACAGAGGATGAGGTCCACATTTGCCACAACCA $\begin{array}{lllllllllll}D & G & Y & S & Y & P & S\end{array}$

GGACGGCTACAGCTACCCCTCGgtgagtgaccCtctctagaaagccagagcccatggcgg ccccctcccagctggaggcatatgatcctcaagggaccaggccgaggct t ccccagccct ccagatcgaggacagcattaggtgaatgcttctgtgcgctcattcagaatgtcagcggac aatggccttggtggtgtagaggaatgttggataagcaaatagagagctccatcagatggt gacagggcaaagaaagtcaaaaggagttcagaggccgggcgcggtggctcatgcctgtaa tcccaggactttgggaggccgaggctggcggatcacctgaagtcaggagtttgagaccag cttggccatcatgacaaaccccgtctctattaaaatacaaaaattagccaggcgtgg gagtgggcgcctgtaatcccagctactcgggaggccgaggtagaaaatcgcttgaacct aggaggcagaggttgcagtgagccgagatcgcgccactgcattccagcccgggaggcaag agcaaactccatctcaaaaaaaaaaaaaggagttcagaggcccggcatggtggttc acacatgtgatcccagaacttggggaggttgaggcaggagaatcacctgagctcagagtt
38040

38100

38160

38220

38280

38340

38400

38460

38520

38580

38640

38700

38760

38820

38880

38940

39000

39060

39120

39180

39240

39300

39360

39420

39480

Exon 16

39540

39600

39660

39720

39780

39840

39900

39960

40020

40080

40140

40200

40260

40320

40380

40440

40500

40560

40620

40680

40740

40800

40860

40920

40980

41040

41100

41160

41220

41280

41340

41400

41460

41520

41580

41640

41700

41760
Exon 17 
41761

41821

41881

41941

42001

42061

42121

42181

42241

42301

42361

42421

42481

42541

42601

42661

850

42721

42781

42841

42901

42961

43021

43081

43141

43201

43261

43321

43381

43441

43501

43561

43621

43681

43741

43801

43861

43921

43981

44041

44101

44161

44221

44281

44341

44401

44461

44521

44581

44641

44701

44761

44821

44881

44941

45001

45061

45121

45181

45241

45301

45361

45421

45481

45541

45601

45661

45721

45781 caagaccagcctgggcagcacagcaagaccccatctctgcaaaaataaaatttagccc agtgtggtgatgagcgcctagttccagctactagggaggctaaggcaggaggattgcttg aggctaaggtaggagattgagactgcagtgacttgtgattgcgtcactgcgctccagcct gggtgacagagcaagcccttgtctcttaaaaaaaaaaaaattcaaagaagggtttcca gagggccaggagggaggaagggagaggaggtgttttattttttgctttatttttatt ttgagacagagtctctctctgtcacccaggttggagtgcagtgctgtgatcttggctcac tgcaacttctgcctcctgggttcaagcaattcttatgcctcagcctcagcctcctgagta gctgggattacaacactatgcccgggtaatttttgtatttttagtagagacgaggtttcg ccatgttgcccagactggtctcgaactcctgacctcaagtgatccacccgccttggcctc

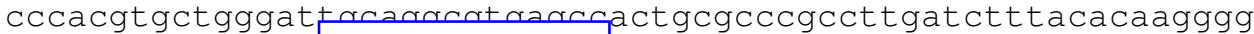
tttagggtaggtagc IVS17-42A>G gagaacagcctgtgcgaaggccetgaggctg gaccgtgcctgttggycนcyayyucyccytagctggagcaaacagagagaggggtaaaa ggcaggaggctaccaggcaggttgtycagagccttgtgggccactggggaggactttggc ttttgccctgagagcggtgggaagtgdctgaatccggtactc ${ }^{*} 52 \mathrm{G}>\mathrm{A}$ ctcctgggggaacatgcttggggatcagotgggggaggctg, $52 \mathrm{G}>\mathrm{A}, \mathrm{gag}$ aagtaggtggcctccagccgtgtttcctgdatgctggactgatagt t Kccgctgtttacc $R$ Q M V S L E D D V A

atttgttggcagAGACAGATGGTCAGTCTGGAGGATGACGTGGCGTGAacatctgcetgg agtcccgtccctgcccagaacccttcctgagacctcgccgrcettgttttattcaaagac agagaagaccaaagcattgcctgccagagctttgttttatatatttattcatctgggagg cagaacaggcttcggacagtgcccatgcaatggattgggttgggattttggtttcttcct ttcctcgtgaaggataagagaaacaggcccgggggg ccaggatgacacctccatttctc tccaggaagttttgagtttctctccaccgtgacacaatcctcaaasatggaagatgaaag gggajgggatgtcaggcccagagaagcaagtg *105T>G acagcagatggcac

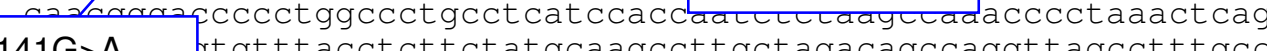
*141G >A ytgtttacctcttctatgcaagccttgctagacagccaggttagcetttgcc crgccaccccgaatcatgacccacccagtgtctttcgaggtgggtttgtaccttcctta agccaggaaagggattcatggcgtcggaaatgatctggctgaatccgtggtggcaccgag accaactcattcaccaatgatgccacttcccagaggcagagcctgagtcactggtcac ccttaatatttattaagtgcctgagacacccggttaccttggccgtgaggacacgtggcc tgcacccaggtgtggctgtcaggacaccagcctggtgcccatcctcccgacccctaccca cttccattcccgtggtctccttgcactttctcagttcagagttgtacactgtgtacattt ggcatttgtgttattattttgcactgttttctgtcgtgtgtgttgggatgggatcccagg ccagggaaagcccgtgtcaatgaatgccggggacagagaggggcaggttgaccgggactt caaagccgtgatcgtgaatatcgagaactgccattgtcgtctttatgtccgcccacctag tgcttccacttctatgcaaatgcctccaagccattcacttccccaatcttgtcgttgatg ggtatgtgtttaaaacatgcacggtgaggccgggcgcagtggctcacgcctgtaatccca gcactttgggaggccgaggcgggtggatcatgaggtcaggagatcgagaccatcctggct aacacgtgaaaccccgtctctactaaaatacaaaaattagccgggcgtggtggcgggc acctgtagtcccagctactcgggaggctgaggcaggagaatggtgtgaacccgggaagcg gagcttgcagtgagccgagattgcgccactgcagtccgcagtctggcctgggcgacagag cgagactccgtctcaaaaaaaaaacaaaaaaaccatgcatggtgcatcagcagccc atggcctctggccaggcatggcgaggctgaggtgggaggatggtttgagctcaggcattt gaggctgtcgtgagctatgattatgccactgctttccagcctgggcaacatagtaagacc ccatctcttaaaaatgaatttggccagacacaggtgcctcacgcctgtaatcccagcac tttgggaggctgagctggatcacttgagttcaggagttggagaccaggcctgagcaacaa agcgagatcccatctctacaaaaccaaaagttaaaatcagctgggtacggtggcacg tgcctgtgatcccagctacttgggaggctgaggcaggaggatcgcctgagcccaggaggt ggaggttgcagtgagccatgatcgagccactgcactccagcctgggcaacagatgaagac cctatttcagaaatacaactataaaaaataataaatcctccagtctggatcgtttgac gggacttcaggttctttctgaaatcgccgtgttactgttgcactgatgtccggagagaca gtgacagcctccgtcagactcccgcgtgaagatgtcacaagggattggcaattgtcccca gggacaaacactgtgtcccccccagtgcagggaaccgtgataagcctttctggtttcgg agcacgtaaatgcgtccctgtacagatagtggggattttttgttatgtttgcactttgta tattggttgaaactgttatcacttatatatatatatatacacacatatatataaatcta tttatttttgcaaaccctggttgctgtatttgttcagtgactattctcggggccetgtgt agggggttattgcctctgaaatgcctcttctttatgtacaaagattatttgcacgaactg gactgtgtgcaacgctttttgggagaatgatgtccccgttgtatgtatgagtggcttctg ggagatgggtgtcacttttaaaccactgtatagaaggtttttgtagcctgaatgtctta ctgtgatcaattaaatttcttaaatgaaccaatttgtctaaactcgatgcacgttcttct gttcgcgcgcttctttttgttttttttttttcctgagatggagcctggctctgtcaccc ctggctggagtgcagtggcatgatctcggcttactgcaagctccgcctcccaggttcaag caattctcctgcctcagcctccctagtagctaggattacaggtgagtgccaccacgcctg gccaatttttttttttttttttttgagacagagtctcgctctgtcacccaggctgga gtgcagtggtgtgatctcggctcactgcaagctctgcctcccaggttaatgccattctcc tgtctcagcctcctgagtagctggggccacaggcgcctgccaccacgcccggctaatttt tttttgtacttctttagtacagacggggtttcaccatgttagccaggatggtctcgatc tcctgaccttgtgatccacctgcttcggcctcccaaagtgctgagattacaggcgtgagc caccgcgggtggccaacgctaattttttgttttttagatggagtcttgctctgtcgcc
41820

41880

41940

42000

42060

42120

42180

42240

42300

42360

42420

42480

42540

42600

42660

42720

42780

42840

42900

42960

43020

43080

43140

43200

43260

43320

43380

43440

43500

43560

43620

43680

43740

43800

43860

43920

43980

44040

44100

44160

44220

44280

44340

44400

44460

44520

44580

44640

44700

44760

44820

44880

44940

45000

45060

45120

45180

45240

45300

45360

45420

45480

45540

45600

45660

45720

45780

45840

\section{Exon 18}


45841

45901

45961

46021

46081

46141

46201

46261 caggctggagtgcagtggcgtgatctctgcctactgcaagctccgcctcccgggttcatg ccattctcctgcctcagcctcctgagtaactgggactacaggcacccgccaccacgcccg gctaatttttgtattttagtagagacagggtttcaccgtgttagccaggatggtcttg atctcctgaccttgtgatccacccgtctcggcctcccaaagtgctgggattagaggtgtg agccaccacacctggcctagcctggctaatttttgtatttttggtagagacggggtttca ccatgttggtcaggctggtcttgaacttctgacctcaggtaatctgcctgcctcagtctc ccaaagtgctgggattacaggtgtgagccaccgcgcctggcctcacttccttctgtcatc tgtttg
45900

45960

46020

46080

46140

46200

46260 


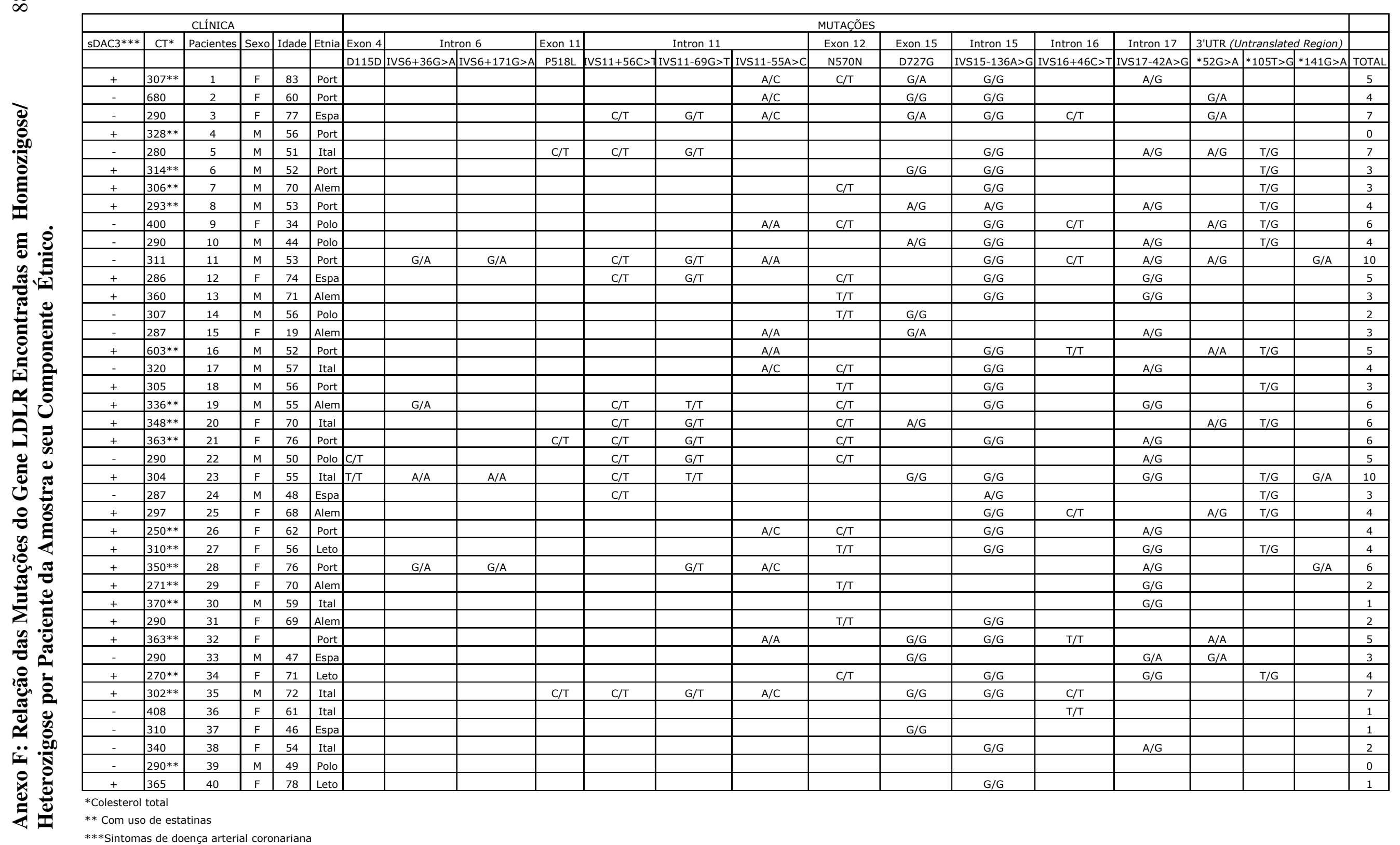




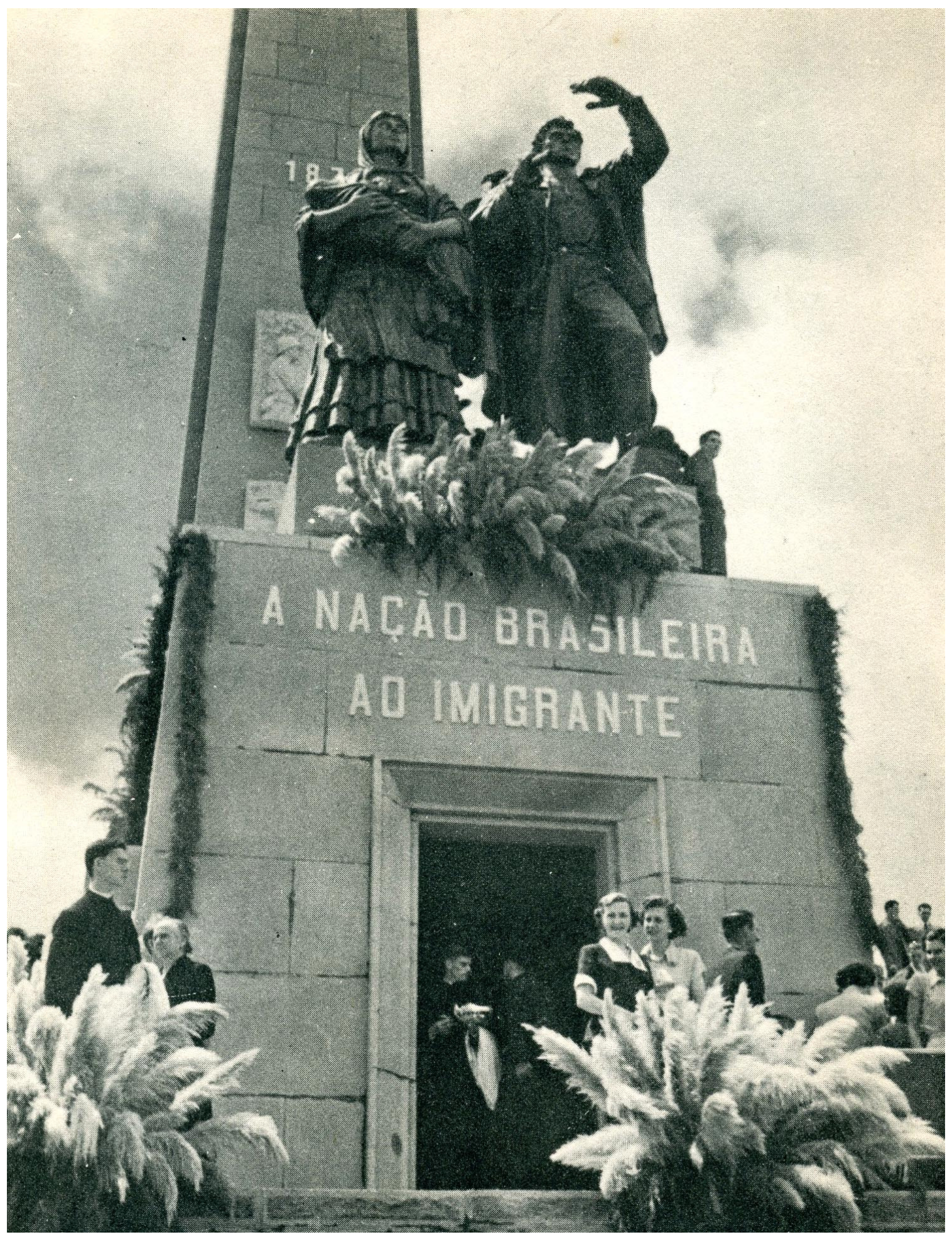

Inauguração do Monumento ao Imigrante, na cidade de Caxias/RS, em 28 de fevereiro de 1954.

Homenagem aos Imigrantes de todas as etnias.

Fonte: Enciclopédia Riograndense 